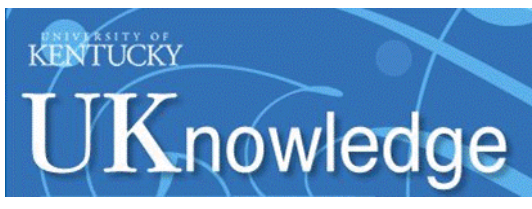

University of Kentucky

UKnowledge

$10-2017$

\title{
Psychosocial Functioning and the Cortisol Awakening Response: Meta-Analysis, $P$-Curve Analysis, and Evaluation of the Evidential Value in Existing Studies
}

Ian Andres Boggero

University of Kentucky, iboggero@gmail.com

Camelia E. Hostinar

University of California - Davis

Eric A. Haak

University of Kentucky, eaha233@uky.edu

Michael L. M. Murphy

Carnegie Mellon University

Suzanne C. Segerstrom

University of Kentucky, segerstrom@uky.edu

Right click to open a feedback form in a new tab to let us know how this document benefits you.

Follow this and additional works at: https://uknowledge.uky.edu/psychology_facpub

Part of the Physiology Commons, and the Psychology Commons

\section{Repository Citation}

Boggero, Ian Andres; Hostinar, Camelia E.; Haak, Eric A.; Murphy, Michael L. M.; and Segerstrom, Suzanne C., "Psychosocial Functioning and the Cortisol Awakening Response: Meta-Analysis, $P$-Curve Analysis, and Evaluation of the Evidential Value in Existing Studies" (2017). Psychology Faculty Publications. 168.

https://uknowledge.uky.edu/psychology_facpub/168 
Psychosocial Functioning and the Cortisol Awakening Response: Meta-Analysis, $P$-Curve Analysis, and Evaluation of the Evidential Value in Existing Studies

\section{Notes/Citation Information}

Published in Biological Psychology, v. 129, p. 207-230.

(C) 2017 Elsevier B.V. All rights reserved.

This manuscript version is made available under the CC-BY-NC-ND 4.0 license https://creativecommons.org/licenses/by-nc-nd/4.0/.

The document available for download is the author's post-peer-review final draft of the article.

\section{Digital Object Identifier (DOI)}

https://doi.org/10.1016/j.biopsycho.2017.08.058 
Published in final edited form as:

Biol Psychol. 2017 October ; 129: 207-230. doi:10.1016/j.biopsycho.2017.08.058.

\title{
Psychosocial Functioning and the Cortisol Awakening Response: Meta-analysis, P-curve Analysis, and Evaluation of the Evidential Value in Existing Studies
}

\author{
Ian A. Boggero ${ }^{a}$, Camelia E. Hostinar ${ }^{b}$, Eric A. Haak ${ }^{a}$, Michael L. M. Murphy ${ }^{c}$, and Suzanne \\ C. Segerstrom ${ }^{a}$ \\ aDepartment of Psychology, University of Kentucky, 125 Kastle Hall, Lexington, KY 40506 \\ bDepartment of Psychology, University of California, Davis, 103 Young Hall, Davis, CA 95616 \\ 'Department of Psychology, Carnegie Mellon University, 5000 Forbes Ave, Pittsburgh, PA 15213
}

\section{Abstract}

Cortisol levels rise immediately after awakening and peak approximately 30-45 minutes thereafter.

Psychosocial functioning influences this cortisol awakening response (CAR), but there is

considerable heterogeneity in the literature. The current study used $p$-curve and metaanalysis on

709 findings from 212 studies to test the evidential value and estimate effect sizes of four sets of

findings: those associating worse psychosocial functioning with higher or lower cortisol increase

relative to the waking period (CARi) and to the output of the waking period (AUCw). All four sets of findings demonstrated evidential value. Psychosocial predictors explained 1\%-3.6\% of variance in CARi and AUCw responses. Based on these effect sizes, cross-sectional studies assessing CAR would need a minimum sample size of 617-783 to detect true effects with $80 \%$ power. Depression was linked to higher $\mathrm{AUCw}$ and posttraumatic stress to lower $\mathrm{AUCw}$, whereas inconclusive results were obtained for predictor-specific effects on CARi. Suggestions for future CAR research are discussed.

\begin{abstract}
The replication crisis in psychology has raised questions about the best methods to promote confidence in scientific findings. Some have suggested that "meta-analysis provides the best foundation for progress, even for messy applied questions" (Cumming, 2008, p. 292), because aggregating across studies reduces noise. Others have noted that publication bias and questionable research practices in individual studies can skew meta-analytic results (Simmons, Nelson, \& Simonsohn, 2011), proposing additional ways to analyze the evidential value of a set of findings (Simonsohn, Nelson, \& Simmons, 2014; van Aert, Wicherts, \& van Assen, 2016). Research on relations between hormones and behavior can be particularly "messy" and vulnerable to inconsistency. The literature on psychosocial
\end{abstract}

\footnotetext{
Address correspondence and reprint requests to Ian A. Boggero, M.S., Department of Psychology, University of Kentucky, 125 Kastle Hall, Lexington KY 40506. ian.boggero@uky.edu.

NOTE: * = included in the Chida \& Steptoe (2009) meta-analysis; ** = added for current meta-analysis

Publisher's Disclaimer: This is a PDF file of an unedited manuscript that has been accepted for publication. As a service to our customers we are providing this early version of the manuscript. The manuscript will undergo copyediting, typesetting, and review of the resulting proof before it is published in its final citable form. Please note that during the production process errors may be discovered which could affect the content, and all legal disclaimers that apply to the journal pertain.
} 
functioning and the cortisol awakening response (CAR) has more than doubled in the last six years, but heterogeneity in published findings has partially obscured the nature and direction of these effects. The present study aims to assess the evidential value of the published literature linking psychosocial functioning to the CAR.

Cortisol is a steroid hormone involved in glucose regulation and metabolism that is frequently labeled a stress hormone because its levels change markedly in response to stressors (see Sapolsky, 2004 for a review). Cortisol levels rise steeply immediately after awakening in the morning and peak approximately 30-45 minutes thereafter; from there, they slowly decrease throughout the day. This early peak in cortisol is known as the CAR (Pruessner, 1997). The CAR is responsive to stress perception and anticipation of daily stressors, making it particularly interesting to psychologists (Fries, Dettenborn, \& Kirschbaum, 2009).

A meta-analysis of 62 studies revealed considerable heterogeneity in findings linking psychosocial functioning to the CAR (Chida \& Steptoe, 2009). For instance, CAR measures were negatively correlated with depression in one study (O'Donnell et al., 2008) but positively correlated in another (Mommersteeg et al., 2006). Heterogeneity in the literature linking psychosocial functioning to the CAR is the rule rather than the exception; in fact, in four of seven types of psychosocial predictors, studies showing both positive and negative associations exist (Chida \& Steptoe, 2009). Heterogeneity may result from inconsistency in how the CAR is measured (Stadler et al., 2016) and from small sample sizes $(\mathrm{N}<100)$ that are characteristic of the literature. With small sample sizes, observed effects may misestimate both the size and the direction of any true underlying effect (Gelman \& Carlin, 2014). Misestimations of direction are unlikely to be detected because there are no norms for the CAR, making it impossible to tell whether CAR values represent hyporesponsiveness, normal responses, or hyperresponsiveness.

To further complicate matters, different researchers operationalize and measure the CAR differently. Most researchers quantify the dynamic increases that occur during the first waking hour (CARi). Others compute the area under the curve relative to the waking period (AUCw) to quantify total cortisol output, although this is not strictly a measure of CAR because it is influenced by cortisol levels prior to awakening and not entirely by dynamic increases in cortisol that happen post-wakening (Stadler et al., 2016). In studies in which both CARi and AUCw were measured, their relationships to measures of psychosocial functioning were not the same (e.g., Bhattacharyya et al., 2008; Chida \& Steptoe, 2009; Ellenbogen et al., 2006; Mommersteeg et al., 2006; Sonnenschein et al., 2007; Whitehead et al., 2007), suggesting possible measure-dependent effects.

Yet another source of heterogeneity in the literature emerges from specific subytpes of psychosocial predictors having unique associations with the CAR. Chida and Steptoe (2009) described seven different types of psychosocial predictors: job stress, general life stress (non-work-related), depression, anxiety (including neuroticism and negative affect), fatigue/ burnout/exhaustion, posttraumatic stress, and positive psychosocial traits. These different predictors may have different relationships with the CAR. For example, AUCw was positively related to general life stress but negatively related to posttraumatic stress (Chida \& 
Steptoe, 2009). Similarly, CARi was positively correlated with job stress and general life stress but negatively correlated with fatigue, burnout, or exhaustion and not reliably associated with positive affect. Meta-analytic findings, therefore, suggest that psychosocial predictors can be related to higher or lower CAR, depending on the nature of the predictor.

Meta-analysis is designed to aggregate across individual findings and extract the commonalities from the idiosyncrasies. The latest meta-analysis on psychosocial functioning and CAR was a step in the right direction (Chida \& Steptoe, 2009). However, a potential problem with meta-analysis is the file drawer problem, where studies are "filed away" unpublished if they fail to find statistically significant relationships. When studies are statistically significant, they make their way into the literature. Over time, this practice artificially inflates Type I error and may make it appear that relationships exist when in reality they do not (Rosenthal et al., 1979). To the degree that a meta-analysis includes a disproportionate number of Type I errors, its results - although superior to individual findings - may nonetheless be biased.

New statistical tools allow researchers to test a set of findings for evidential value in less biased ways. Specifically, $p$-curve analysis is based on the mathematical principle that if the null hypothesis is true, the probability of a $p$-value falling within a range of possible values is the same for all bins of the same size (Simonsohn, Nelson, \& Simmons, 2014a, 2014b, 2015). Thus, given that the null hypothesis is true (i.e., studies lack evidential value), the probability of $p$ falling between $.01-.02$ is equal to the probability of it falling between .02 - .03, .03 -.04, or .04 - .05. In this case, a curve of all the significant $p$-values within a set of findings (i.e., a $p$-curve) will be flat. However, if a set of findings contains evidential value, more significant $p$-values from that set will fall in the $.01-.02$ and $.02-.03$ bins than in the . $03-.04$ and $.04-.05$ bins, and the $p$-curve will be positively skewed. Thus, by assembling the $p$-values for any set of significant findings and calculating the slope of that line, evidential value can be determined (Simonsohn et al., 2014a, 2014b, 2015). Moreover, if one knows all the $p$-values from a set of findings, one can approximate the distribution used to obtain those $p$-values, resulting in an unbiased estimate of effect size (Simonsohn et al., 2014a). This point estimate can then be compared to a meta-analytic point estimate to assess for systematic bias in the literature.

\section{The Current Study}

Although the extant literature suggests that psychosocial functioning and the CAR are associated, the nature of these associations remains unclear. In some studies, psychosocial variables were related to higher CAR and in other studies, to lower CAR (Chida \& Steptoe, 2009). Moreover, the relationship between psychosocial functioning and the CAR may not be the same for different measures of the CAR, and may not be consistent for all psychosocial predictors. The current study aims to clarify the following questions regarding the relationships between psychosocial functioning and the CAR by combining $p$-curve and meta-analytic techniques: First, do the sets of findings associating psychosocial functioning to higher or lower CAR differ in evidential value? Second, what is the effect size for each of these sets of findings? Third, is there evidence of systematic bias in the extant literature? A secondary aim of the study was to examine predictor-specific effects. 


\section{Methods}

\section{Data Sources and Study Selection}

The current study updated the literature testing relationships between psychosocial functioning and the CAR. It included studies previously reviewed by Chida and Steptoe (2009) and added new findings from the past six years. Methods for updating the literature were based on those described by Chida and Steptoe (2009). Articles were identified using the search terms "cortisol" and "awakening" and "response" simultaneously (thus allowing the terms to be out of order) using the Endnote X7.2 (Thompson Reuters) software to search across the following databases: Medline, PsycINFO, Pubmed, and Web of Science. The search terms were allowed to appear in "Any field" for the Pubmed and PsycINFO databases, or in "Title/Keywords/Abstract" for Web of Science and Medline. Articles that were duplicates across these databases, published in foreign language journals, dissertations, conference abstracts, and letters to the editor were removed at a first pass. Reference sections of the identified articles were searched for other relevant articles. To avoid overlap with the previous meta-analysis, the search dates for the updated literature were restricted to articles published between October 1, 2008 and July 1, 2015. Inclusion criteria required articles to (1) be written in English, (2) be published in a peer-reviewed journal, (3) include at least one measure of psychosocial functioning, and (4) include at least one measure of the CAR. Articles were excluded if the population of interest had medical conditions/disorders known to influence cortisol, including pregnant or post-partum women, chronic pain disorders, circadian rhythm disorders, endocrine disorders, hormonal treatments, diabetes, cardiovascular disease, or other medical conditions. Biological predictors of the CAR (genetics or gene $\times$ environment interactions, family history of psychopathology, sleep patterns and disorders, chronotype), as well as intervention studies or effects of laboratory manipulations, were also excluded. Studies including participants with intellectual or developmental disabilities, dementia, or other cognitive impairments were excluded because there was insufficient research to synthesize these studies separately. Lastly, studies focusing on within-subject psychosocial changes were excluded because the current study focused on individual differences instead of intraindividual shifts, and there has recently been a thorough review on within-subject effects on the CAR (Law, Hucklebridge, Thorn, Evans, \& Clow, 2013).

Where different articles reported on the same cohort (e.g., from large publicly available datasets), they were treated as multiple findings from the same study. In cases where articles met inclusion criteria but provided insufficient data for analysis, the corresponding authors were contacted. Of 32 authors contacted, 19 responded, and 17 provided additional data. In total, 159 articles met criteria for the updated literature review. These were combined with 54 articles from the Chida and Steptoe (2009) analysis. Thus, the current study included 709 findings from 212 articles. Figure 1 provides a flowchart of the included articles.

\section{Data Abstraction}

The following information was abstracted for each article added in the current study: title, author, publication year, sample size, psychosocial predictor measurement method, CAR formula used, test statistic, statistic pertaining to psychosocial functioning/CAR relationship, 
and information to compute quality score (described below). Suitable formulas for CARi included the mean cortisol value post-awakening minus the wakening value (MINC), the absolute increase in cortisol as indexed by the maximum value minus the minimum value (AINC), the absolute cortisol values where the effect size was assessed through repeatedmeasures analysis (ACOR), the slope of the CAR curve (slope), or the ratio of cortisol values at wakening to 30 minutes post wakening (T0/T1 ratio). For $\mathrm{AUCw}$, the overall volume of cortisol released during the waking period as indexed by the total area under the curve was used.

A quality score for each study was computed based on whether the studies controlled for each of the following: (1) age, (2) gender, (3) smoking status, (4) medications that influenced cortisol, (5) weekday versus weekend collection days (6) waking time, and (7) adherence to protocol. Moreover, (8) clear instructions for collection had to be provided to participants. A point was awarded for each of these eight criteria that was explicitly described in the article, leading to a total research quality score ranging from 0 to 8 . Data abstraction for the articles in the current study was done by one of the first three authors (IB, $\mathrm{CH}, \mathrm{EH}$ ) and double-checked by another of these authors. A randomly selected subset of 15 articles were independently coded by all three authors, and there was high corroboration on the data that were extracted ( $>90 \%$ agreement on each variable). Discrepancies were settled by group discussions among authors. For articles published before 2009, data were drawn from the Chida and Steptoe (2009) meta-analysis (Table 1, pp. 268-272).

\section{Data Analysis}

To test for evidential value, $p$-curves were computed for the following four sets of associations: (1) worse psychosocial functioning with higher CARi, (2) worse psychosocial functioning with lower CARi, (3) worse psychosocial functioning with higher AUCw, and (4) worse psychosocial functioning with lower AUCw. A p-curve-derived estimate of effect size was computed from each of the four $p$-curves. Next, meta-analysis was used to estimate effects for these four categories, and these meta-analytic estimates were compared to the $p$ curve-derived estimate of effect size. Details for these procedures are discussed below.

P-curve analysis for evidential value-To compute $p$-curves, directionality for all predictors was changed so that higher values reflected worse psychosocial functioning. $P$ curve analyses requires that all findings be independent of one another. If more than one significant relationship was reported from the same sample, or if samples were partially overlapping (i.e., females only in one effect, and males and females in another), the effect with the largest sample size was chosen for inclusion in the $p$-curve. $T$-values and degrees of freedom (n-2) from significant findings were entered into a publicly available $p$-curve calculator provided by Simonsohn and colleagues (2013; Version 4.05; http://www.pcurve.com/). To test for evidential value, the $p$-curve calculator estimated the probability of obtaining that $p$-value if the null were true. Flat curves (neither right nor left skewed) indicated that findings lacked evidential value or were underpowered to detect evidential value. These alternatives were differentiated by testing the set of findings against a null of $33 \%$ power as outlined by Simonsohn et al. (2014); if significant, findings could be assumed to lack evidential value; otherwise, evidential value could not be confirmed or denied. 
$\boldsymbol{P}$-curve analysis for estimates of effect size-Using R syntax, significant $p$-values of a set of findings were used to estimate the effect size of those findings (see Simonsohn et al., 2014b for the syntax). $P$-curve-derived effect size estimates for each of the four sets of findings were computed. Only significant, findings could be assumed findings from independent samples were entered. Effect sizes were computed in Cohen's $d$ and were then converted into $r$ using the formula $r=d / \sqrt{ }\left(d^{2}+4\right)$.

Meta-analysis-Methods described by Chida and Steptoe (2009) were followed to allow for the aggregation of their findings with findings retrieved for the current study. Metaanalytic estimate of effect sizes were transformed into the correlation coefficient $r$. When multiple estimates of the same correlation were provided, associations adjusted for covariates were included. Bivariate correlations were used when there was no covariate adjustment for analyses involving the CAR, or when there was insufficient information to extract an effect size from the covariate-adjusted analyses. Because variance of correlation coefficients depended strongly on sample size (Borenstein, Hedges, Higgins, \& Rothstein, 2009), the $r$ values derived from each study were transformed to Fisher's $z$ and analyses were conducted on these values. The $z$ values were later back-transformed into $r$ values to facilitate interpretation of the meta-analytic findings.

The effect sizes were aggregated using the Comprehensive Meta-Analysis software version 2.2.064. Each random-effects model yielded an aggregate weighted effect size $r$ ranging in value from -1.00 to 1.00, interpreted the same way as a correlation coefficient. Each $r$ statistic was weighted before aggregation by multiplying its value by the inverse of its variance; this procedure enabled larger studies to contribute to effect size estimates to a greater extent than smaller ones. 95\% confidence intervals were computed to assess whether aggregate effect sizes were statistically significant. A heterogeneity coefficient was used to determine whether the studies yielded consistent findings. Publication bias was assessed using Egger's unweighted regression asymmetry test, which tests the asymmetry of the funnel plot of effect sizes plotted by sample size (Egger, Smith, Schneider, \& Minder, 1997).

Because several studies included multiple psychosocial predictors of the CAR, analyses were conducted by including all the effect sizes. To address concerns regarding the nonindependence of effects drawn from the same sample, the same analyses were conducted again by selecting a single effect size at random from each study, and also by combining all the effect sizes from any study into a single average. Results did not differ with these approaches; thus, reported results include all effect sizes.

Analyses for predictor-specific effects-Chida and Steptoe (2009) described seven categories of psychosocial predictors that have been associated with the CAR: job stress, general life stress, depression, anxiety, fatigue/burnout/exhaustion, posttraumatic stress, and positive psychosocial traits. Because there were not enough significant $p$-values to compute independent $p$-curves by directionality and predictor type, $p$-values for both directions were entered simultaneously for each predictor. Thus, these $p$-curves tested whether there was evidential value for each predictor being associated with the CAR. Meta-analysis described the nature and directionality of the relationships. 


\section{Results}

\section{Study Characteristics and Quality}

Table 1 reveals that studies were, on average, of medium to high quality, although quality scores varied considerably. The average number of sampling days was just over two days. The most frequently assessed psychosocial predictors were those assessing general life stress, depression, positive psychosocial traits, and anxiety/neuroticism/negative affect. Details for each of the studies are provided in Table 2.

\section{Findings Associating Worse Psychosocial Functioning with Higher CARi}

$P$-curve analysis revealed that the findings associating worse psychosocial functioning with higher CARi had evidential value ( $k=37 ; p=.001$; see Figure 2a). The $p$-curve-derived estimate of effect size for this set of findings was $r=.08$. When using traditional metaanalytic techniques $(n=273)$, the overall effect size was $r=.09, C I=[0.08,0.11], p<.001$. Approximately $37 \%$ of the significant findings in this set involved general life stress, $15 \%$ depression, $14 \%$ anxiety/neuroticism/negative affect, $12 \%$ positive psychosocial traits, $11 \%$ job stress, $8 \%$ posttraumatic stress, and 3\% fatigue/burnout/exhaustion.

\section{Evidential Value of Findings Associating Worse Psychosocial Functioning to Lower CARi}

$P$-curve analysis revealed that the findings associating worse psychosocial functioning with lower CARi also had evidential value $(k=42 ; p<.001$; see Figure $2 \mathrm{~b})$. The $p$-curve-derived estimate of effect size for this set of findings was $r=.09$. When using traditional metaanalytic techniques $(n=275)$, the overall effect size was $r=.12, C I=[0.10,0.15], p<.001$. Approximately $33 \%$ of the significant findings in this set involved general life stress, $23 \%$ positive psychosocial traits, $17 \%$ depression, $9 \%$ anxiety/neuroticism/negative affect, $7 \%$ posttraumatic stress, $6 \%$ fatigue/burnout/exhaustion, and 5\% job stress.

\section{Findings Associating Worse Psychosocial Functioning with Higher AUCw}

Similar to CARi findings, $p$-curve analysis revealed that the findings associating worse psychosocial functioning with higher AUCw had evidential value $(k=19 ; p=.008$; see Figure 2c). The $p$-curve-derived estimate of effect size for this set of findings was $r=.09$. When using traditional meta-analytic techniques $(n=120)$, the overall effect size was $r=$. $08, C I=[0.07,0.10], p<.001$. Approximately $24 \%$ of the significant findings in this set involved depression, $19 \%$ general life stress, $17 \%$ positive psychosocial traits, $16 \%$ anxiety/ neuroticism/negative affect, $12 \%$ job stress, $7 \%$ fatigue/burnout/exhaustion, and $5 \%$ posttraumatic stress.

\section{Findings Associating Worse Psychosocial Functioning with Lower AUCw}

Finally, $p$-curve analysis revealed that the findings associating worse psychosocial functioning with lower AUCw had evidential value ( $k=19 ; p=.006$; see Figure 2d). The $p$ curve-derived estimate of effect size for this set of findings was $r=.19$. When using traditional meta-analytic techniques $(n=87)$, the overall effect size was $r=.10, C I=[0.08$, $0.13], p<.001$. Approximately $22 \%$ of the significant findings in this set involved general 
life stress, $18 \%$ positive psychosocial traits, $16 \%$ anxiety/neuroticism/negative affect, $14 \%$ posttraumatic stress, $11 \%$ job stress, $10 \%$ depression, and $9 \%$ fatigue/burnout/exhaustion.

\section{Predictor-Specific Effects}

$P$-curves and meta-analyses were conducted to describe the evidential value and directionality of the relationships among specific psychosocial predictors and CARi. Results from $p$-curve and meta-analysis did not corroborate. Results from $p$-curve analysis suggest stronger evidential value for findings associating general life stress, depression, and posttraumatic stress with CARi. However, using meta-analytic estimates, the fatigue/ burnout/exhaustion predictors were most strongly associated with a lower CARi $(r=.09, p$ $=.003$; Table 2), although there was a trend-level indication of publication bias (Egger's test: $p=.07)$. Meta-analyses did not find significant results for any other predictor, but $p$-curve analyses could not conclude that evidential value for these other predictors was lacking; it may be that true effects exist but that the current study was underpowered to detect them. Table 3 and Figure 3 present $p$-curve and meta-analytic results of the seven predictors and CARi.

With regard to AUCw, both $p$-curve and meta-analysis results revealed that depression predictors had evidential value and were linked to greater AUCw output $(r=.07, p<.001$, Table 4). Posttraumatic stress predictors also contained evidential value and were associated with lower AUCw output ( $r=.08, p=.03$, Table 4$)$. There was no evidence of publication bias for the meta-analysis regarding depression predictors (Egger' test: $p=.56$ ), however, there was a trend suggesting publication bias for studies reporting associations of posttraumatic stress (Egger's test: $p=.06$ ). $P$-curve analyses were not able to establish lack of evidential value for any of the seven predictors, again leaving open the possibility that true effects exist but that the current study was underpowered to detect them. Figure 3 reveals forest plots for the predictor-specific associations with both CARi and AUCW.

\section{Quality of the Study as a Potential Source of Variance}

Analysis of variance (ANOVA) was conducted to test if different sets of findings differed in study quality. There was no difference in mean study quality among those findings associating worse psychosocial functioning to higher CARi $(M=6.00, S D=1.70)$, lower CARi $(M=6.08, S D=1.73)$, higher AUCw $(M=6.14, S D=1.49)$, or lower AUCw $(M=$ $6.38, S D=1.20), F(3,203)=0.25, p=.83$. Additionally, neither of the seven predictor types significantly differed from each other in study quality, $F(6,693)=0.87, p=.52$.

\section{Discussion}

Psychosocial predictors are thought to influence the CAR, but describing the nature of these associations has proven difficult because of heterogeneity in the literature. This heterogeneity is partially the result of methodological and operationalization inconsistencies across studies and potential measure-dependent and/or predictor-specific associations (Chida $\&$ Steptoe, 2009; Stadler et al., 2016). Meta-analysis has attempted to clarify the nature of the relationships between psychosocial predictors and the CAR, but meta-analyses can be biased by Type 1 error. $P$-curve analysis tests whether a set of findings in the published 
literature contains evidential value (Simonsohn et al., 2014a, 2014b, 2015), making $p$-curves an ideal complement to meta-analysis. Together, $p$-curves and meta-analysis can describe the evidential value of a set of findings and provide an estimate of the effect size of those findings.

The present study aimed to combine $p$-curve and meta-analytic techniques to answer four questions in the literature of psychosocial predictors and the CAR: first, did findings associating psychosocial functioning to higher or lower CAR differ in evidential value? Second, what was the effect size for these sets of findings? Third, was there any evidence for systematic bias in the literature? Fourth, did some psychosocial predictors demonstrate greater evidential value than others?

\section{Evidential Value of Findings Associating Psychosocial Predictors to the CAR}

The co-existence of positive and negative association between psychosocial predictors and the CAR could be explained in one of three potential ways: 1) there is no true relationship, and both the positive and negative associations are spurious; 2) there is either a positive or negative relationship between psychosocial predictors and the CAR, and the other direction is spurious; or 3) there are true positive and negative associations between psychosocial predictors and the CAR, and neither set is spurious. The current study independently examined the evidential value of four sets of findings: those associating worse psychosocial functioning to higher or lower CARi, and those associating worse psychosocial functioning to higher or lower AUCw. Results revealed that all four sets of findings demonstrated significant evidential value (scenario 3 above). Although seemingly contradictory, these results suggest that there are likely important moderators that explain which predictors are associated with what measures, and for whom. In other endocrinological outcomes like diurnal cortisol, stressor-dependent factors like the duration, intensity, and appraisal of the stressor are known to moderate biological responses (e.g., Armario, Marti, Molina, De Pable, \& Valdes, 1996; Burke, Dacis, Otte, \& Mohrn, 2005; Segerstom \& Miller, 2004), and they likely play a role in the CAR as well. Unfortunately, the current study was underpowered to detect such individual difference- or stressor-dependent effects: there are not enough findings in the extant literature, nor is there a theoretical framework for making predictions about moderation. Analysis revealed that study quality among different CAR measures and different predictor types was similar, suggesting that the methodological inconsistencies are not systematically biasing the literature in any predictable way. Future work aimed at identifying moderators of the psychosocial functioning and CAR relationship is essential, as the current lack of empirically-supported theory in this area represents perhaps the greatest shortcoming in the CAR literature.

\section{Effect Sizes of Findings Associating Psychosocial Predictors to the CAR, and Implications for Power Analysis}

Despite all four sets of findings demonstrating significant evidential value, the estimate of $p$ curve-derived effect sizes across the four sets was not equivalent. Effect sizes for each of the four sets of findings were calculated in two ways: using $p$-curve-derived estimates and using traditional meta-analytic techniques. Corroboration of these two methods was high. The associations between psychosocial predictors and CARi were small, with psychosocial 
predictors explaining approximately $1 \%$ of variance in CARi $(r=.08$ for higher CARi and . 11 for lower CARi using $p$-curve-derived estimate, $r=.09$ and .12 for meta-analytic estimates, respectively). These small effects were similar to those reported by Chida and Steptoe (2009), with $r$ 's ranging from -.065 to .069 depending on the specific predictor.

For findings examining total cortisol output, those associating worse psychosocial functioning to greater AUCw has a similar effect size ( $r=.09$ from the $p$-curve-derived estimate and .08 from the meta-analytic estimate). However, findings associating worse psychosocial functioning to lower AUCw had a larger effect, with approximately $3.6 \%$ of variance being accounted for $(r=.19$ from the $p$-curve-derived estimate and .10 from the meta-analytic estimate). To the extent that the $p$-curve-derived estimate can be considered a less biased measure for gauging effect size, this finding suggests that total cortisol output during the waking period is more heavily affected by psychosocial predictors than is the dynamic increase that occurs after awakening. It may be that worse psychosocial functioning over time blunts the overall output of the CAR system while keeping the dynamic component intact. If indeed the CARi represents an adaptive response to stressors, this may be the most adaptive pattern for those high in psychosocial stress: it would allow them to maintain dynamic flexibility in the CAR system without having chronically high levels of cortisol output overall. Nevertheless, this explanation remains speculative and remains to be tested with future research.

One implication of these estimates is that regardless of CAR measure, future studies should be powered to detect small effects $(r=.10)$. Using two publicly-available power calculators (GPower and the UCSF Clinical and Translation Science Institute Sample Size Calculator [http://www.sample-size.net/correlation-sample-size/]), a cross-sectional study would need a minimum sample size of 617-783 to detect true effects with $80 \%$ power. In the current study, approximately $11 \%$ of the studies had at least this sample size; approximately $58 \%$ had a sample size less than 100, and $28 \%$ had a sample size less than 50. Although obtaining over 600 people for a study may seem unfeasible or prohibitively expensive, there are also substantial costs to running underpowered studies. On one hand, underpowered studies may fail to find significant effects when in reality they exist; in those instances, the resources spent for that study are lost and Type II error appears in the literature or, more likely, contribute to the file drawer problem. On the other hand, correlations obtained with small sample sizes are unstable and can result in Type I error. As a result, running underpowered studies can significantly contribute to the current replicability crisis in psychology; running adequately powered studies presents a costly but feasible and scientifically rigorous solution. Thus, future work with larger samples is needed to help clarify the relationships between psychosocial predictors and the CAR.

The small effect sizes also beg the question of clinical significance: are these effects meaningful in the real world? Prentice and Miller (1992) argue that small effects are impressive when the dependent variable is not expected to be easily influenced by the independent variable. The fact that psychosocial events - even those that are imagined, anticipated, or long-passed - can produce reliable shifts in a physiological system associated with energy mobilization is meaningful. It suggests that the CAR may promote adaptive physiological responses to complex social stimuli, and may have implications for when, 
how, and why the CAR evolved (for a review of the functions of the CAR, see Fries, Dettenborn, \& Kirschbaum, 2009). Moreover, small effects of psychosocial variables on other endocrinological and immunological outcomes are found in the literature, yet these lines of study remain active because psychosocial stressors are common enough that even small effects, if they occur frequently enough and for long enough, can produce a sizeable impact on physiology. For example, diurnal cortisol levels demonstrate small to moderate correlations with depression ( $r=.18$; Burke et al., 2005) and chronic stress (Miller, Chen, and Zhou, 2007), and these relationships depend on a number of measurement, appraisal, and contextual variables (Miller, Chen, and Zhou, 2007). Likewise, some enumerative measures of immune functioning like monocyte counts, T-lymphocyte counts, and granulocyte counts have small to moderate correlations $(r$ 's $<.10)$ with acute time-limited stress and chronic stress, although correlations are larger for other measueres of immunity like immunoglobulin and cytokine levels ( $r$ 's between .10 and .30; Segerstrom \& Miller, 2004). Thus, in the greater context of psychoneuroendocrinological research, the CAR may not be the most sensitive biological marker for chronic stress, but still sensitive enough that continuing to study the relationships is a worthwhile endeavor.

Future studies investigating the CAR and psychosocial functioning should sample the CAR over more days. The modal number of sampling days in the studies reviewed was one (range $=1$ to 9). As is true for other diurnal cortisol parameters (Segerstrom et al., 2014), the amount of variance in the CAR that generalizes beyond the day on which it was collected is small (36-60\% for AUC [baseline, 30, 45, and 60 minutes]; 15-37\% for increase; Hellhammer et al., 2007.) As a consequence, reliable measurement of the CAR can require sampling over up to 6 days (Hellhammer et al., 2007). Notably, there were too few studies with a sufficient number of days to compare the $p$-curves of those with theoretically insufficient and sufficient sampling frames for reliability, and almost none of the studies reported the empirical reliability of their CAR measurement. Future research on the CAR should be evaluated in light of the reliability of cortisol measurement, particularly because unreliable measurement can yield estimates of relationships that are incorrect in both magnitude (e.g., an estimate is either larger or smaller than the true underlying relationship) and sign (e.g., a positive estimate is obtained when the true underlying relationship is negative) (Gelman \& Carlin, 2014). When effect sizes are small, reliable measurement is also important to maintain statistical power (Kanyongo, Brook, Kyei-Blankson, \& Gocmen, 2007).

\section{Testing for Systematic Bias in the Literature}

Systematic bias in the literature occurs when there are publishing practices that make some findings (i.e., significant findings) more likely to make their way into the published literature than others. Because $p$-curve calculations use only published significant effects, comparing estimates of effect sizes between $p$-curves and standard meta-analysis can highlight systematic bias. As discussed above, the only discrepancy betweet $p$-curve-derived estimates and meta-analytic estimates was in the set associating worse psychosocial functioning to lower AUCw. However, the directionality of the discrepancy suggests that the published literature is systematically underestimating the true effects (i.e., the $p$-curve estimate is larger than the meta-analysis estimate). It should be noted that this set had a relatively small 
number of independent, statistically significant findings $(k=19)$. Future work should examine associations of psychosocial predictors and $\mathrm{AUCw}$ using large samples so that more precise estimates of these associations can be calculated. Aside from this notable exception, the high corroboration between $p$-curve and meta-analytic estimates suggests a lack of systematic bias in the literature. This is corroborated by the fact that Egger's test of publication bias in the meta-analytic estimates were nonsignificant for both CARi and AUCw.

A second cause of systematic bias is introduced by researchers who engage in questionable research practices (QRPs; Simmons et al., 2011). One particularly common QRP is $p$ hacking, where researchers perform unplanned post-hoc analyses to reduce the $p$-value of a hypothesized relationship to below the .05 cutoff. Examples of $p$-hacking include adding covariates atheoretically, selectively removing outliers, or performing analyses on a subset of the population, among other strategies. In most cases, researchers will $p$-hack until the $p$ value falls to just under .05. If a set of findings contains a substantial number of $p$-hacked findings, the $p$-curve for that set of findings will contain more $p$-values in the $.04-.05$ bin than any other bin, and will be right-skewed.

A visual analysis of the four sets of $p$-curves in the current study reveals that they were all left-skewed (see Firgure 2), suggesting that $p$-hacking is not biasing the CAR literature. Thus, despite the recent controversies surrounding questionable research practices in psychology and other disciplines, evidence from this study suggests that the associations of psychosocial functioning and the CAR represent true effects with evidential value. This is particularly refreshing news because the potential for researchers to engage in $p$-hacking and other questionable research practices is high in CAR research, as there are a number of design decisions, analytical techniques, and ambiguities with operational definitions which can be modified post-hoc. Adherence to guidelines (Stadler et al., 2016) will ensure that the field continues moving in the current direction of honest, reliable science.

\section{Predictor-Specific Effects}

A secondary aim of the current study was to examine whether specific categories of psychosocial predictors were associated with CARi or AUCw. Of the seven categories previously defined by Chida and Steptoe (2009), it was found that only fatigue/burnout/ exhaustion was negatively correlated with CARi. This corroborates meta-analytic results from Chida and Steptoe (2009). It may be that fatigue takes a physiological toll on the body's ability to respond dynamically. Alternatively, under conditions of fatigue, the body may attempt to conserve resources in anticipation of anticipated challenges (Evans, Boggero, \& Segerstrom, 2016). The other six categories had nonsignificant effects. However, $p$-curve analysis testing against evidential value were non-significant in all cases, suggesting that the extant literature is underpowered to detect effects if they exist.

AUCw was positively associated with depression but negatively associated with PTSD. As with CARi, the other associations were not statistically significant, but $p$-curves could not rule out the possibility that they contain evidential value. Despite not being statistically significant, the direction of the correlations revealed that job stress and anxiety/neuroticism/ negative affect were positively correlated with $\mathrm{CARi}$ and $\mathrm{AUCw}$, whereas general life stress 
and positive psychosocial traits were negatively correlated with CARi and AUCw. These trends highlight the possibility that future-oriented predictors like anxiety and job stress, where there is an anticipation of future negative events, may be associated with increased CAR, but this observation is speculative and should be corroborated by future research.

\section{Limitations}

The current study is not without limitations. First, the articles and findings reported in the current study were all from the published literature; poster abstracts, conference proceedings, and unpublished data were not included. The $p$-curves could test for the presence of systematic bias in the literature. A full examination of the true, unbiased estimates of CAR in published and unpublished findings was beyond the scope or aims of the study. Nevertheless, the inclusion of only published studies should be taken into consideration when interpreting the findings; it may be that the true CAR effects are smaller than those reported in the current study. A second limitation is that the study only tested bivariate correlations among psychosocial predictors and levels of CARi and AUCw, but other more dynamic measures of the CAR are possible. For example, some have argued that the flexibility of the CAR rather than its magnitude is more strongly linked to psychosocial predictors (Mikolajczak et al., 2010). A third limitation is that the current study only examined linear effects, despite some studies describing quadratic effects (Gustafsson et al., 2010). A fourth limitation is that alternate conceptualizations of psychosocial predictors besides the seven categories reported are possible. Some of the seven categories are theoretically ambiguous and frequently co-occur in the real world (e.g., depression and anxiety). Nevertheless, solid theoretical scaffolding exists for the seven categories, and in an attempt to build upon the scaffolding, the same categories were retained. A fifth limitation is that the time window of psycholosocial predictors was not assessed. Questionnaires that ask about lifetime history of depressive symptoms, for example, may have different relations to the CAR than those that ask about depressive symptoms in the last two weeks, or even in the last 24 hours. Theoretical advances in predicting the time window that would be most meaningfully related to the CAR remains an important area for future research; it is possible that these associations will be predictor-specific. Finally, a limitation of the current study is that it used strict inclusion criteria of healthy participants and as such, results cannot generalize to medically compromised populations.

Despite these limitations, the study has several significant strengths. First, it provides a concrete example of how $p$-curves and meta-analysis can complement each other to shed light on situations where there appears to be a "tale of two literatures." Second, the current study presents the most complete analysis of the literature on psychosocial functioning and CAR to date - a literature that has more than doubled within the last six years and will probably continue to expand. Third, the current study provides specific goals for future research in the area of theory development, and provides concrete recommendations for the power of future studies. It addresses concrete strategies that could help to increase the replicability of CAR findings. 


\section{Conclusion}

In conclusion, psychosocial functioning is known to influence the CAR. The current study found that the largest evidential value existed for findings associating worse psychosocial functioning with lower AUCw. Findings associating depression, posttraumatic stress, anxiety, and fatigue demonstrated evidential value, and evidential value could not be ruled out for other psychosical predictors. Moving forward, theoretical developments regarding why some predictors but not others are associated with some measures of CAR but not others remains an important question - perhaps the most important question. To answer this question, more adequately powered, methodologically rigorous studies are needed. Recently published guidelines provide concrete and clear recommendations for researchers (Stadler et al., 2016), and results from the current study suggest that large samples are needed to minimize the likelihood that Type I and II error rates make their way into the literature. Nevertheless, the current study finds reliable evidence that psychosocial functioning influence the CAR, and provides the most thorough estimate of effect sizes by predictor and CAR measure to date. Future exploration of these associations may lead to meaningful insights regarding the effects of psychosocial functioning on human stress physiology.

\section{Acknowledgments}

The authors would like to thank Tim Bogg, Nienke Bosch, Joaquín Cabrera, Lea Doughterty, Kimberly Dienes, Andrea Dietrich, Nanna Eller, Romano Endrighi, Gloria Garcia-Banda, Meena Kumari, Lindsay Hoyt, Brian Lovell, Andrea Oskis, Michael Sladek, Richard Slatcher, Robert Stawski, and Michael Wirth for providing additional requested data. The authors would also like to thank Uri Simonsohn and Andrew Steptoe for providing requested statistical and methodological help. Finally, the authors would like to thank Greg Miller for his helpful comments throughout the project and on earlier versions of the manuscript.

Research reported in this publication was supported by the National Institute on Aging of the National Institutes of Health (F31-AG048692, K02-AG033629). The content is solely the responsibility of the authors and does not necessarily represent the official views of the National Institutes of Health.

\section{References}

*. Adam EK. Transactions among adolescent trait and state emotion and diurnal and momentary cortisol activity in naturalistic settings. Psychoneuroendocrinology. 2006; 31:664-679. DOI: 10.1016/j.psyneuen.2006.01.010 [PubMed: 16584847]

*. Adam EK, Hawkley LC, Kudielka BM, Cacioppo JT. Day-to-day dynamics of experience-cortisol associations in a population-based sample of older adults. Proceedings of National Academy of Science. 2006; 103:17058-17063. DOI: 10.1073/pnas.0605053103

*. Alderling M, Theorell T, de la Torre B, Lundberg I. The demand control model and circadian saliva cortisol variations in a Swedish population based sample (the PART study). BMC Public Health. 2006; 6:1-8. DOI: 10.1186/1471-2458-6-288 [PubMed: 16390547]

Armario A, Marti O, Molina T, De Pablo J, Valdes M. Acute stress markers in humans: response of plasma glucose, cortisol and prolactin to two examinations differing in the anxiety they provoke. Psychoneuroendocrinology. 1996; 21(1):17-24. doi: http://dx.doi.org/ 10.1016/0306-4530(95)00048-8. [PubMed: 8778900]

**. Aubry JM, Jermann F, Gex-Fabry M, Bockhorn L, Van der Linden M, Gervasoni N, et al. Bondolfi G. The cortisol awakening response in patients remitted from depression. Journal of Psychiatric Research. 2010; 44(16):1199-1204. DOI: 10.1016/j.jpsychires.2010.04.015 [PubMed: 20471032]

**. Baes CW, Martins CMS, Tofoli SMC, Juruena MF. Early life stress in depressive patients: HPA axis response to GR and MR agonist. Frontiers in Psychiatry. 2014; 5:1-12. DOI: 10.3389/fpsyt. 2014.00002 [PubMed: 24478729] 
*. Barnett RC, Steptoe A, Gareis KC. Marital-role quality and stress-related psychobiological indicators. Annals of Behavioral Medicine. 2005; 30:36-43. DOI: 10.1207/ s15324796abm3001_5 [PubMed: 16097904]

*. Bhagwagar Z, Hafizi S, Cowen PJ. Increase in concentration of waking salivary cortisol in recovered patients with depression. American Journal Psychiatry. 2003; 160:1890-1891. DOI: 10.1176/ appi.ajp.160.10.1890

*. Bhagwagar Z, Hafizi S, Cowen PJ. Increased salivary cortisol after waking in depression. Psychopharmacology. 2005; 182:54-57. DOI: 10.1007/s00213-005-0062-z [PubMed: 15991000]

Bhattacharyya MR, Molloy GJ, Steptoe A. Depression is associated with flatter cortisol rhythms in patients with coronary artery disease. Journal of Psychosomatic Research. 2008; 65:107-113. DOI: 10.1016/j.jpsychores.2008.03.012 [PubMed: 18655854]

**. Bogg T, Slatcher RB. Activity mediates conscientiousness' relationship to diurnal cortisol slope in a national sample. Health Psychology. 2015; 34:1195-1199. DOI: 10.1037/hea0000243 [PubMed: 26030310]

Borenstein, MH., Higgins, LV., Rothstein, JPT., HR. Introduction to meta-analysis. Chichester, England: Wiley; 2009. 2009doi:10, 9780470743386

**. Bosch NM, Riese H, Dietrich A, Ormel J, Verhulst FC, Oldehinkel AJ. Preadolescents' somatic and cognitive-affective depressive symptoms are differentially related to cardiac autonomic function and cortisol: the TRAILS study. Psychosomatic Medicine. 2009; 71(9):944-950. DOI: 10.1097/ PSY.0b013e3181bc756b [PubMed: 19834052]

**. Bouma EM, Riese H, Ormel J, Verhulst FC, Oldehinkel AJ. Adolescents' cortisol responses to awakening and social stress; effects of gender, menstrual phase and oral contraceptives. The TRAILS study. Psychoneuroendocrinology. 2009; 34(6):884-893. DOI: 10.1016/j.psyneuen. 2009.01.003 [PubMed: 19195792]

Burke HM, Davis MC, Otte C, Mohr DC. Depression and cortisol responses to psychological stress: A meta-analysis. Psychoneuroendocrinology. 2005; 30:846-856. DOI: 10.1016/j.psyneuen. 2005.02.010 [PubMed: 15961250]

**. Camfield DA, Wetherell MA, Scholey AB, Cox KH, Fogg E, White DJ, et al. Pipingas A. The effects of multivitamin supplementation on diurnal cortisol secretion and perceived stress. Nutrients. 2013; 5(11):4429-4450. DOI: 10.3390/nu5114429. [PubMed: 24284609]

*. Chan SWY, Goodwin GM, Harmer CJ. Highly neurotic never-depressed students have negative biases in information processing. Psychological Medicine. 2007; 37:1281-1291. DOI: 10.1017/ S0033291707000669 [PubMed: 17493298]

Chida Y, Steptoe A. Cortisol awakening response and psychosocial factors: a systematic review and meta-analysis. Biological Psychology. 2009; 80(3):265-278. DOI: 10.1016/j.biopsycho. 2008.10.004 [PubMed: 19022335]

**. Chui H, Hoppmann CA, Gerstorf D, Walker R, Luszcz MA. Cumulative load of depressive symptoms is associated with cortisol awakening response in very old age. Research in Human Development. 2014; 11(2):126-141. DOI: 10.1080/15427609.2014.906738

**. Clingerman EM, Brown A. Stress in migrant farmworkers during premigration. Biological Research for Nursing. 2012; 14(1):27-37. DOI: 10.1177/1099800410396703 [PubMed: 21278168]

**. Cropley M, Rydstedt LW, Devereux JJ, Middleton B. The relationship between work-related rumination and evening and morning salivary cortisol secretion. Stress and Health. 2015; 31(2): 150-157. DOI: 10.1002/Smi.2538 [PubMed: 24166947]

Cumming G. Replication and p intervals: p values predict the future only vaguely, but confidence intervals do much better. Perspectives on Psychological Science. 2008; 3(4):286-300. DOI: 10.1111/j.1745-6924.2008.00079.x [PubMed: 26158948]

**. Daubenmier J, Hayden D, Chang V, Epel E. It's not what you think, it's how you relate to it: Dispositional mindfulness moderates the relationship between psychological distress and the cortisol awakening response. Psychoneuroendocrinology. 2014; 48:11-18. DOI: 10.1016/ j.psyneuen.2014.05.012 [PubMed: 24971591]

*. de Kloet CS, Vermeten E, Heijnen CJ, Geuze E, Lentjes EGWM, Westenberg HGM. Enhanced cortisol suppression in response to dexamethasone administration in traumatized veterans with 
and without posttraumatic stress syndrome. Psychoneuroendocrinology. 2007; 32:215-226. DOI: 10.1016/j.psyneuen.2006.12.009 [PubMed: 17296270]

*. de Vente W, van Amsterdam JGC, Kamphuis JH, Emmelkamp PMG. Physiological differences between burnout patients and healthy controls: Blood pressure, heart rate, and cortisol responses. Occupational and Environmental Medicine. 2003; 60:i54-i61. DOI: 10.1136/oem.60.suppl_1.i54 [PubMed: 12782748]

*. de Vugt ME, Nicolson NA, Lousberg R, Jolle J, Verhey FRJ. Behavioral problems in dementia patients and salivary cortisol patterns in caregivers. Journal of Neuropsychiatry and Clinical Neuroscience. 2005; 17:201-207.

**. Dedovic K, Engert V, Duchesne A, Lue SD, Andrews J, Efanov SI, et al. Pruessner JC. Cortisol awakening response and hippocampal volume: Vulnerability for major depressive disorder? Biological Psychiatry. 2010; 68(9):847-853. DOI: 10.1016/j.biopsych.2010.07.025 [PubMed: 20864090]

**. Díaz MM, Bocanegra OL, Teixeira RR, Tavares M, Soares SS, Espindola FS. The relationship between the cortisol awakening response, mood states, and performance. The Journal of Strength \& Conditioning Research. 2013; 27(5):1340-1348. DOI: 10.1519/JSC.0b013e318267a612 [PubMed: 22836604]

**. Dienes KA, Hazel NA, Hammen CL. Cortisol secretion in depressed, and at-risk adults. Psychoneuroendocrinology. 2013; 38(6):927-940. DOI: 10.1016/j.psyneuen.2012.09.019 [PubMed: 23122890]

**. Dietrich A, Ormel J, Buitelaar JK, Verhulst FC, Hoekstra PJ, Hartman CA. Cortisol in the morning and dimensions of anxiety, depression, and aggression in children from a general population and clinic-referred cohort: an integrated analysis. The TRAILS study. Psychoneuroendocrinology. 2013; 38(8):1281-1298. DOI: 10.1016/j.psyneuen.2012.11.013 [PubMed: 23237815]

**. Doane LD, Adam EK. Loneliness and cortisol: Momentary, day-to-day, and trait associations. Psychoneuroendocrinology. 2010; 35(3):430-441. DOI: 10.1016/j.psyneuen.2009.08.005 [PubMed: 19744794]

**. Doane LD, Chen FR, Sladek MR, Van Lenten SA, Granger DA. Latent trait cortisol (LTC) levels: Reliability, validity, and stability. Psychoneuroendocrinology. 2015; 55:21-35. DOI: 10.1016/ j.psyneuen.2015.01.017 [PubMed: 25705799]

**. Doane LD, Franz CE, Prom-Wormley E, Eaves LJ, Mendoza SP, Hellhammer DH, et al. Jacobson KC. Negative emotionality, depressive symptoms and cortisol diurnal rhythms: Analysis of a community sample of middle-aged males. Hormones and Behavior. 2011; 60(2):202-209. DOI: 10.1016/j.yhbeh.2011.05.003 [PubMed: 21619882]

**. Donoho CJ, Weigensberg MJ, Emken BA, Hsu JW, Spruijt-Metz D. Stress and abdominal fat: Preliminary evidence of moderation by the cortisol awakening response in Hispanic peripubertal girls. Obesity. 2011; 19(5):946-952. DOI: 10.1038/oby.2010.287 [PubMed: 21127479]

**. Drake EC, Sladek MR, Doane LD. Daily cortisol activity, loneliness, and coping efficacy in late adolescence A longitudinal study of the transition to college. International Journal of Behavioral Development. 2016; 40(4):334-345. DOI: 10.1177/0165025415581914 [PubMed: 28979055]

**. Duan H, Yuan Y, Zhang L, Qin S, Zhang K, Buchanan TW, Wu J. Chronic stress exposure decreases the cortisol awakening response in healthy young men. Stress. 2013; 16(6):630-637. DOI: 10.3109/10253890.2013.840579 [PubMed: 23992539]

*. Ebrecht M, Hextall J, Kirtley LG, Taylor A, Dyson M, Weinman J. Perceived stress and cortisol levels predict speed of wound healing in healthy male adults. Psychoneuroendocrinology. 2004; 29:798-809. DOI: 10.1016/S0306-4530(03)00144-6 [PubMed: 15110929]

*. Edwards S, Hucklebridge F, Clow A, Evans P. Components of the diurnal cortisol cycle in relation to upper respiratory symptoms and perceived stress. Psychosomatic Medicine. 2003; 65:320-327. DOI: 10.1097/01.PSY.0000033123.70631.8E [PubMed: 12652001]

*. Eek FC, Garde AH, Hansen A ${ }^{\circ}$ M, Persson R, Ørbæk P, Karlson B. The cortisol awakening response - an exploration of intraindividual stability and negative responses. Scandinavian Journal of Work Environment \& Health Supplement. 2006; 2:15-21.

Egger M, Smith GD, Schneider M, Minder C. Bias in meta-analysis detected by a simple, graphical test. BMJ. 1997; 315(7109):629-634. DOI: 10.1136/bmj.315.7109.629 [PubMed: 9310563] 
Egger M, Smith GD, Schneider M, Minder C. Bias in meta-analysis detected by a simple, graphical test. BMJ. 1997; 315:629-634. DOI: 10.1136/bmj.315.7109.629 [PubMed: 9310563]

**. Ellenbogen MA, Hodgins S. Structure provided by parents in middle childhood predicts cortisol reactivity in adolescence among the offspring of parents with bipolar disorder and controls. Psychoneuroendocrinology. 2009; 34(5):773-785. DOI: 10.1016/j.psyneuen.2008.12.011 [PubMed: 19193493]

*. Ellenbogen MA, Hodgins S, Walker CD, Couture S, Adam S. Daytime cortisol and stress reactivity in the offspring of parents with bipolar disorder. Psychoneuroendocrinology. 2006; 31:11641180. DOI: 10.1016/j.psyneuen.2006.08.004 [PubMed: 17055665]

**. Eller NH, Kristiansen J, Hansen AM. Long-term effects of psychosocial factors of home and work on biomarkers of stress. International Journal of Psychophysiology. 2011; 79(2):195-202. DOI: 10.1016/j.ijpsycho.2010.10.009 [PubMed: 21034783]

*. Eller NH, Netterstrøm B, Hansen AM. Psychosocial factors at home and at work and levels of salivary cortisol. Biological Psychology. 2006; 73:280-287. DOI: 10.1016/j.biopsycho. 2006.05.003 [PubMed: 16824664]

**. Endrighi R, Hamer M, Steptoe A. Associations of trait optimism with diurnal neuroendocrine activity, cortisol responses to mental stress, and subjective stress measures in healthy men and women. Psychosomatic Medicine. 2011; 73(8):672-678. DOI: 10.1097/PSY.0b013e31822f9cd7 [PubMed: 21949426]

**. Engert V, Efanov SI, Dedovic K, Dagher A, Pruessner JC. Increased cortisol awakening response and afternoon/evening cortisol output in healthy young adults with low early life parental care. Psychopharmacology. 2011; 214(1):261-268. DOI: 10.1007/s00213-010-1918-4 [PubMed: 20596856]

Evans DR, Boggero IA, Segerstrom SC. Explaining self-regulatory fatigue and 'ego depletion': Lessons from physical fatigue. Personality and Social Psychology Review. 2016; 20(4):291-310. DOI: $10.1177 / 1088868315597841$

**. Fairchild G, van Goozen SH, Stollery SJ, Brown J, Gardiner J, Herbert J, Goodyer IM. Cortisol diurnal rhythm and stress reactivity in male adolescents with early-onset or adolescence-onset conduct disorder. Biological Psychiatry. 2008; 64(7):599-606. DOI: 10.1016/j.biopsych. 2008.05.022 [PubMed: 18620338]

**. Fekedulegn D, Burchfiel CM, Violanti JM, Hartley TA, Charles LE, Andrew ME, Miller DB. Associations of long-term shift work with waking salivary cortisol concentration and patterns among police officers. Industrial Health. 2012; 50(6):476-486. DOI: 10.2486/indhealth. 2012-0043 [PubMed: 23047078]

**. Franz CE, Spoon K, Thompson W, Hauger RL, Hellhammer DH, Jacobson KC, et al. Kremen WS. Adult cognitive ability and socioeconomic status as mediators of the effects of childhood disadvantage on salivary cortisol in aging adults. Psychoneuroendocrinology. 2013; 38(10):21272139. DOI: 10.1016/j.psyneuen.2013.04.001 [PubMed: 23684478]

**. Freitag CM, Hänig S, Palmason H, Meyer J, Wüst S, Seitz C. Cortisol awakening response in healthy children and children with ADHD: impact of comorbid disorders and psychosocial risk factors. Psychoneuroendocrinology. 2009; 34(7):1019-1028. DOI: 10.1016/j.psyneuen. 2009.01.018 [PubMed: 19278790]

Fries E, Dettenborn L, Kirschbaum C. The cortisol awakening response (CAR): Facts and future directions. International Journal of Psychophysiology. 2009; 72(1):67-73. DOI: 10.1016/ j.ijpsycho.2008.03.014 [PubMed: 18854200]

**. Garcia-Banda G, Chellew K, Fornes J, Perez G, Servera M, Evans P. Neuroticism and cortisol: pinning down an expected effect. International Journal of Psychophysiology. 2014; 91(2):132138. DOI: 10.1016/j.ijpsycho.2013.12.005 [PubMed: 24361230]

**. Gartland N, O'Connor DB, Lawton R, Bristow M. Exploring day-to-day dynamics of daily stressor appraisals, physical symptoms and the cortisol awakening response. Psychoneuroendocrinology. 2014; 50:130-138. DOI: 10.1016/j.psyneuen.2014.08.006 [PubMed: 25217853]

Gelman A, Carlin J. Beyond power calculations assessing type s (sign) and type m (magnitude) errors. Perspectives on Psychological Science. 2014; 9(6):641-651. DOI: 10.1177/1745691614551642 [PubMed: 26186114] 
**. Gonzalez-Bono E, De Andres-Garcia S, Moya-Albiol L. The cortisol awakening response in caregivers of schizophrenic offspring shows sensitivity to patient status. Anxiety Stress and Coping. 2011; 24(1):107-120. DOI: 10.1080/10615806.2010.481792

**. Gonzalez-Cabrera J, Fernandez-Prada M, Iribar-Ibabe C, Peinado JM. Acute and chronic stress increase salivary cortisol: a study in the real-life setting of a national examination undertaken by medical graduates. Stress. 2014; 17(2):149-156. DOI: 10.3109/10253890.2013.876405 [PubMed: 24351081]

**. Gostisha AJ, Vitacco MJ, Dismukes AR, Brieman C, Merz J, Shirtcliff EA. Beyond physiological hypoarousal: The role of life stress and callous-unemotional traits in incarcerated adolescent males. Hormones and Behavior. 2014; 65(5):469-479. DOI: 10.1016/j.yhbeh.2014.03.016 [PubMed: 24726789]

**. Grant N, Hamer M, Steptoe A. Social isolation and stress-related cardiovascular, lipid, and cortisol responses. Annals of Behavioral Medicine. 2009; 37(1):29-37. DOI: 10.1007/s12160-009-9081-Z [PubMed: 19194770]

*. Greaves-Lord K, Ferdinand RF, Oldehinkel AJ, Sondeijker FEPL, Ormel J, Verhulst FC. Higher cortisol awakening response in young adolescents with persistent anxiety problems. Acta Psychiatrica Scandinavica. 2007; 116:137-144. DOI: 10.1111/j.1600-0447.2007.01001.x [PubMed: 17650276]

*. Grossi G, Perski A, Ekstedt M, Johansson T, Lindstro“m M, Holm K. The morning salivary cortisol response in burnout. Journal of Psychosomatic Research. 2005; 59:103-111. DOI: 10.1016/ j.jpsychores.2005.02.009 [PubMed: 16186006]

**. Gustafsson PE, Anckarsater H, Lichtenstein P, Nelson N, Gustafsson PA. Does quantity have a quality all its own? Cumulative adversity and up- and down-regulation of circadian salivary cortisol levels in healthy children. Psychoneuroendocrinology. 2010; 35(9):1410-1415. DOI: 10.1016/j.psyneuen.2010.04.004 [PubMed: 20444551]

**. Gustafsson PE, Janlert U, Virtanen P, Hammarstrom A. The association between long-term accumulation of temporary employment, the cortisol awakening response and circadian cortisol levels. Psychoneuroendocrinology. 2012; 37(6):789-800. DOI: 10.1016/j.psyneuen.2011.09.011 [PubMed: 21996053]

**. Hansen AM, Hogh A, Persson R. Frequency of bullying at work, physiological response, and mental health. Journal of Psychosomatic Research. 2011; 70(1):19-27. DOI: 10.1016/ j.jpsychores.2010.05.010 [PubMed: 21193097]

**. Hansen AM, Thomsen JF, Kaergaard A, Kolstad HA, Kaerlev L, Mors O, et al. Mikkelsen S. Salivary cortisol and sleep problems among civil servants. Psychoneuroendocrinology. 2012; 37(7):1086-1095. DOI: 10.1016/j.psyneuen.2011.12.005 [PubMed: 22208999]

*. Harris A, Ursin H, Murison R, Erksen HR. Coffee, stress and cortisol in nursing staff. Psychoneuroendorinology. 2007; 32:322-330. DOI: 10.1016/j.psyneuen.2007.01.003

**. Hartman CA, Hermanns VW, de Jong PJ, Ormel J. Self- or parent report of (co-occurring) internalizing and externalizing problems, and basal or reactivity measures of HPA-axis functioning: A systematic evaluation of the internalizing-hyperresponsivity versus externalizinghyporesponsivity HPA-axis hypothesis. Biological Psychology. 2013; 94(1):175-184. DOI: 10.1016/j.biopsycho.2013.05.009 [PubMed: 23735709]

**. Härtwig EA, Aust S, Heuser I. HPA system activity in alexithymia: A cortisol awakening response study. Psychoneuroendocrinology. 2013; 38(10):2121-2126. DOI: 10.1016/j.psyneuen. 2013.03.023 [PubMed: 23627992]

**. Heaney JL, Phillips AC, Carroll D. Ageing, depression, anxiety, social support and the diurnal rhythm and awakening response of salivary cortisol. International Journal of Psychophysiology. 2010; 78(3):201-208. DOI: 10.1016/j.ijpsycho.2010.07.009 [PubMed: 20688111]

**. Heim C, Nater UM, Maloney E, Boneva R, Jones JF, Reeves WC. Childhood trauma and risk for chronic fatigue syndrome: association with neuroendocrine dysfunction. Archives of General Psychiatry. 2009; 66(1):72-80. DOI: 10.1001/archgenpsychiatry.2008.508 [PubMed: 19124690]

**. Hek K, Direk N, Newson RS, Hofman A, Hoogendijk WJ, Mulder CL, Tiemeier H. Anxiety disorders and salivary cortisol levels in older adults: a population-based study. Psychoneuroendocrinology. 2013; 38(2):300-305. DOI: 10.1016/j.psyneuen.2012.06.006 [PubMed: 22776419] 
Hellhammer J, Fries E, Schweisthal OW, Schlotz W, Stone AA, Hagemann D. Several daily measurements are necessary to reliably assess the cortisol rise after awakening: State-and trait components. Psychoneuroendocrinology. 2007; 32(1):80-86. DOI: 10.1016/j.psyneuen. 2006.10.005 [PubMed: 17127010]

**. Hibel LC, Mercado E, Trumbell JM. Parenting stressors and morning cortisol in a sample of working mothers. Journal of Family Psychology. 2012; 26(5):738-743. DOI: 10.1037/a0029340 [PubMed: 22866929]

**. Hicks AM, Diamond LM. Don't go to bed angry: Attachment, conflict, and affective and physiological reactivity. Personal Relationships. 2011; 18(2):266-284. DOI: 10.1111/j. 1475-6811.2011.01355.x

**. Hill EM, Billington R, Krägeloh C. The cortisol awakening response and the big five personality dimensions. Personality and Individual Differences. 2013; 55(5):600-605. DOI: 10.1016/j.paid. 2013.05.010

**. Holleman M, Vreeburg SA, Dekker JJM, Penninx BWJH. The relationships of working conditions, recent stressors and childhood trauma with salivary cortisol levels. Psychoneuroendocrinology. 2012; 37(6):801-809. DOI: 10.1016/j.psyneuen.2011.09.012 [PubMed: 22000684]

**. Hoyt LT, Craske MG, Mineka S, Adam EK. Positive and negative affect and arousal: Crosssectional and longitudinal associations with adolescent cortisol diurnal rhythms. Psychosomatic Medicine. 2015; 77(4):392-401. DOI: 10.1097/Psy.0000000000000178 [PubMed: 25905661]

**. Imeraj L, Antrop I, Roeyers H, Swanson J, Deschepper E, Bal S, Deboutte D. Time of day effects in arousal: disrupted diurnal cortisol profiles in children with ADHD. Journal of Child Psychology and Psychiatry. 2012; 53(7):782-789. DOI: 10.1111/j.1469-7610.2012.02526.x [PubMed: 22324289]

**. Isaksson J, Nilsson KW, Lindblad F. Early psychosocial adversity and cortisol levels in children with attention-deficit/hyperactivity disorder. European Child and Adolescent Psychiatry. 2013; 22(7):425-432. DOI: 10.1007/s00787-013-0383-0 [PubMed: 23397493]

**. Isaksson J, Nilsson KW, Lindblad F. The pressure-activation-stress scale in relation to ADHD and cortisol. European Child and Adolescent Psychiatry. 2015; 24(2):153-161. DOI: 10.1007/ s00787-014-0544-9 [PubMed: 24737123]

*. Izawa S, Sugaya N, Ogawa N, Nagano Y, Nakano M, Nakase E, Shirotsuki K, Yamada KC, Machida K, Kodama M, Nomura S. Episodic stress associated with writing a graduation thesis and free cortisol secretion after awakening. International Journal of Psychophysiology. 2007; 64:141-145. DOI: 10.1016/j.ijpsycho.2007.01.004 [PubMed: 17316855]

**. Jabben N, Nolen WA, Smit JH, Vreeburg SA, Beekman ATF, Penninx BWJH. Co-occurring manic symptomatology influences HPA axis alterations in depression. Journal of Psychiatric Research. 2011; 45(9):1208-1213. DOI: 10.1016/j.jpsychires.2011.03.010 [PubMed: 21450306]

**. Jarcho MR, Slavich GM, Tylova-Stein H, Wolkowitz OM, Burke HM. Dysregulated diurnal cortisol pattern is associated with glucocorticoid resistance in women with major depressive disorder. Biological Psychology. 2013; 93(1):150-158. DOI: 10.1016/j.biopsycho.2013.01.018 [PubMed: 23410758]

**. Jobin J, Wrosch C, Scheier MF. Associations between dispositional optimism and diurnal cortisol in a community sample: When stress is perceived as higher than normal. Health Psychology. 2014; 33(4):382-391. DOI: 10.1037/a0032736 [PubMed: 23668853]

*. Johnson DM, Delahanty DL, Pinna K. The cortisol awakening response as a function of PTSD severity and abuse chronicity in sheltered battered women. Journal of Anxiety Disorders. 2008; 22:793-800. DOI: 10.1016/j.janxdis.2007.08.006 [PubMed: 17890049]

**. Johnson MM, Caron KM, Mikolajewski AJ, Shirtcliff EA, Eckel LA, Taylor J. Psychopathic traits, empathy, and aggression are differentially related to cortisol awakening response. Journal of Psychopathology and Behavioral Assessment. 2014; 36(3):380-388. DOI: 10.1007/ s10862-014-9412-7

*. Kallen VL, Tulen JHM, Utens EMWJ, Treffers PDA, de Jong FH, Ferdinand RF. Associations between HPA axis functioning and level of anxiety in children and adolescents with an anxiety disorder. Depression and Anxiety. 2008; 25:131-141. DOI: 10.1002/da.20287 [PubMed: 17340603] 
Kanyongo GY, Brook GP, Kyei-Blankson L, Gocmen G. Reliability and statistical power: How measurement fallibility affects power and required sample sizes for several parametric and nonparametric statistics. Journal of Modern Applied Statistical Methods. 2007; 6(1):81-90. DOI: 10.22237/jmasm/1177992480

**. Kaplow JB, Shapiro DN, Wardecker BM, Howell KH, Abelson JL, Worthman CM, Prossin AR. Psychological and environmental correlates of HPA axis functioning in parentally bereaved children: Preliminary findings. Journal of Traumatic Stress. 2013; 26(2):233-240. DOI: 10.1002/ jts.21788 [PubMed: 23526635]

**. Karhula K, Harma M, Sallinen M, Lindholm H, Hirvonen A, Elovainio M, et al. Puttonen S. Association of job strain with cortisol and alpha-amylase among shift-working health care professionals in laboratory and field. Biological Research for Nursing. 2015; 18:101-112. DOI: 10.1177/1099800415577801 [PubMed: 25827426]

**. Keeshin BR, Strawn JR, Out D, Granger DA, Putnam FW. Cortisol awakening response in adolescents with acute sexual abuse related posttraumatic stress disorder. Depression and Anxiety. 2014; 31(2):107-114. DOI: 10.1002/da.22154 [PubMed: 23893710]

**. Kim HK, Tiberio SS, Capaldi DM, Shortt JW, Squires EC, Snodgrass JJ. Intimate partner violence and diurnal cortisol patterns in couples. Psychoneuroendocrinology. 2015; 51:35-46. DOI: 10.1016/j.psyneuen.2014.09.013 [PubMed: 25286224]

**. Klaassens ER, Giltay EJ, van Veen T, Veen G, Zitman FG. Trauma exposure in relation to basal salivary cortisol and the hormone response to the dexamethasone/CRH test in male railway employees without lifetime psychopathology. Psychoneuroendocrinology. 2010; 35(6):878-886. DOI: 10.1016/j.psyneuen.2009.11.012 [PubMed: 20036072]

**. Klaassens ER, van Noorden MS, Giltay EJ, van Pelt J, van Veen T, Zitman FG. Effects of childhood trauma on HPA-axis reactivity in women free of lifetime psychopathology. Progress in Neuro-Psychopharmacology \& Biological Psychiatry. 2009; 33(5):889-894. DOI: 10.1016/ j.pnpbp.2009.04.011 [PubMed: 19389455]

**. Klein LC, Kim K, Almeida DM, Femia EE, Rovine MJ, Zarit SH. Anticipating an easier day: Effects of adult day services on daily cortisol and stress. Gerontologist. 2014; doi: 10.1093/ geront/gnu060

**. Klein M, Weksler N, Gidron Y, Heldman E, Gurski E, Smith ORF, Gurman GM. Do waking salivary cortisol levels correlate with anesthesiologist's job involvement? Journal of Clinical Monitoring and Computing. 2012; 26(6):407-413. DOI: 10.1007/s10877-012-9367-8 [PubMed: 22592182]

*. Kliewer W. Violence exposure and cortisol responses in urban youth. International Journal of Behavioral Medicine. 2006; 13:109-120. DOI: 10.1207/s15327558ijbm1302_2 [PubMed: 16712428]

**. Knack JM, Jensen-Campbell LA, Baum A. Worse than sticks and stones? Bullying is associated with altered HPA axis functioning and poorer health. Brain and Cognition. 2011; 77(2):183-190. DOI: 10.1016/j.bandc.2011.06.011 [PubMed: 21839567]

**. Kuehl LK, Hinkelmann K, Muhtz C, Dettenborn L, Wingenfeld K, Spitzer C, et al. Otte C. Hair cortisol and cortisol awakening response are associated with criteria of the metabolic syndrome in opposite directions. Psychoneuroendocrinology. 2015; 51:365-370. DOI: 10.1016/j.psyneuen. 2014.09.012 [PubMed: 25462908]

**. Kuehner C, Huffziger S, Witt SH, Rietschel M. PCLO rs2522833 impacts HPA system activity in healthy young adults. Translational Psychiatry. 2011; doi: 10.1038/tp.2011.11

**. Kuhlman KR, Geiss EG, Vargas I, Lopez-Duran NL. Differential associations between childhood trauma subtypes and adolescent HPA-axis functioning. Psychoneuroendocrinology. 2015; 54:103-114. DOI: 10.1016/j.psyneuen.2015.01.020 [PubMed: 25704913]

**. Kumari M, Badrick E, Chandola T, Adam EK, Stafford M, Marmot MG, et al. Kivimaki M. Cortisol secretion and fatigue: associations in a community based cohort. Psychoneuroendocrinology. 2009; 34(10):1476-1485. DOI: 10.1016/j.psyneuen.2009.05.001 [PubMed: 19497676]

**. Kumari M, Head J, Bartley M, Stansfeld S, Kivimaki M. Maternal separation in childhood and diurnal cortisol patterns in mid-life: findings from the Whitehall II study. Psychological Medicine. 2013; 43(03):633-643. DOI: 10.1017/S0033291712001353 [PubMed: 22785027] 
**. Lac G, Dutheil F, Brousse G, Triboulet-Kelly C, Chamoux A. Saliva DHEAS changes in patients suffering from psychopathological disorders arising from bullying at work. Brain and Cognition. 2012; 80(2):277-281. DOI: 10.1016/j.bandc.2012.07.007 [PubMed: 22940752]

**. Laceulle OM, Nederhof E, van Aken MA, Ormel J. Adolescent personality: Associations with basal, awakening, and stress-induced cortisol responses. Journal of Personality. 2014; 83:262273. DOI: 10.1111/jopy.12101 [PubMed: 24730365]

**. Lai JC, Chong AM, Siu OT, Evans P, Chan CL, Ho RT. Humor attenuates the cortisol awakening response in healthy older men. Biological Psychology. 2010; 84(2):375-380. DOI: 10.1016/ j.biopsycho.2010.03.012 [PubMed: 20303378]

**. Lai JC, Chong AM, Siu OT, Evans P, Chan CL, Ho RT. Social network characteristics and salivary cortisol in healthy older people. The Scientific World Journal. 2012; 2012:1-8. DOI: 10.1100/2012/929067

*. Lai JCL, Evans PD, Ng SH, Chong AML, Siu OT, Chan CLW, et al. Chan CC. Optimism, positive affectivity, and salivary cortisol. British Journal of Health Psychology. 2005; 10:467-484. DOI: 10.1348/135910705X26083 [PubMed: 16238860]

**. Lamers F, Vogelzangs N, Merikangas KR, de Jonge P, Beekman ATF, Penninx BWJH. Evidence for a differential role of HPA-axis function, inflammation and metabolic syndrome in melancholic versus atypical depression. Molecular Psychiatry. 2013; 18(6):692-699. DOI: 10.1038/Mp.2012.144 [PubMed: 23089630]

*. Langelaan S, Bakker AB, Schaufeli WB, van Rhenen W, van Doornen LJP. Do burned-out and work-engaged employees differ in the functioning of the hypothalamic-pituitary-adrenal axis? Scandinavian Journal of Work Environment \& Health. 2006; 32:339-348. doi: www.jstor.org/ stable/40967586.

**. Laudenslager ML, Noonan C, Jacobsen C, Goldberg J, Buchwald D, Bremner JD, et al. Manson SM. Salivary cortisol among American Indians with and without posttraumatic stress disorder (PTSD): gender and alcohol influences. Brain, Behavior, and Immunity. 2009; 23(5):658-662. DOI: $10.1016 /$ j.bbi.2008.12.007

Law R, Hucklebridge F, Thorn L, Evans P, Clow A. State variation in the cortisol awakening response. Stress. 2013; 16(5):483-492. DOI: 10.3109/10253890.2013.817552 [PubMed: 23805796]

Law R, Hucklebridge F, Thorn L, Evans P, Clow A. State variation in the cortisol awakening response. Stress. 2013; 16(5):483-492. DOI: 10.3109/10253890.2013.817552 [PubMed: 23805796]

**. Lederbogen F, Kuhner C, Kirschbaum C, Meisinger C, Lammich J, Holle R, et al. Ladwig KH. Salivary cortisol in a middle-aged community sample: results from 990 men and women of the KORA-F3 Augsburg study. European Journal of Endocrinology. 2010; 163(3):443-451. DOI: 10.1530/Eje-10-0491 [PubMed: 20576743]

**. Leggett AN, Zarit SH, Kim K, Almeida DM, Klein LC. Depressive mood, anger, and daily cortisol of caregivers on high- and low-stress days. Journals of Gerontology Series B: Psychological Sciences and Social Sciences. 2014; doi: 10.1093/geronb/gbu070

**. Liao J, Brunner EJ, Kumari M. Is there an association between work stress and diurnal cortisol patterns? Findings from the Whitehall II study. PloS one. 2013; 8(12):e81020. 10.1371/ journal.pone.0081020. [PubMed: 24312516]

**. Lindholm H, Ahlberg J, Sinisalo J, Hublin C, Hirvonen A, Partinen M, et al. Savolainen A. Morning cortisol levels and perceived stress in irregular shift workers compared with regular daytime workers. Sleep Disorders. 2012; 2012:1-5. DOI: 10.1155/2012/789274

**. Lovell B, Moss M, Wetherell MA. Perceived stress, common health complaints and diurnal patterns of cortisol secretion in young, otherwise healthy individuals. Hormones and Behavior. 2011; 60(3):301-305. DOI: 10.1016/j.yhbeh.2011.06.007 [PubMed: 21722644]

**. Lovell B, Moss M, Wetherell MA. With a little help from my friends: Psychological, endocrine and health corollaries of social support in parental caregivers of children with autism or ADHD. Research in Developmental Disabilities. 2012; 33(2):682-687. DOI: 10.1016/j.ridd.2011.11.014 [PubMed: 22186636]

**. Lovell B, Moss M, Wetherell MA. The psychophysiological and health corollaries of child problem behaviours in caregivers of children with autism and ADHD. Journal of Intellectual Disability Research. 2015; 59(2):150-157. DOI: 10.1111/Jir.12081 [PubMed: 23889770] 
**. Lu S, Gao W, Wei Z, Wu W, Liao M, Ding Y, et al. Li L. Reduced cingulate gyrus volume associated with enhanced cortisol awakening response in young healthy adults reporting childhood trauma. PLoS ONE. 2013; 8(7):e69350.doi: 10.1371/journal.pone.0069350 [PubMed: 23894454]

**. Madsen KS, Jernigan TL, Iversen P, Frokjaer VG, Mortensen EL, Knudsen GM, Baaré WF. Cortisol awakening response and negative emotionality linked to asymmetry in major limbic fibre bundle architecture. Psychiatry Research: Neuroimaging. 2012; 201(1):63-72. DOI: 10.1016/ j.pscychresns.2011.07.015 [PubMed: 22285720]

**. Maina G, Bovenzi M, Palmas A, Filon FL. Associations between two job stress models and measures of salivary cortisol. International Archives of Occupational and Environmental Health. 2009; 82(9):1141-1150. DOI: 10.1007/s00420-009-0439-0 [PubMed: 19554345]

**. Maina G, Palmas A, Bovenzi M, Filon FL. Salivary cortisol and psychosocial hazards at work. American Journal of Industrial Medicine. 2009; 52(3):251-260. DOI: 10.1002/ajim.20659 [PubMed: 19023870]

**. Mangold D, Marino E, Javors M. The cortisol awakening response predicts subclinical depressive symptomatology in Mexican American adults. Journal of Psychiatric Research. 2011; 45(7):902909. DOI: 10.1016/j.jpsychires.2011.01.001 [PubMed: 21300376]

**. Mangold D, Mintz J, Javors M, Marino E. Neuroticism, acculturation and the cortisol awakening response in Mexican American adults. Hormones and Behavior. 2012; 61(1):23-30. DOI: 10.1016/j.yhbeh.2011.09.009 [PubMed: 21983226]

**. Mangold D, Wand G, Javors M, Mintz J. Acculturation, childhood trauma and the cortisol awakening response in Mexican-American adults. Hormones and Behavior. 2010; 58(4):637646. DOI: 10.1016/j.yhbeh.2010.06.010 [PubMed: 20600049]

**. Marchand A, Juster RP, Durand P, Lupien SJ. Burnout symptom sub-types and cortisol profiles: What's burning most? Psychoneuroendocrinology. 2014; 40:27-36. DOI: 10.1016/j.psyneuen. 2013.10.011 [PubMed: 24485473]

**. Marsman R, Nederhof E, Rosmalen JGM, Oldehinkel AJ, Ormel J, Buitelaar JK. Family environment is associated with HPA-axis activity in adolescents. The TRAILS study. Biological Psychology. 2012; 89(2):460-466. DOI: 10.1016/j.biopsycho.2011.12.013 [PubMed: 22212280]

**. Marsman R, Rosmalen JG, Oldehinkel AJ, Ormel J, Buitelaar JK. Does HPA-axis activity mediate the relationship between obstetric complications and externalizing behavior problems? The TRAILS study. European Child and Adolescent Psychiatry. 2009; 18(9):565-573. DOI: 10.1007/ s00787-009-0014-y [PubMed: 19353232]

*. Meinlschmidt G, Heim C. Decreased cortisol awakening response after early loss experience. Psychoneuroendocrinology. 2005; 30:568-576. DOI: 10.1016/j.psyneuen.2005.01.006 [PubMed: 15808926]

**. Mello AF, Juruena MF, Maciel MR, Cavalcante-Nobrega LP, Cividanes GC, Fossaluza V, et al. Mari Jde J. Factors related to the cortisol awakening response of children working on the streets and siblings, before and after 2 years of a psychosocial intervention. Psychiatry Research. 2015; 225(3):625-630. DOI: 10.1016/j.psychres.2014.11.034 [PubMed: 25500347]

**. Merwin SM, Smith VC, Dougherty LR. "It takes two": The interaction between parenting and child temperament on parents' stress physiology. Developmental Psychobiology. 2015; 57(3): 336-348. DOI: 10.1002/Dev.21301 [PubMed: 25784159]

**. Mikolajczak M, Quoidbach J, Vanootighem V, Lambert F, Lahaye M, Fillee C, de Timary P. Cortisol awakening response (CAR)'s flexibility leads to larger and more consistent associations with psychological factors than CAR magnitude. Psychoneuroendocrinology. 2010; 35(5):752757. DOI: 10.1016/j.psyneuen.2009.11.003 [PubMed: 19959296]

Mikolajczak M, Quoidbach J, Vanootighem V, Lambert F, Lahaye M, Fillée C, de Timary P. Cortisol awakening response (CAR)'s flexibility leads to larger and more consistent associations with psychological factors than CAR magnitude. Psychoneuroendocrinology. 2010; 35(5):752-757. DOI: 10.1016/j.psyneuen.2009.11.003 [PubMed: 19959296]

Miller GE, Chen E, Zhou ES. If it goes up, must it come down? Chronic stress and the hypothalamicpituitary-adrenocortical axis in humans. Psychological Bulletin. 2007; 133(1):25-45. DOI: 10.1037/0033-2909.133.1.25 [PubMed: 17201569] 
*. Mommersteeg PMC, Heijnen CJ, Verbraak MJPM, van Doornen LJP. Clinical burnout is not reflected in the cortisol awakening response, the day curve or the response to a low-dose dexamethasone suppression test. Psychoneuroendocrinology. 2006; 31:216-225. DOI: 10.1016/ j.psyneuen.2005.07.003 [PubMed: 16150550]

**. Mossink JCL, Verkuil B, Burger AM, Tollenaar MS, Brosschot JF. Ambulatory assessed implicit affect is associated with salivary cortisol. Frontiers in Psychology. 2015; 6:1-10. DOI: 10.3389/ fpsyg.2015.00111 [PubMed: 25688217]

**. Moya-Albiol L, Serrano MA, Salvador A. Job satisfaction and cortisol awakening response in teachers scoring high and low on burnout. Spanish Journal of Psychology. 2010; 13(2):629-636. [PubMed: 20977013]

**. Nagy T, Salavecz G, Simor P, Purebl G, Bódizs R, Dockray S, Steptoe A. Frequent nightmares are associated with blunted cortisol awakening response in women. Physiology \& Behavior. 2015; 147:233-237. DOI: 10.1016/j.physbeh.2015.05.001 [PubMed: 25953663]

**. Nelemans SA, Hale WW, Branje SJT, van Lier PAC, Jansen LMC, Platje E, et al. Meeus WHJ. Persistent heightened cortisol awakening response and adolescent internalizing symptoms: A 3year longitudinal community study. Journal of Abnormal Child Psychology. 2014; 42(5):767777. DOI: 10.1007/s10802-013-9820-2 [PubMed: 24189903]

**. Neu M, Matthews E, King NA, Cook PF, Laudenslager ML. Anxiety, depression, stress, and cortisol levels in mothers of children undergoing maintenance therapy for childhood acute lymphoblastic leukemia. Journal of Pediatric Oncology Nursing. 2014; 31(2):104-113. DOI: 10.1177/1043454213520346 [PubMed: 24608702]

*. Neylan TC, Brunet A, Pole N, Best SR, Metzler TJ, Yehuda R, Marmar CR. PTSD symptoms predict waking salivary cortisol levels in police officers. Psychoneuroendocrinology. 2005; 30:373-381. DOI: 10.1016/j.psyneuen.2004.10.005 [PubMed: 15694117]

*. Nicolson NA, Diest RV. Salivary cortisol patterns in vital exhaustion. Journal of Psychosomatic Research. 2000; 49:335-342. DOI: 10.1016/S0022-3999(00)00166-5 [PubMed: 11164057]

*. O'Donnell K, Badrick E, Kumari M, Steptoe A. Psychological coping styles and cortisol over the day in healthy older adults. Psychoneuroendocrinology. 2008; 33:601-611. DOI: 10.1016/ j.psyneuen.2008.01.015 [PubMed: 18329182]

**. O'Connor DB, Hendrickx H, Dadd T, Elliman TD, Willis TA, Talbot D, et al. Dye L. Cortisol awakening rise in middle-aged women in relation to psychological stress. Psychoneuroendocrinology. 2009; 34(10):1486-1494. DOI: 10.1016/j.psyneuen.2009.05.002 [PubMed: 19520518]

**. Okamura H, Tsuda A, Matsuishi T. The relationship between perceived loneliness and cortisol awakening responses on work days and weekends. Japanese Psychological Research. 2011; 53(2):113-120. DOI: 10.1111/j.1468-5884.2011.00459.x

**. Olsson EMG, Roth WT, Melin L. Psychophysiological characteristics of women suffering from stress-related fatigue. Stress and Health. 2010; 26(2):113-126. DOI: 10.1002/Smi.1271

**. Ong AD, Fuller-Rowell TE, Bonanno GA, Almeida DM. Spousal loss predicts alterations in diurnal cortisol activity through prospective changes in positive emotion. Health Psychology. 2011; 30(2):220-227. DOI: 10.1037/A0022262 [PubMed: 21401256]

**. Oosterholt BG, Maes JH, Van der Linden D, Verbraak MJ, Kompier MA. Burnout and cortisol: evidence for a lower cortisol awakening response in both clinical and non-clinical burnout. Journal of Psychosomatic Research. 2015; 78(5):445-451. DOI: 10.1016/j.jpsychores. 2014.11.003 [PubMed: 25433974]

**. Oskis A, Clow A, Loveday C, Hucklebridge F, Sbarra DA. Biological stress regulation in female adolescents: A key role for confiding. Journal of Youth and Adolescence. 2015; 44(5):10661077. DOI: 10.1007/s10964-014-0182-z [PubMed: 25200034]

**. Oskis A, Loveday C, Hucklebridge F, Thorn L, Clow A. Anxious attachment style and salivary cortisol dysregulation in healthy female children and adolescents. Journal of Child Psychology and Psychiatry. 2011; 52(2):111-118. DOI: 10.1111/j.1469-7610.2010.02296.x [PubMed: 20695930] 
**. Österberg K, Karlson B, Hansen ÅM. Cognitive performance in patients with burnout, in relation to diurnal salivary cortisol. Stress. 2009; 12(1):70-81. DOI: 10.1080/10253890802049699 [PubMed: 18951245]

**. Peng H, Long Y, Li J, Guo Y, Wu H, Yang Y, et al. Ning Y. Hypothalamic-pituitary-adrenal axis functioning and dysfunctional attitude in depressed patients with and without childhood neglect. BMC psychiatry. 2014; 14(1):1-9. DOI: 10.1186/1471-244X-14-45

**. Pinna KLM, Johnson DM, Delahanty DL. PTSD, comorbid depression, and the cortisol waking response in victims of intimate partner violence: Preliminary evidence. Anxiety Stress and Coping. 2014; 27(3):253-269. DOI: 10.1080/10615806.2013.852185

**. Platje E, Vermeiren RRJM, Raine A, Doreleijers TAH, Keijsers LGMT, Branje SJT, et al. Jansen LMC. A longitudinal biosocial study of cortisol and peer influence on the development of adolescent antisocial behavior. Psychoneuroendocrinology. 2013; 38(11):2770-2779. DOI: 10.1016/j.psyneuen.2013.07.006 [PubMed: 23927935]

*. Polk DE, Cohen S, Doyle WJ, Skoner DP, Kirschbaum C. State and trait affect as predictors of salivary cortisol in healthy adults. Psychoneuroendocrinology. 2005; 30:261-272. DOI: 10.1016/ j.psyneuen.2004.08.004 [PubMed: 15511600]

*. Portella MJ, Harmer CJ, Cowen P, Goodwin GM. Enhanced early morning salivary cortisol in neuroticism. American Journal of Psychiatry. 2005; 162:807-809. [PubMed: 15800161]

Prentice DA, Miller DT. When small effects are impressive. Psychological Bulletin. 1992; 112(1):160_ 164. DOI: 10.1037/0033-2909.112.1.160

Pruessner JC, Wolf OT, Hellhammer DH, Buske-Kirschbaum A, Von Auer K, Jobst S, et al. Kirschbaum C. Free cortisol levels after awakening: a reliable biological marker for the assessment of adrenocortical activity. Life Sciences. 1997; 61(26):2539-2549. DOI: 10.1016/ S0024-3205(97)01008-4 [PubMed: 9416776]

*. Pruessner JC, Hellhammer DH, Kirschbaum C. Burnout, perceived stress, and cortisol responses to awakening. Psychosomatic Medicine. 1999; 61:197-204. doi:0033-3174/99/6102-0197. [PubMed: 10204973]

*. Pruessner M, Hellhammer DH, Pruessner JC, Lupien SJ. Self-reported depressive symptoms and stress levels in healthy young men: associations with the cortisol response to awakening. Psychosomatic Medicine. 2003; 65:92-99. DOI: 10.1097/01.PSY.0000040950.22044.10 [PubMed: 12554820]

**. Quevedo K, Johnson AE, Loman ML, LaFavor TL, Gunnar M. The confluence of adverse early experience and puberty on the cortisol awakening response. International Journal of Behavioral Development. 2012; 36(1):19-28. DOI: 10.1177/0165025411406860 [PubMed: 22383860]

*. Quirin M, Pruessner JC, Kuhl J. HPA system regulation and adult attachment anxiety: individual differences in reactive and awakening cortisol. Psychoneuroendocrinology. 2008; 33:581-590. DOI: 10.1016/j.psyneuen.2008.01.013 [PubMed: 18329180]

**. Rademaker AR, Kleber RJ, Geuze E, Vermetten E. Personality dimensions harm avoidance and self-directedness predict the cortisol awakening response in military men. Biological Psychology. 2009; 81(3):177-183. DOI: 10.1016/j.biopsycho.2009.04.002 [PubMed: 19428168]

**. Rane LJ, Fekadu A, Papadopoulos AS, Wooderson SC, Poon L, Markopoulou K, Cleare AJ. Psychological and physiological effects of caring for patients with treatment-resistant depression. Psychological Medicine. 2012; 42(09):1825-1833. DOI: 10.1017/S0033291711003035 [PubMed: 22251699]

**. Ranjit N, Diez-Roux AV, Sanchez B, Seeman T, Shea S, Shrager S, Watson K. Association of salivary cortisol circadian pattern with cynical hostility: multiethnic study of atherosclerosis. Psychosomatic Medicine. 2009; 71(7):748-755. DOI: 10.1097/PSY.0b013e3181ad23e7 [PubMed: 19592518]

**. Rhebergen D, Korten NC, Penninx BW, Stek ML, van der Mast RC, Oude Voshaar R, Comijs HC. Hypothalamic-pituitary-adrenal axis activity in older persons with and without a depressive disorder. Psychoneuroendocrinology. 2015; 51:341-350. DOI: 10.1016/j.psyneuen.2014.10.005 [PubMed: 25462906]

**. Rickenbach EH, Almeida DM, Seeman TE, Lachman ME. Daily stress magnifies the association between cognitive decline and everyday memory problems: An integration of longitudinal and 
diary methods. Psychology and Aging. 2014; 29(4):852-862. DOI: 10.1037/A0038072 [PubMed: 25365691]

*. Roberts ADL, Wessely S, Chalder T, Papadopoulos A, Cleare AJ. Salivary cortisol response to awakening in chronic fatigue syndrome. British Journal of Psychiatry. 2004; 184:136-141. DOI: 10.1192/bjp.184.2.136 [PubMed: 14754825]

*. Rohleder N, Joksimovic L, Wolf JM, Kirschbaum C. Hypocortisolism and increased glucocorticoid sensitivity of pro-inflammatory cytokine production in Bosnian war refugees with posttraumatic stress disorder. Biological Psychiatry. 2004; 55:745-751. DOI: 10.1016/j.biopsych.2003.11.018 [PubMed: 15039004]

Rosenthal R. The file drawer problem and tolerance for null results. Psychological Bulletin. 1979; 86(3):638-641. DOI: 10.1037/0033-2909.86.3.638

**. Ruhé HG, Khoenkhoen SJ, Ottenhof KW, Koeter MW, Mocking RJ, Schene AH. Longitudinal effects of the SSRI paroxetine on salivary cortisol in Major Depressive Disorder. Psychoneuroendocrinology. 2015; 52:261-271. DOI: 10.1016/j.psyneuen.2014.10.024 [PubMed: 25544738]

**. Ruiz-Robledillo N, Moya-Albiol L. Self-reported health and Cortisol Awakening Response in parents of people with Asperger syndrome: The role of trait anger and anxiety, coping and burden. Psychology \& Health. 2013; 28(11):1246-1264. DOI: 10.1080/08870446.2013.800517 [PubMed: 23713979]

**. Ruiz-Robledillo N, Moya-Albiol L. Emotional intelligence modulates cortisol awakening response and self-reported health in caregivers of people with autism spectrum disorders. Research in Autism Spectrum Disorders. 2014; 8(11):1535-1543. DOI: 10.1016/j.rasd.2014.08.003

**. Ruiz-Robledillo N, De Andres-Garcia S, Perez-Blasco J, Gonzalez-Bono E, Moya-Albiol L. Highly resilient coping entails better perceived health, high social support and low morning cortisol levels in parents of children with autism spectrum disorder. Research in Developmental Disabilities. 2014; 35(3):686-695. DOI: 10.1016/j.ridd.2013.12.007 [PubMed: 24405793]

**. Ruiz-Robledillo N, Gonzalez-Bono E, Moya-Albiol L. Lack of institutional support entails disruption in cortisol awakening response in caregivers of people with high-functioning autism. Journal of Health Psychology. 2014; 19(12):1586-1596. DOI: 10.1177/1359105313496444 [PubMed: 23933951]

Sapolsky, RM. Why zebras don't get ulcers: The acclaimed guide to stress, stress-related diseases, and coping-now revised and updated. Macmillan; 2004.

**. Saridjan NS, Velders FP, Jaddoe VW, Hofman A, Verhulst FC, Tiemeier H. The longitudinal association of the diurnal cortisol rhythm with internalizing and externalizing problems in preschoolers. The Generation R Study. Psychoneuroendocrinology. 2014; 50:118-129. DOI: 10.1016/j.psyneuen.2014.08.008 [PubMed: 25202831]

*. Schlotz W, Hellhammer J, Schulz P, Stone AA. Perceived work overload and chronic worrying predict weekend-weekday differences in the cortisol awakening response. Psychosomatic Medicine. 2004; 66:207-214. doi:0033-3174/04/6602-0207. [PubMed: 15039505]

*. Schulz P, Kirschbaum C, Pru“ bner J, Hellhammer D. Increased free cortisol secretion after awakening in chronically stressed individuals due to work overload. Stress Medicine. 1998; 14:91-97.

Segerstrom SC, Miller GE. Psychological stress and the human immune system: a meta-analytic study of 30 years of inquiry. Psychological Bulletin. 2004; 130(4):601-630. DOI: 10.1037/0033-2909.130.4.601 [PubMed: 15250815]

**. Shibuya I, Nagamitsu S, Okamura H, Ozono S, Chiba H, Ohya T, et al. Matsuishi T. High correlation between salivary cortisol awakening response and the psychometric profiles of healthy children. Biopsychosocial Medicine. 2014; 8(1):1-9. DOI: 10.1186/1751-0759-8-9 [PubMed: 24383884]

Simmons JP, Nelson LD, Simonsohn U. False-positive psychology undisclosed flexibility in data collection and analysis allows presenting anything as significant. Psychological Science. 2011; 22:1359-1366. DOI: 10.1177/0956797611417632 [PubMed: 22006061]

Simonsohn U, Nelson LD, Simmons JP. P-curve: A key to the file-drawer. Journal of Experimental Psychology: General. 2014a; 143(2):534-547. DOI: 10.1037/a0033242 [PubMed: 23855496] 
Simonsohn U, Nelson LD, Simmons JP. p-Curve and effect size correcting for publication bias using only significant results. Perspectives on Psychological Science. 2014b; 9(6):666-681. DOI: 10.1177/1745691614553988 [PubMed: 26186117]

Simonsohn, Uri, Simmons, Joseph P., Nelson, Leif D. Better P-curves: Making P-curve analysis more robust to errors, fraud, and ambitious P-hacking: A reply to Ulrich and Miller (2015). Journal of Experimental Psychology: General. 2015; 144:1146-1152. [PubMed: 26595842]

*. Sjögren E, et al. Leanderson P, Kristenson M. Diurnal saliva cortisol levels and relations to psychosocial factors in a population sample of middle-aged Swedish men and women. International Journal of Behavioral Medicine. 2006; 13:193-200. DOI: 10.1207/ s15327558ijbm1303_2 [PubMed: 17078769]

**. Sjödin F, Kjellberg A, Knutsson A, Landström U, Lindberg L. Noise and stress effects on preschool personnel. Noise and Health. 2012; 14(59):166-178. [PubMed: 22918147]

**. Sjörs A, Jonsdottir IH. No alterations in diurnal cortisol profiles before and during the treatment in patients with stress-related exhaustion. International Journal of Occupational Medicine and Environmental Health. 2015; 28(1):120-129. DOI: 10.13075/ijomeh.1896.00208 [PubMed: 26159953]

**. Sjors A, Ljung T, Jonsdottir IH. Long-term follow-up of cortisol awakening response in patients treated for stress-related exhaustion. BMJ Open. 2012; 2(4):1-8. DOI: 10.1136/ bmjopen-2012-001091

**. Sjors A, Ljung T, Jonsdottir IH. Diurnal salivary cortisol in relation to perceived stress at home and at work in healthy men and women. Biological Psychology. 2014; 99:193-197. DOI: 10.1016/ j.biopsycho.2014.04.002 [PubMed: 24746849]

**. Sladek MR, Doane LD. Daily diary reports of social connection, objective sleep, and the cortisol awakening response during adolescents' first year of college. Journal of Youth and Adolescence. 2015; 44(2):298-316. DOI: 10.1007/s10964-014-0244-2 [PubMed: 25537099]

*. Smeets T, Geraerts E, Jelicic M, Merckelbach H. Delayed recall of childhood sexual abuse memories and the awakening rise and diurnal pattern of cortisol. Psychiatry Research. 2007; 152:197-204. DOI: 10.1016/j.psychres.2006.07.008 [PubMed: 17449112]

**. Smyth N, Hucklebridge F, Thorn L, Evans P, Clow A. Salivary cortisol as a biomarker in social science research. Social and Personality Psychology Compass. 2013; 7(9):605-625. DOI: $10.1111 / \mathrm{spc} 3.12057$

*. Sonnenschein M, Mommersteeg PMC, Houtveen JH, Sorbi MJ, Schaufeli WB, van Doornen LJP. Exhaustion and endocrine functioning in clinical burnout: an in-depth study using the experience sampling method. Biological Psychology. 2007; 75:176-184. DOI: 10.1016/j.biopsycho. 2007.02.001 [PubMed: 17379387]

**. Stafford M, Gardner M, Kumari M, Kuh D, Ben-Shlomo Y. Social isolation and diurnal cortisol patterns in an ageing cohort. Psychoneuroendocrinology. 2013; 38(11):2737-2745. DOI: 10.1016/j.psyneuen.2013.07.002 [PubMed: 23920224]

**. Stalder T, Evans P, Hucklebridge F, Clow A. Associations between the cortisol awakening response and heart rate variability. Psychoneuroendocrinology. 2011; 36(4):454-462. DOI: 10.1016/ j.psyneuen.2010.07.020 [PubMed: 20732747]

Stalder T, Kirschbaum C, Kudielka BM, Adam EK, Pruessner JC, Wüst S, et al. Miller R. Assessment of the cortisol awakening response: Expert consensus guidelines. Psychoneuroendocrinology. 2016; 63:414-432. DOI: 10.1016/j.psyneuen.2015.10.010 [PubMed: 26563991]

**. Stawski RS, Cichy KE, Piazza JR, Almeida DM. Associations among daily stressors and salivary cortisol: Findings from the National Study of Daily Experiences. Psychoneuroendocrinology. 2013; 38(11):2654-2665. DOI: 10.1016/j.psyneuen.2013.06.023 [PubMed: 23856186]

**. Steinheuser V, Ackermann K, Schonfeld P, Schwabe L. Stress and the city: Impact of urban upbringing on the (re)activity of the hypothalamus-pituitary-adrenal axis. Psychosomatic Medicine. 2014; 76(9):678-685. DOI: 10.1097/Psy.0000000000000113 [PubMed: 25333499]

*. Steptoe A, Brydon L, Kunz-Ebrecht S. Changes in financial strain over three years, ambulatory blood pressure, and cortisol responses to awakening. Psychosomatic Medicine. 2005; 67:281287. doi:0033-3174/05/6702-0281. [PubMed: 15784795] 
*. Steptoe A, Gibson EL, Hamer M, Wardle J. Neuroendocrine and cardiovascular correlates of positive affect measured by ecological momentary assessment and by questionnaire. Psychoneuroendocrinology. 2007; 32:56-64. DOI: 10.1016/j.psyneuen.2006.10.001 [PubMed: 17157442]

Steptoe A, Hamer M, Chida Y. The effects of acute psychological stress on circulating inflammatory factors in humans: a review and meta-analysis. Brain, Behavior, and Immunity. 2007; 21(7):901912. DOI: 10.1016/j.bbi.2007.03.011

*. Steptoe A, Owen N, Kunz-Ebrecht SR, Brydon L. Loneliness and neuroendocrine, cardiovascular, and inflammatory stress responses in middle-aged men and women. Psychoneuroendocrinology. 2004; 29:593-611. DOI: 10.1016/S0306-4530(03)00086-6 [PubMed: 15041083]

*. Steptoe A, Siegrist J, Kirschbaum C, Marmot M. Effort-reward imbalance, overcommitment, and measure of cortisol and blood pressure over the working day. Psychosomatic Medicine. 2004; 66:323-329. doi:0033-3174/04/6603-0323. [PubMed: 15184690]

*. Stetler C, Miller GE. Blunted cortisol response to awakening in mild to moderate depression: regulatory influences of sleep patterns and social contacts. Journal of Abnormal Psychology. 2005; 114:687-705. DOI: 10.1037/0021-843X.114.4.697

**. Strahler K, Ehrlenspiel F, Heene M, Brand R. Competitive anxiety and cortisol awakening response in the week leading up to a competition. Psychology of Sport and Exercise. 2010; 11(2):148-154. DOI: $10.1016 /$ j.psychsport.2009.10.003

**. Tang A, Beaton EA, Schulkin J, Hall GB, Schmidt LA. Revisiting shyness and sociability: A preliminary investigation of hormone-brain-behavior relations. Frontiers in Psychology. 2014; 5:1-11. DOI: 10.3389/fpsyg.2014.01430 [PubMed: 24474945]

*. ter Wolbeek M, van Doornen LJP, Coffeng LE, Kavelaars A, Heijnen CJ. Cortisol and severe fatigue: a longitudinal study in adolescent girls. Psychoneuroendocrinology. 2007; 32:171-182. DOI: 10.1016/j.psyneuen.2006.12.003 [PubMed: 17287088]

*. Therrien F, Drapeau V, Lalonde J, Lupien SJ, Beaulieu S, Tremblay A, Richard D. Awakening cortisol response in lean, obese, and reduced obese individuals: effect of gender and fat distribution. Obesity. 2007; 15:377-385. DOI: 10.1038/oby.2007.509 [PubMed: 17299111]

*. Therrien F, Drapeau V, Lupien SJ, Beaulieu S, Dore' J, Tremblay A, Richard D. Awakening cortisol response in relation to psychosocial profiles and eating behaviors. Physiological Behavior. 2007; 93:282-288. DOI: 10.1016/j.physbeh.2007.08.019

**. Thomas KS, Bower JE, Williamson TJ, Hoyt MA, Wellisch D, Stanton AL, Irwin M. Posttraumatic disorder symptoms and blunted diurnal cortisol production in partners of prostate cancer patients. Psychoneuroendocrinology. 2012; 37(8):1181-1190. DOI: 10.1016/j.psyneuen. 2011.12.008 [PubMed: 22222119]

**. Thorn L, Evans P, Cannon A, Hucklebridge F, Evans P, Clow A. Seasonal differences in the diurnal pattern of cortisol secretion in healthy participants and those with self-assessed seasonal affective disorder. Psychoneuroendocrinology. 2011; 36(6):816-823. DOI: 10.1016/j.psyneuen. 2010.11.003 [PubMed: 21145663]

**. Tomiyama AJ, Epel ES, McClatchey TM, Poelke G, Kemeny ME, Mccoy SK, Daubenmier J. Associations of weight stigma with cortisol and oxidative stress independent of adiposity. Health Psychology. 2014; 33(8):862-867. DOI: 10.1037/Hea0000107 [PubMed: 25068456]

*. Tops T, Riese H, Oldehinkel AJ, Rijsdijk FV, Ormel J. Rejection sensitivity relates to hypocortisolism and depressed mood state in young women. Psychoneuroendocrinology. 2008; 33:551-559. DOI: 10.1016/j.psyneuen.2008.01.011 [PubMed: 18329181]

**. Tu MT, Zunzunegui MV, Guerra R, Alvarado B, Guralnik JM. Cortisol profile and depressive symptoms in older adults residing in Brazil and in Canada. Aging Clinical and Experimental Research. 2013; 25(5):527-537. DOI: 10.1007/s40520-013-0111-0 [PubMed: 23959958]

**. Ulrike S, Reinhold L, Dirk H. Major depression in young girls is related to altered cortisol awakening response. European Child \& Adolescent Psychiatry. 2013; 22(6):379-384. DOI: 10.1007/s00787-012-0371-9 [PubMed: 23292185]

**. Vammen MA, Mikkelsen S, Hansen AM, Grynderup MB, Andersen JH, Bonde JP, et al. Thomsen JF. Salivary cortisol and depression in public sector employees: Cross-sectional and short term 
follow-up findings. Psychoneuroendocrinology. 2014; 41:63-74. DOI: 10.1016/j.psyneuen. 2013.12.006 [PubMed: 24495608]

van Aert RCM, Micherts JM, van Assen MALM. Conducting meta-analyses based on p-values: Reservations and recommendations for applying p-uniform and p-curve. Perspectives on Psychological Science. 2016; 11(5):713-729. DOI: 10.1177/1745691616650874 [PubMed: 27694466]

**. van Liempt S, Arends J, Cluitnnans PJM, Westenberg HGM, Kahn RS, Vermetten E. Sympathetic activity and hypothalamo-pituitary-adrenal axis activity during sleep in post-traumatic stress disorder: A study assessing polysomnography with simultaneous blood sampling. Psychoneuroendocrinology. 2013; 38(1):155-165. DOI: 10.1016/j.psyneuen.2012.05.015 [PubMed: 22776420]

**. van Santen A, Vreeburg SA, Van der Does AW, Spinhoven P, Zitman FG, Penninx BW. Psychological traits and the cortisol awakening response: results from the Netherlands Study of Depression and Anxiety. Psychoneuroendocrinology. 2011; 36(2):240-248. DOI: 10.1016/ j.psyneuen.2010.07.014 [PubMed: 20724080]

**. Vargas I, Lopez-Duran N. Dissecting the impact of sleep and stress on the cortisol awakening response in young adults. Psychoneuroendocrinology. 2014; 40:10-16. DOI: 10.1016/j.psyneuen. 2013.10.009 [PubMed: 24485471]

**. Veen G, van Vliet IM, DeRijk RH, Giltay EJ, van Pelt J, Zitman FG. Basal cortisol levels in relation to dimensions and DSM-IV categories of depression and anxiety. Psychiatry Research. 2011; 185(1-2):121-128. DOI: 10.1016/j.psychres.2009.07.013 [PubMed: 20537715]

**. von Polier GG, Herpertz-Dahlmann B, Konrad K, Wiesler K, Rieke J, Heinzel-Gutenbrunner M, et al. Vloet TD. Reduced cortisol in boys with early-onset conduct disorder and callousunemotional traits. BioMed Research International. 2013; 2013:1-9. DOI: 10.1155/2013/349530

**. Vreeburg SA, Hartman CA, Hoogendijk WJG, van Dyck R, Zitman FG, Ormel J, Penninx BWJH. Parental history of depression or anxiety and the cortisol awakening response. British Journal of Psychiatry. 2010; 197(3):180-185. DOI: 10.1192/bjp.bp.109.076869 [PubMed: 20807961]

**. Vreeburg SA, Hoogendijk WJ, van Pelt J, DeRijk RH, Verhagen JC, van Dyck R, et al. Penninx BW. Major depressive disorder and hypothalamic-pituitary-adrenal axis activity: Results from a large cohort study. Archives of General Psychiatry. 2009; 66(6):617-626. DOI: 10.1001/ archgenpsychiatry.2009.50 [PubMed: 19487626]

**. Vreeburg SA, Zitman FG, van Pelt J, DeRijk RH, Verhagen JC, van Dyck R, et al. Penninx BW. Salivary cortisol levels in persons with and without different anxiety disorders. Psychosomatic Medicine. 2010; 72(4):340-347. DOI: 10.1097/PSY.0b013e3181d2f0c8 [PubMed: 20190128]

**. Wahbeh H, Oken BS. Salivary cortisol lower in posttraumatic stress disorder. Journal of Traumatic Stress. 2013; 26(2):241-248. DOI: 10.1002/jts.21798 [PubMed: 23529862]

*. Wahbeh H, Kishiyama SS, Zajdel D, Oken BS. Salivary cortisol awakening response in mid Alzheimer disease, caregivers, and noncaregivers. Alzheimer Disease \& Associated Disorders. 2008; 22:181-183. DOI: 10.1097/WAD.0b013e31815a9dff [PubMed: 18525292]

**. Walker S, O'Connor DB, Schaefer A, Talbot D, Hendrickx H. The cortisol awakening response: Associations with trait anxiety and stress reactivity. Personality and Individual Differences. 2011; 51(2):123-127. DOI: 10.1016/j.paid.2011.03.026

**. Wardenaar KJ, Vreeburg SA, van Veen T, Giltay EJ, Veen G, Penninx BWJH, Zitman FG. Dimensions of depression and anxiety and the hypothalamo-pituitary-adrenal axis. Biological Psychiatry. 2011; 69(4):366-373. DOI: 10.1016/j.biopsych.2010.09.005 [PubMed: 21030010]

*. Weekes NY, Lewis RS, Goto SG, Garrison-Jakel J, Patel F, Lupien S. The effect of an environmental stressor on gender differences on the awakening cortisol response. Psychoneuroendocrinology. 2008; 33:766-772. DOI: 10.1016/j.psyneuen.2008.03.003 [PubMed: 18541385]

**. Weik U, Deinzer R. Alterations of postawakening cortisol parameters during a prolonged stress period: Results of a prospective controlled study. Hormones and Behavior. 2010; 58(3):405-409. DOI: 10.1016/j.yhbeh.2010.06.001 [PubMed: 20638949]

*. Wessa M, Rohleder N, Kirschbaum C, Flor H. Altered cortisol awakening response in posttraumatic stress disorder. Psychoneuroendocrinology. 2006; 31:209-215. DOI: 10.1016/j.psyneuen. 2005.06.010 [PubMed: 16154709] 
Whitehead DL, Perkins-Porras L, Strike PC, Magid K, Steptoe A. Cortisol awakening response is elevated in acute coronary syndrome patients with typed personality. Journal of Psychosomatic Research. 2007; 62:419-425. DOI: 10.1016/j.jpsychores.2006.11.005 [PubMed: 17383493]

**. Wilcox RR, Granger DA, Szanton S, Clark F. Cortisol diurnal patterns, associations with depressive symptoms, and the impact of intervention in older adults: Results using modern robust methods aimed at dealing with low power due to violations of standard assumptions. Hormones and Behavior. 2014; 65(3):219-225. DOI: 10.1016/j.yhbeh.2014.01.005 [PubMed: 24468639]

**. Williams SR, Cash E, Daup M, Geronimi EMC, Sephton SE, Woodruff-Borden J. Exploring patterns in cortisol synchrony among anxious and nonanxious mother and child dyads: A preliminary study. Biological Psychology. 2013; 93(2):287-295. DOI: 10.1016/j.biopsycho. 2013.02.015 [PubMed: 23511898]

**. Wirth M, Burch J, Violanti J, Burchfiel C, Fekedulegn D, Andrew M, et al. Vena JE. Shiftwork duration and the awakening cortisol response among police officers. Chronobiology International. 2011; 28(5):446-457. DOI: 10.3109/07420528.2011.573112 [PubMed: 21721860]

**. Wolfram M, Bellingrath S, Feuerhahn N, Kudielka BM. Cortisol responses to naturalistic and laboratory stress in student teachers: Comparison with a non-stress control day. Stress and Health. 2013; 29(2):143-149. [PubMed: 22888074]

*. Wright CE, Steptoe A. Subjective socioeconomic position, gender and cortisol responses to waking in an elderly population. Psychoneuroendocrinology. 2005; 30:582-590. DOI: 10.1016/ j.psyneuen.2005.01.007 [PubMed: 15808928]

*. Wüst S, Federenko I, Hellhammer DH, Kirschbaum C. Genetic factors, perceived chronic stress, and the free cortisol response to awakening. Psychoneuroendocrinology. 2000; 25:707-720. DOI: 10.1016/S0306-4530(00)00021-4 [PubMed: 10938450]

**. Zeiders KH, Doane LD, Roosa MW. Perceived discrimination and diurnal cortisol: Examining relations among Mexican American adolescents. Hormones and Behavior. 2012; 61(4):541-548. DOI: 10.1016/j.yhbeh.2012.01.018 [PubMed: 22342577]

**. Zoccola PM, Dickerson SS, Yim IS. Trait and state perseverative cognition and the cortisol awakening response. Psychoneuroendocrinology. 2011; 36(4):592-595. DOI: 10.1016/ j.psyneuen.2010.10.004 [PubMed: 21050668] 


\section{Highlights}

- $\quad$ Psychosocial predictors explained 1\%-3.6\% of variance in CAR responses

- Depression was linked to higher $\mathrm{AUCw}$ and posttraumatic stress to lower AUCw

- Inconclusive results were obtained for predictor-specific effects on CARi

- $\quad$ Cross-sectional studies of CAR need Ns of 617-783 to detect effects with $80 \%$ power

- There were no indications of questionable research practices biasing the CAR literature 


\section{From Chida \& Steptoe, 2009}

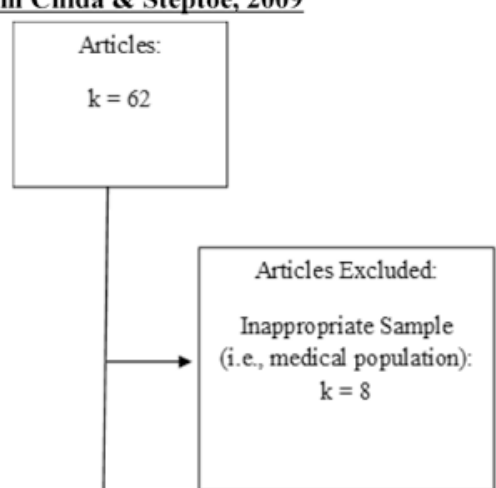

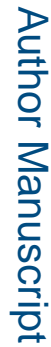

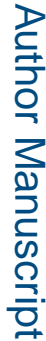

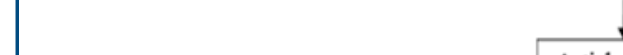

Articles Included:

$\mathrm{k}=54$
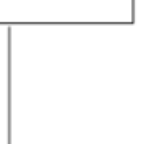

Total Articles:

$\mathrm{k}=212$

Figure 1. Flow Chart of Articles Included in Study

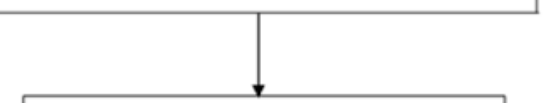

\section{Added in the Current Study}

Articles Meeting

Search Criteria:

$\mathrm{k}=386$

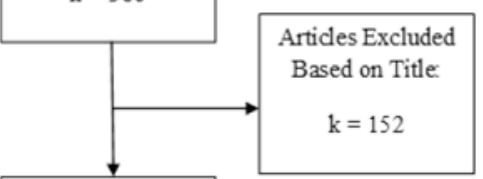

Atricles Retrieved

for Review:

$\mathrm{k}=234$

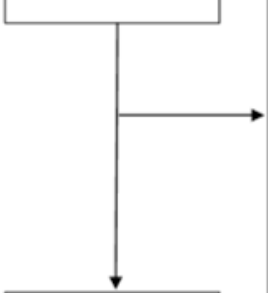

Articles Included:

$\mathrm{k}=158$
Articles Excluded

No Psychosocial Predictor: $\mathrm{k}=21$

No CAR Outcome: $\mathrm{k}=11$

Insufficient Data

Provided: $\mathrm{k}=27$

Inappropriate Sample

(i.e, medical population): $\mathrm{k}=17$ 
a)

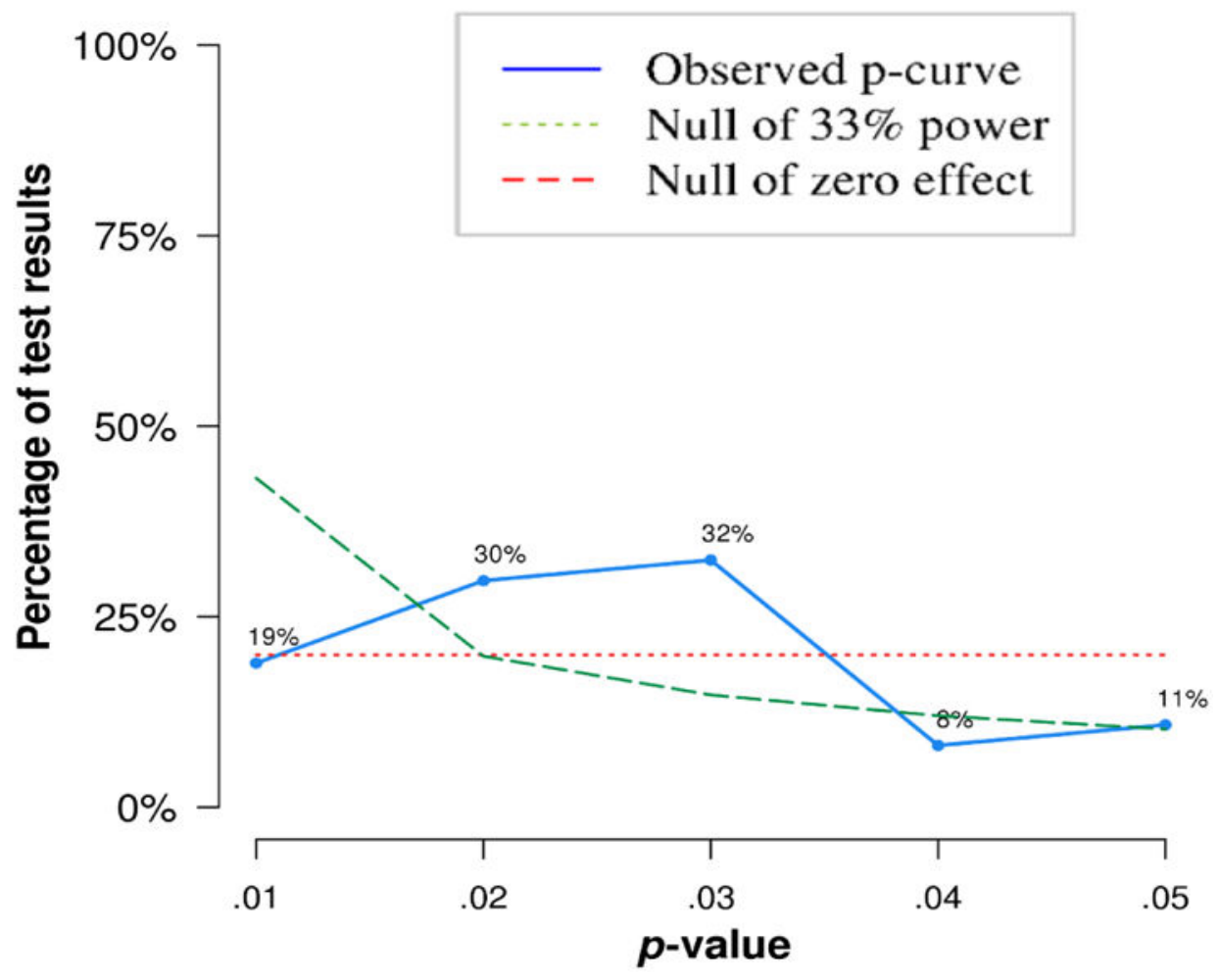


b)

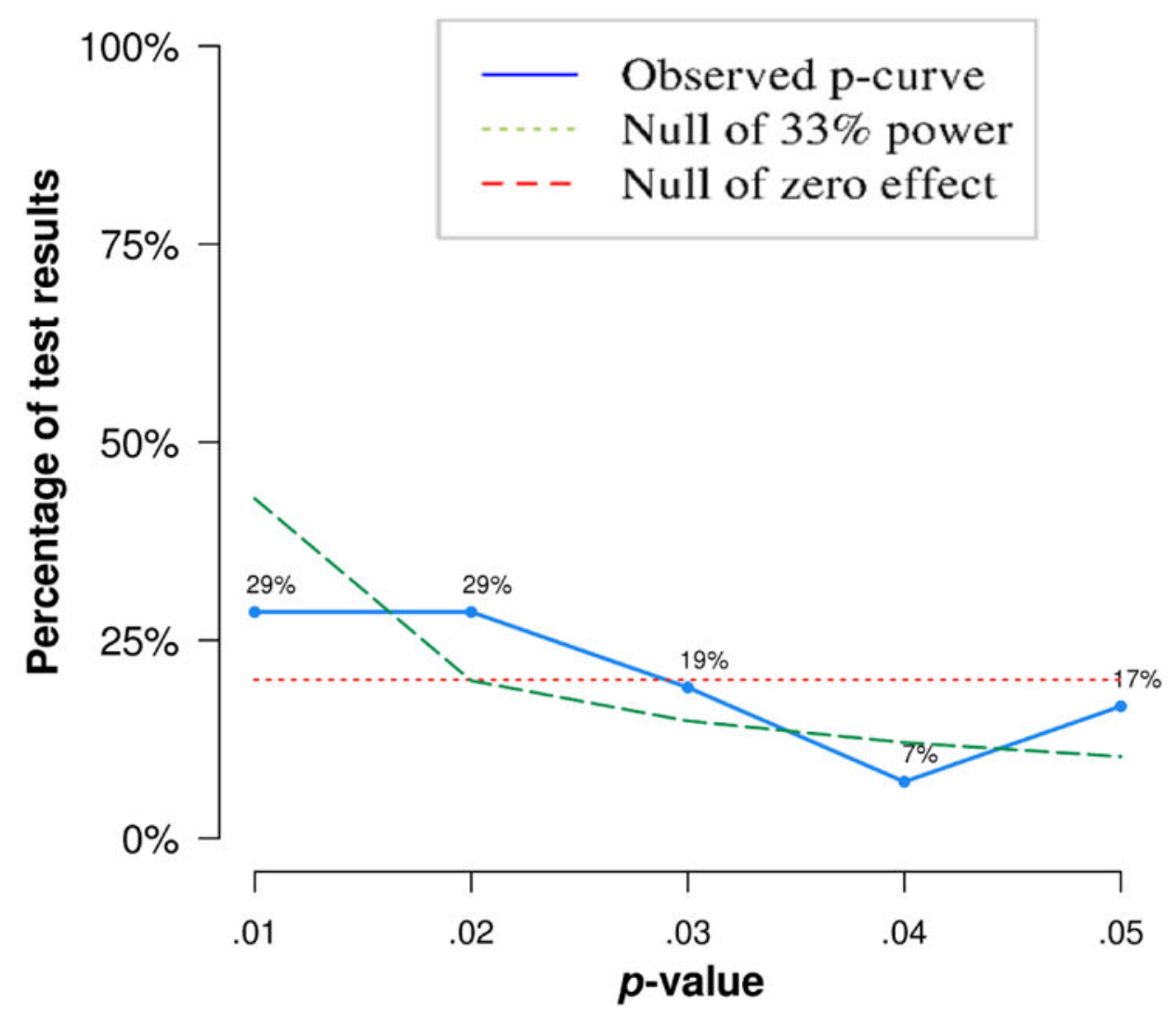


c)

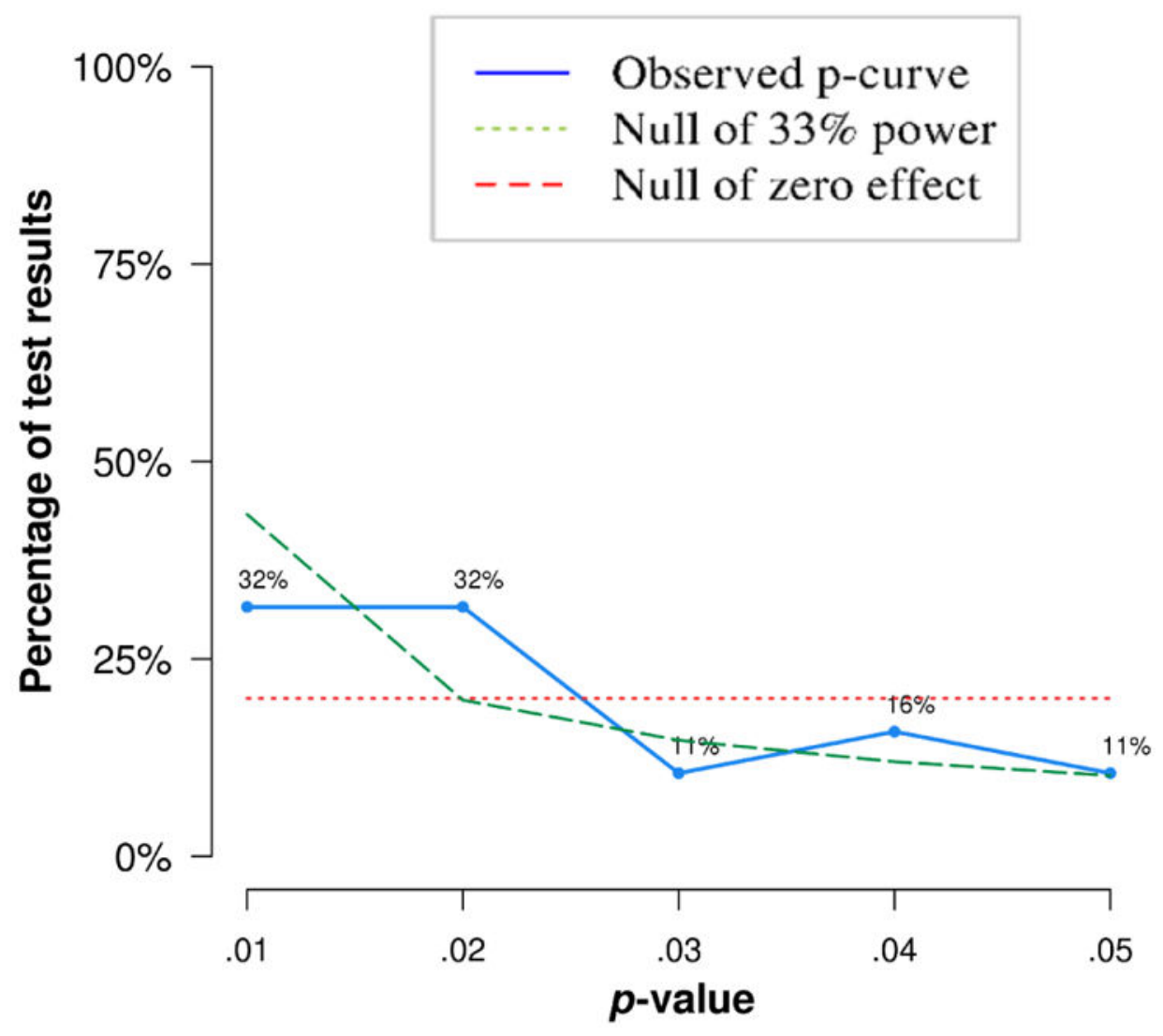




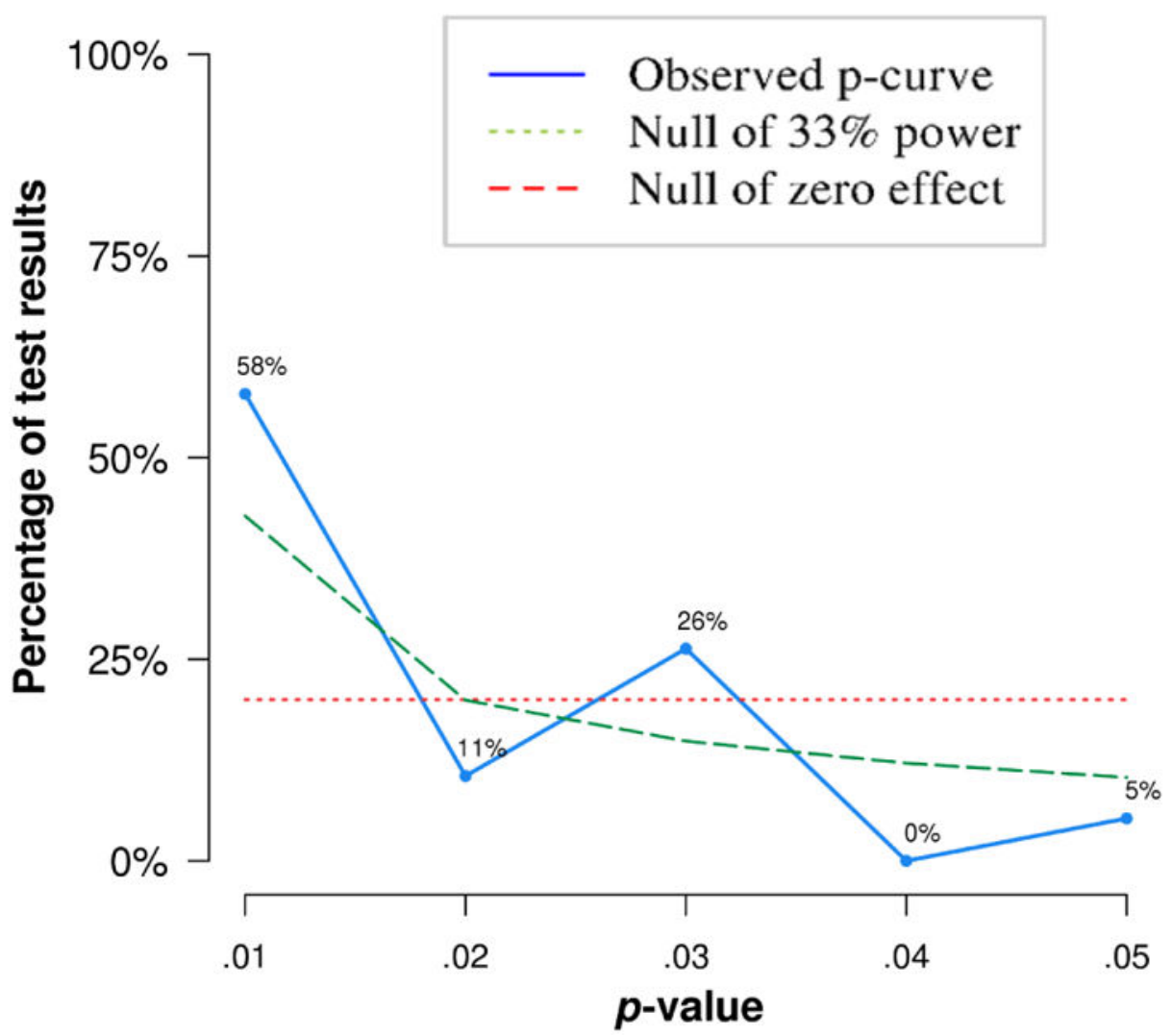

Figure 2. P-curves of Findings Relating the CAR to Psychosocial Functioning Worse psychosocial functioning with higher CARi Worse psychosocial functioning with lower CARi $\mathrm{W}$ orse psychosocial functioning with higher $\mathrm{AUCw}$ Worse psychosocial functioning with lower AUCw Notes: To compute $p$-curves, directionality for all predictors was changed so that higher values reflected worse psychosocial functioning. To test for evidential value, the $p$-curve calculator compares observed $p$-values to $\mathrm{p}$-values that would be obtained if the null were true (i.e., a null hypothesis of zero effect, as shown with the red line). The blue line shows the observed $p$-curve from significant $p$-values. If studies contain evidential value, the blue line will be right-skewed. Flat blue lines (neither right nor left skewed) indicate that findings lack evidential value or are underpowered to detect evidential value. These alternatives are differentiated by testing the set of findings against a null of $33 \%$, shown in the green line. For detailed explanation of $p$-curves, see Simonsohn et al., 2014. 


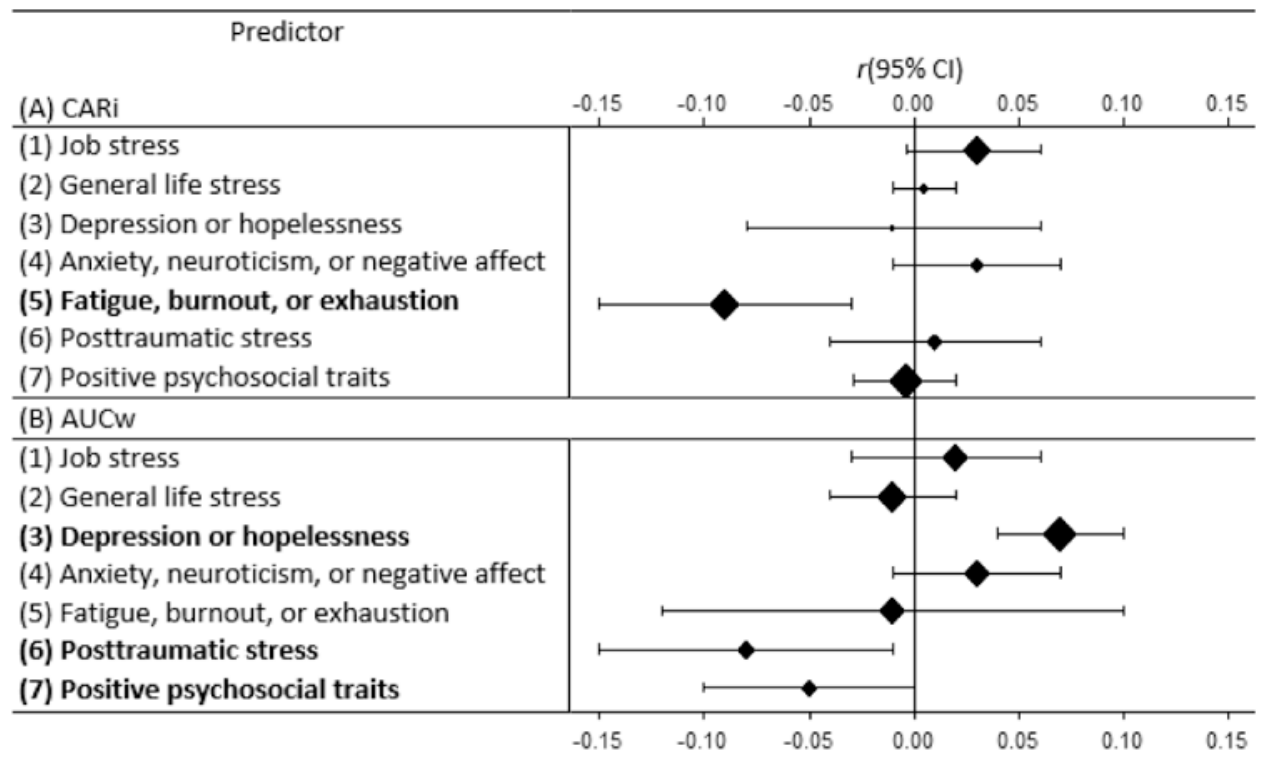

Figure 3. Combined Effect Sizes by Predictor Type

Notes: Forest plot displays predictor-specific associations with both CARi and AUCw. For each association, the aggregate effect size $r$ is shown with its $95 \%$ confidence interval. Solid diamonds represent the aggregate effects in relation to zero and the size of the diamonds is proportional to the variance of the combined effect size from the random-effects metaanalysis. Aggregate effects that are significantly different from zero (CIs do not overlap with zero) are highlighted in bold font in the left column. 
Table 1

Descriptive Statistics of Findings in Meta-Analysis

\begin{tabular}{ll} 
Number of Articles & 212 \\
Number of Findings & 709 \\
Number of Independent Findings & 186 \\
Mean Sample Size of Studies & 244.95 (SD: 520.68; Med: 74; Range: 11 - 4,364) \\
Mean Number of Days Sampled & $2.04(S D: 1.31 ;$ Med: 2; Range: $1-9)$ \\
Mean Quality Score of Studies & 6.08 (SD: 1.64; Med: 6; Range: 1 - 8) \\
Total Number of Findings for each Predictor Type \\
Job Stress & 64 \\
General Life Stress & 221 \\
Depression & 118 \\
Anxiety/Neuroticism/Negative Affect & 91 \\
Fatigue/Burnout/Exhaustion & 37 \\
Posttraumatic Stress & 56 \\
Positive Psychosocial Traits & 122 \\
\hline
\end{tabular}




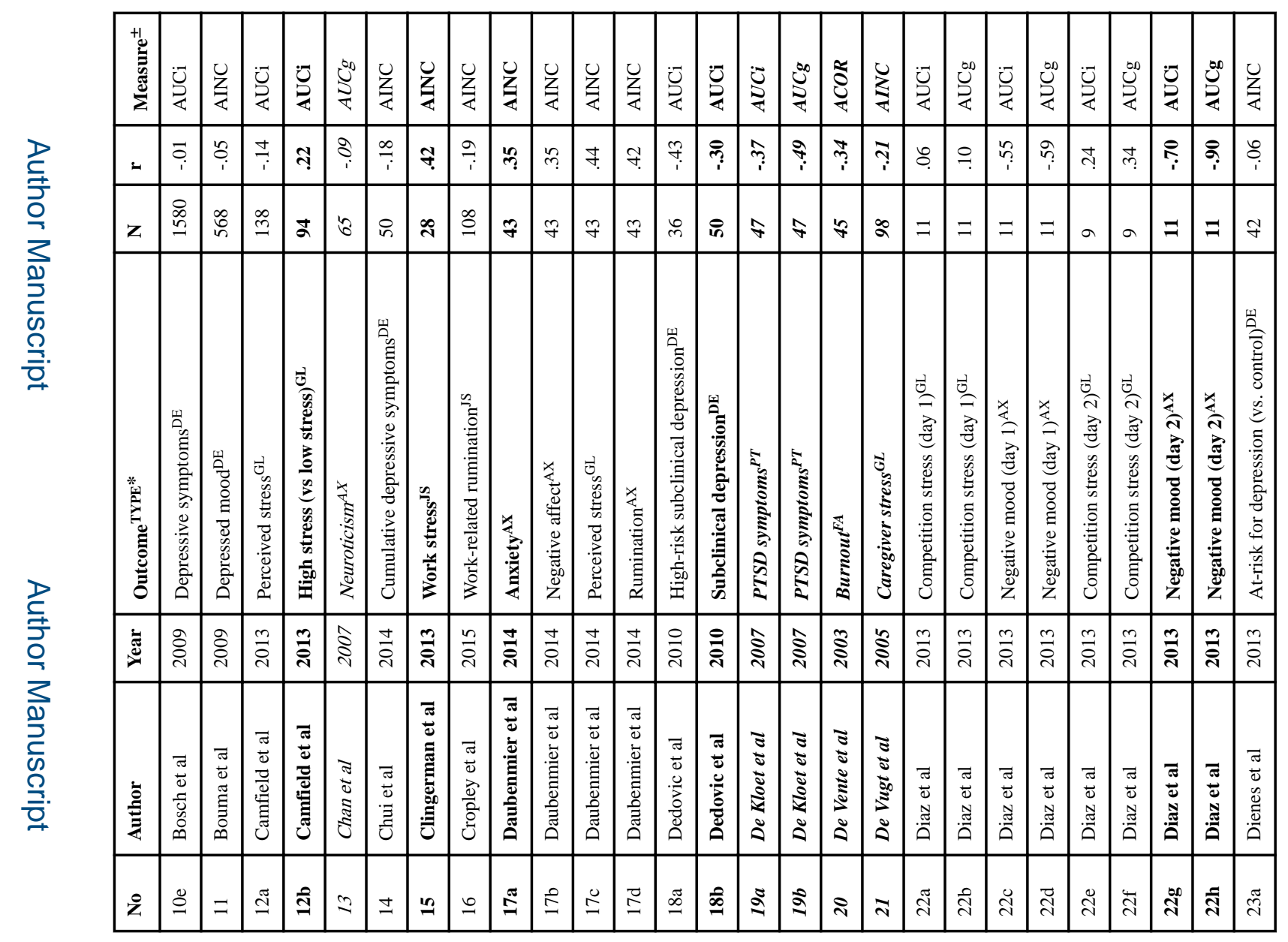

로을

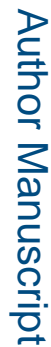

Biol Psychol. Author manuscript; available in PMC 2018 October 01. 


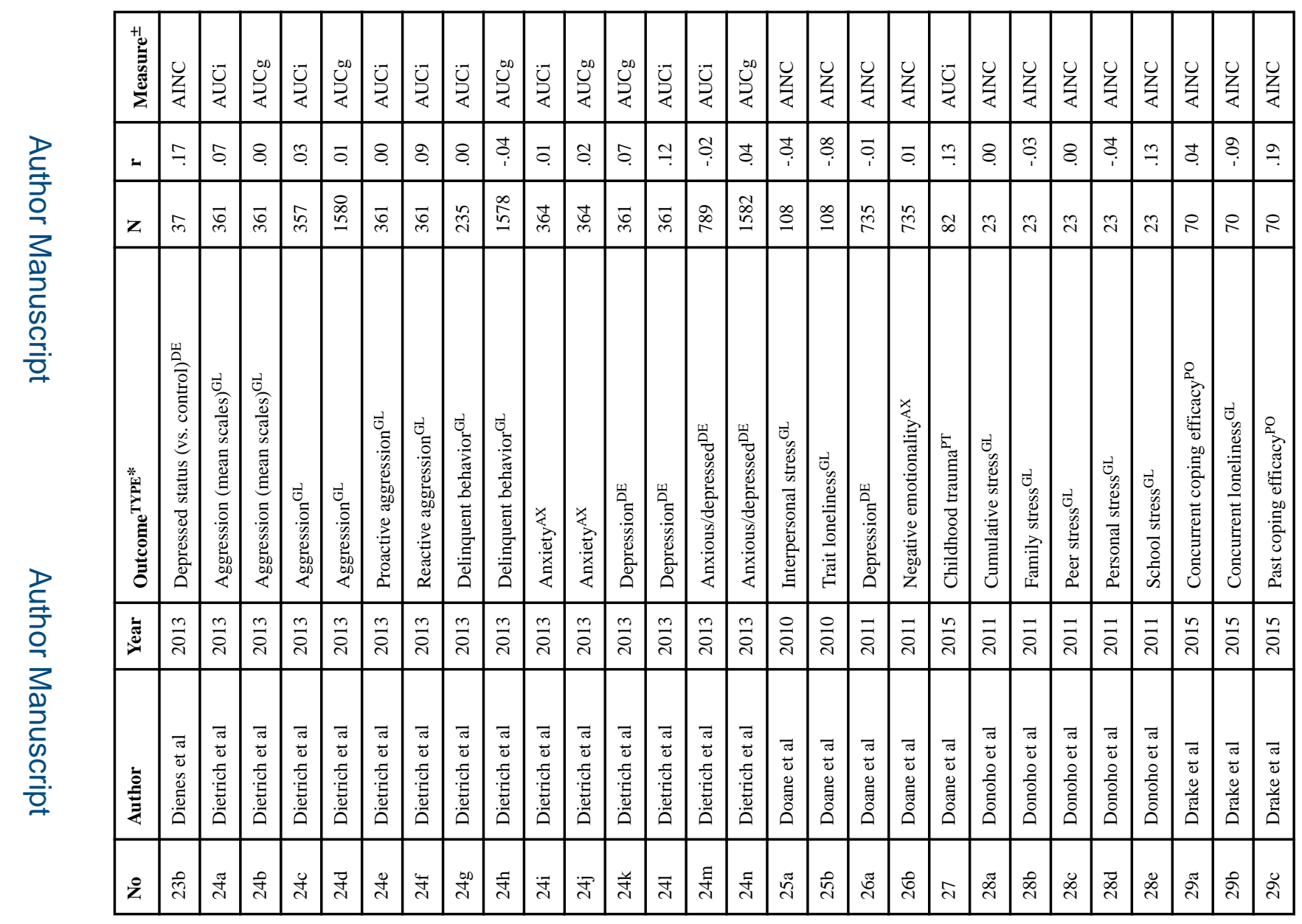

로을

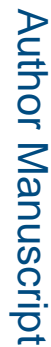

Biol Psychol. Author manuscript; available in PMC 2018 October 01. 


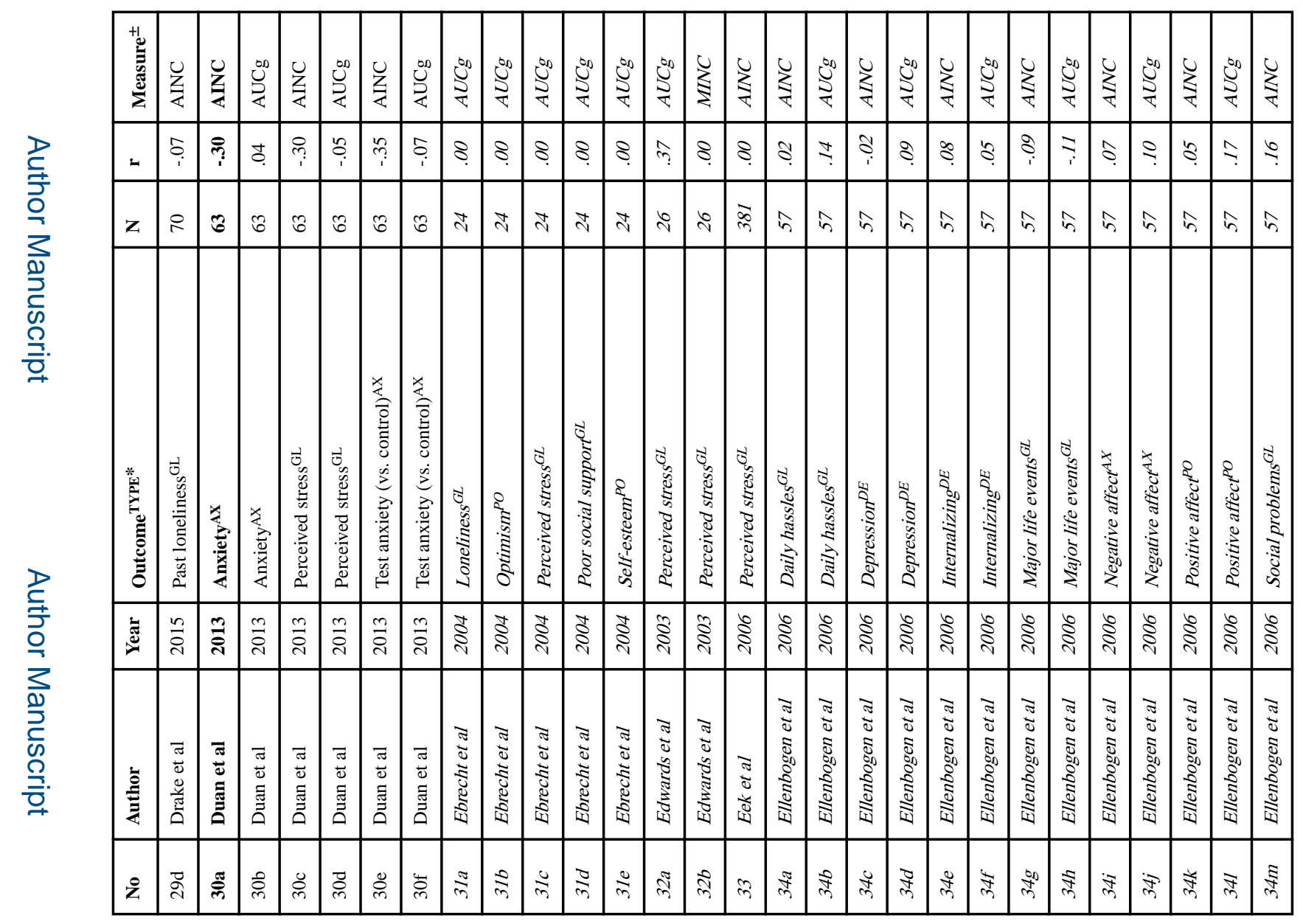

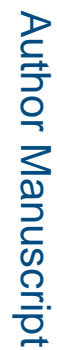

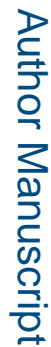

Biol Psychol. Author manuscript; available in PMC 2018 October 01. 


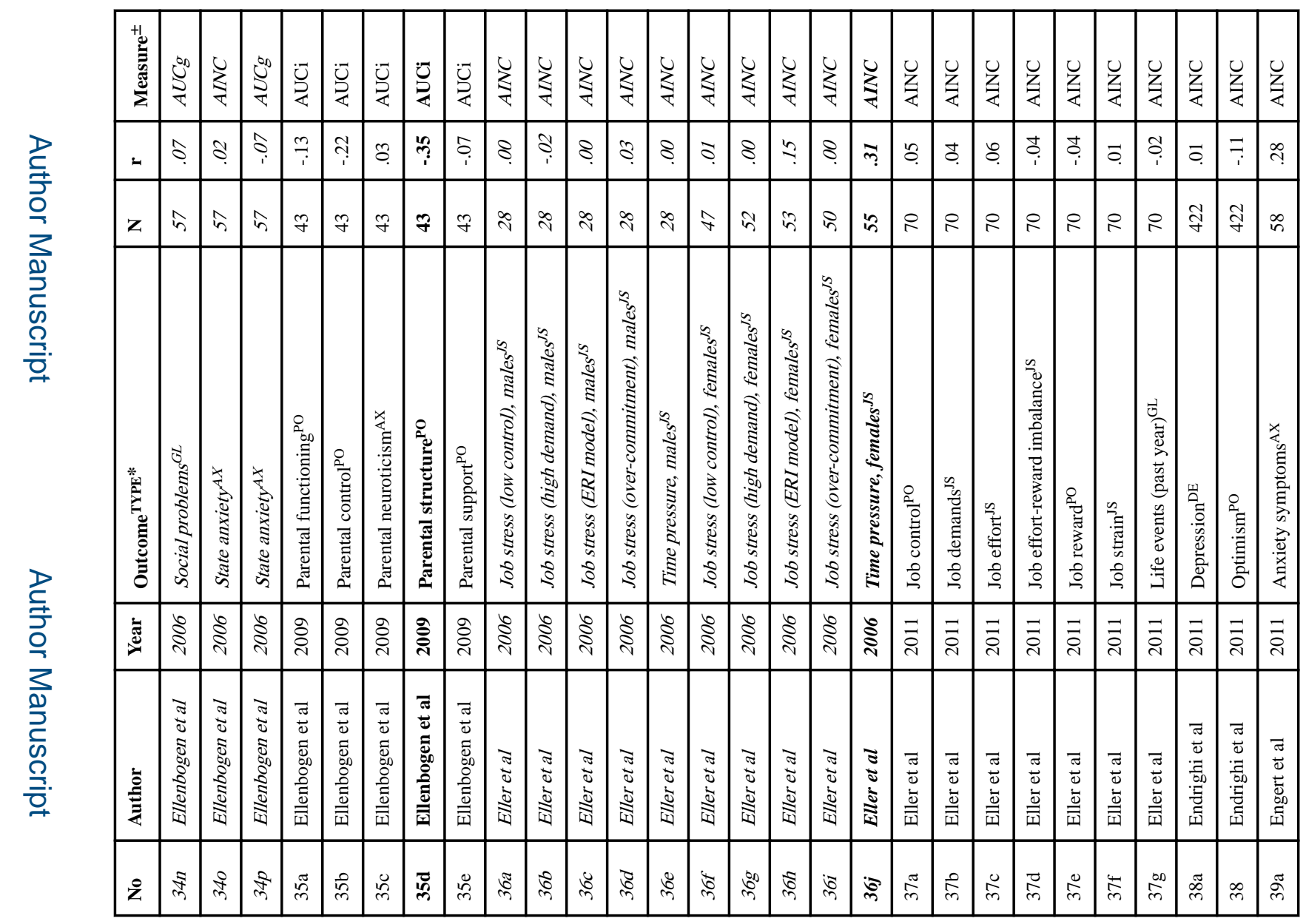

로을

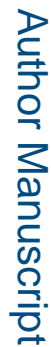

Biol Psychol. Author manuscript; available in PMC 2018 October 01. 


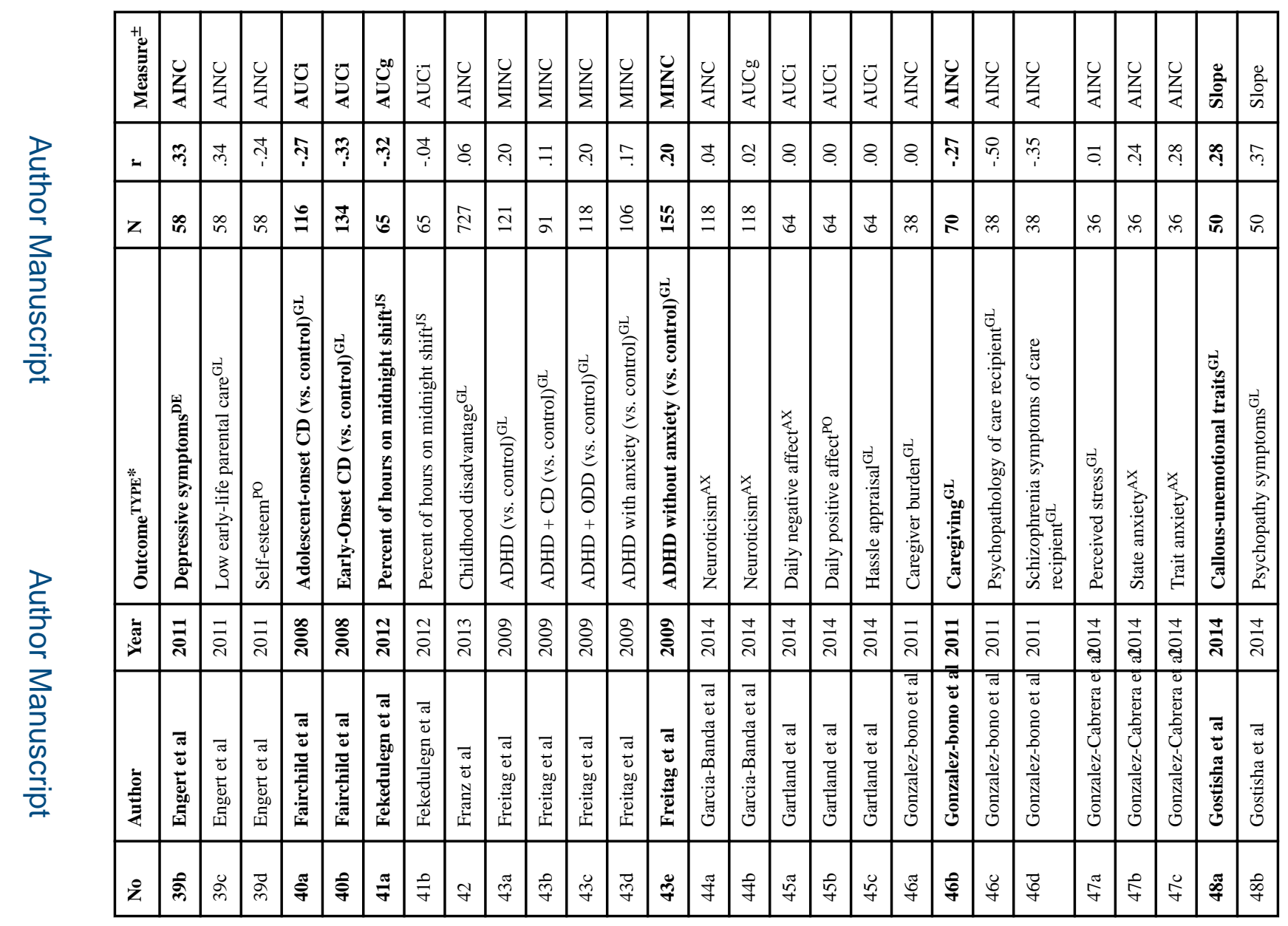

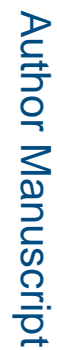

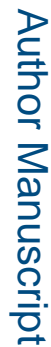

Biol Psychol. Author manuscript; available in PMC 2018 October 01. 


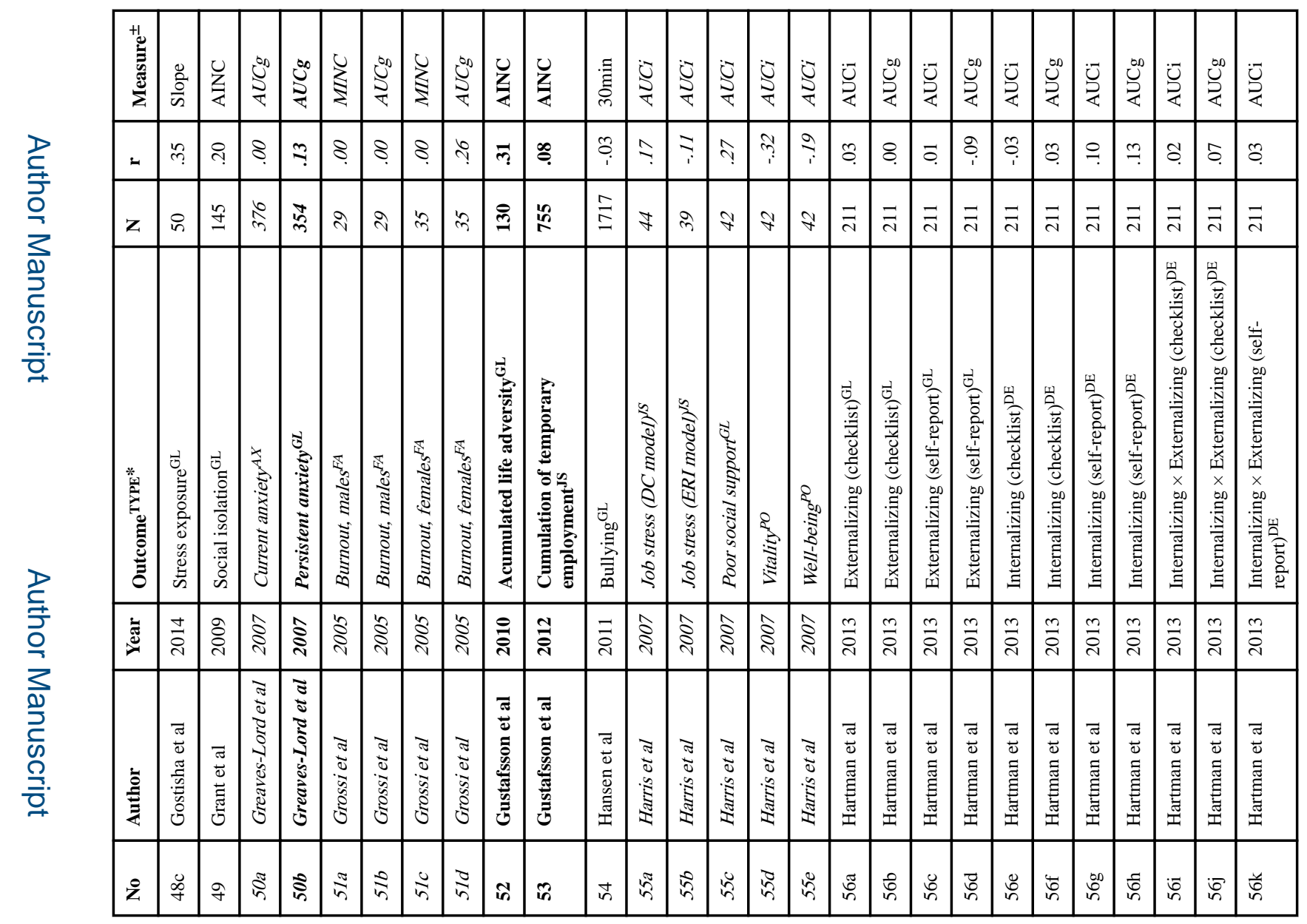

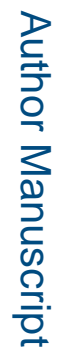

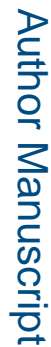

Biol Psychol. Author manuscript; available in PMC 2018 October 01. 


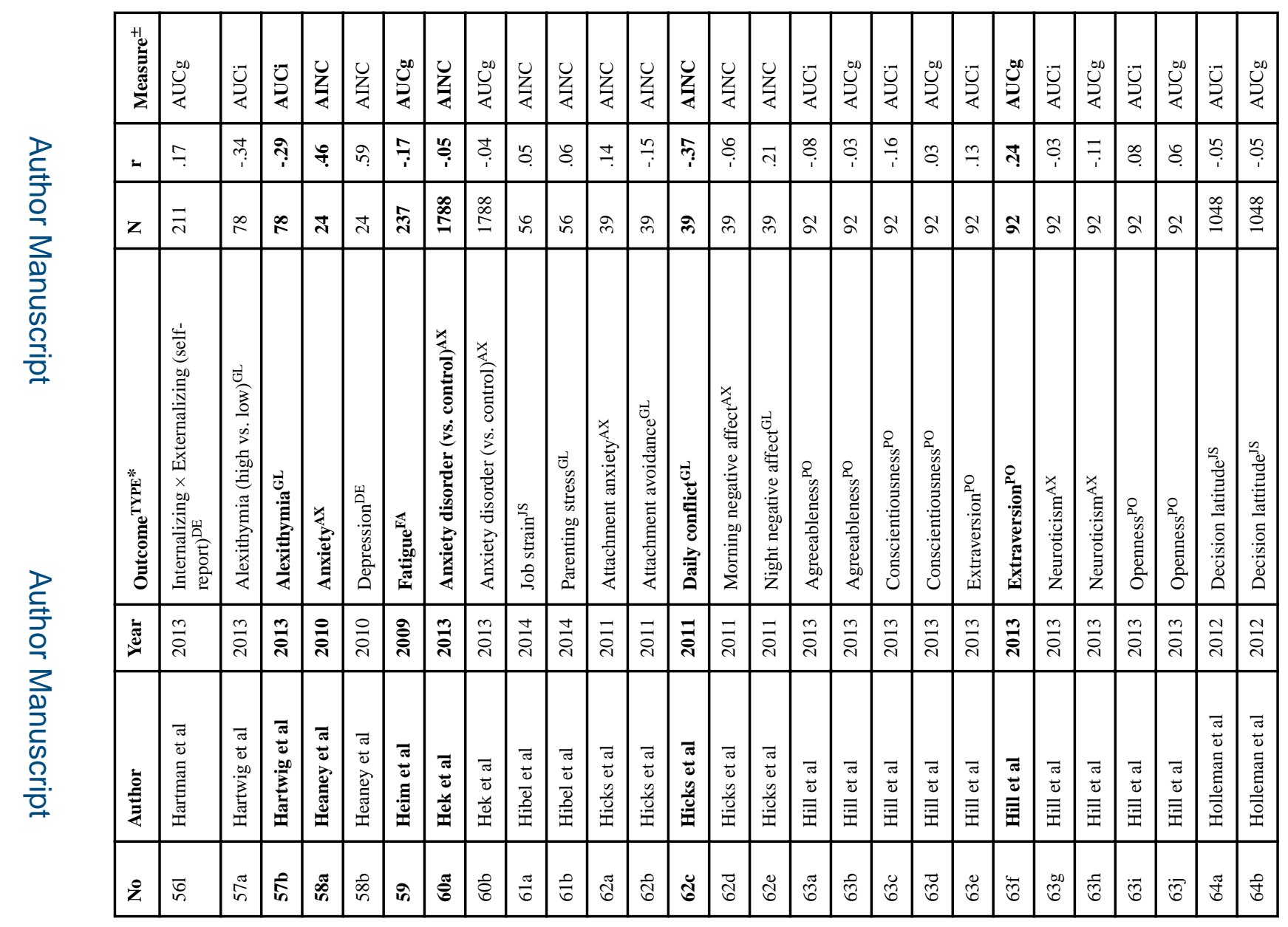

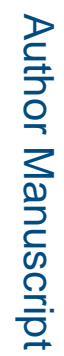

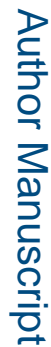

Biol Psychol. Author manuscript; available in PMC 2018 October 01. 


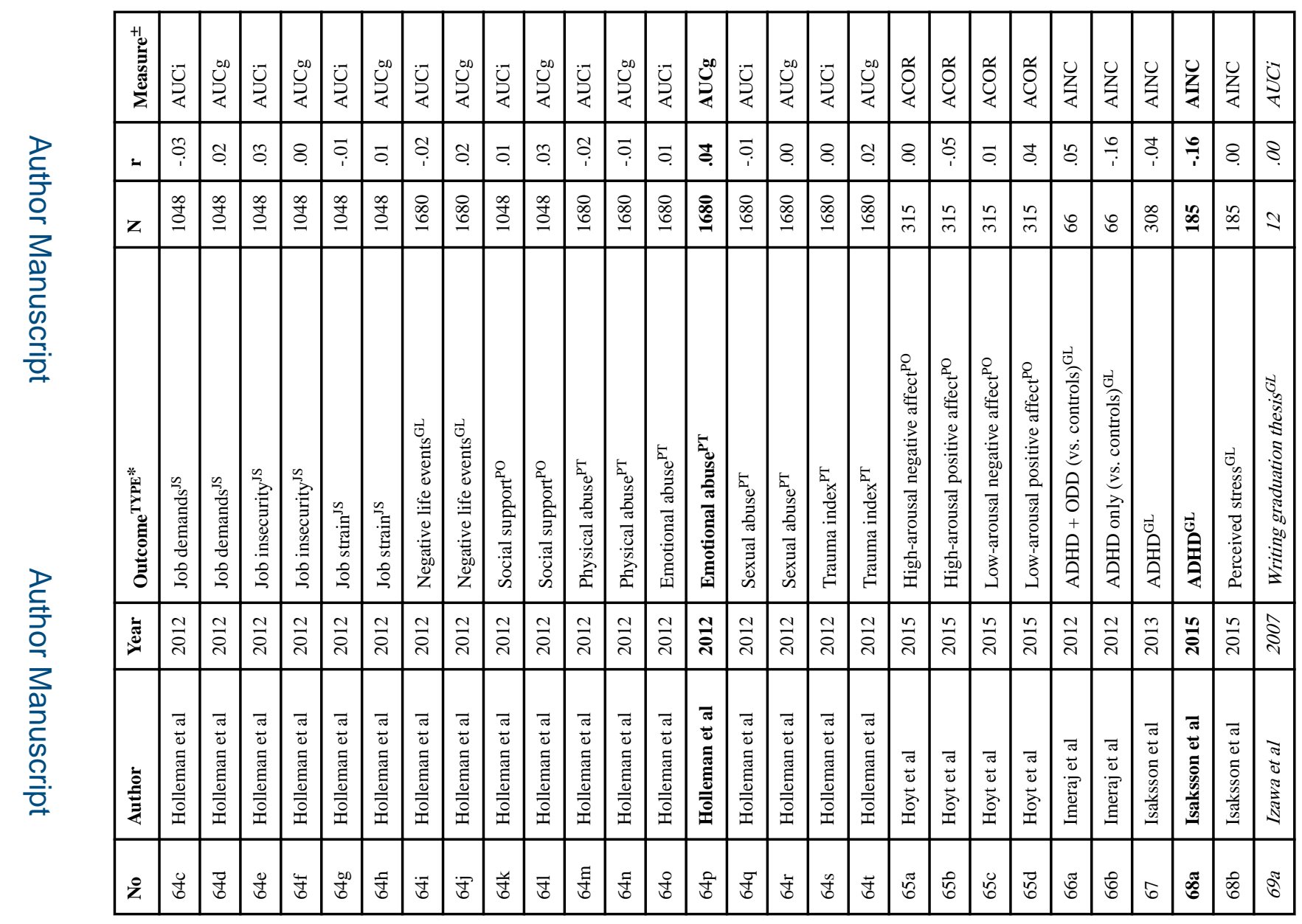

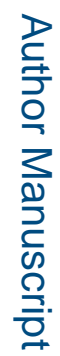

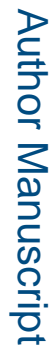

Biol Psychol. Author manuscript; available in PMC 2018 October 01. 


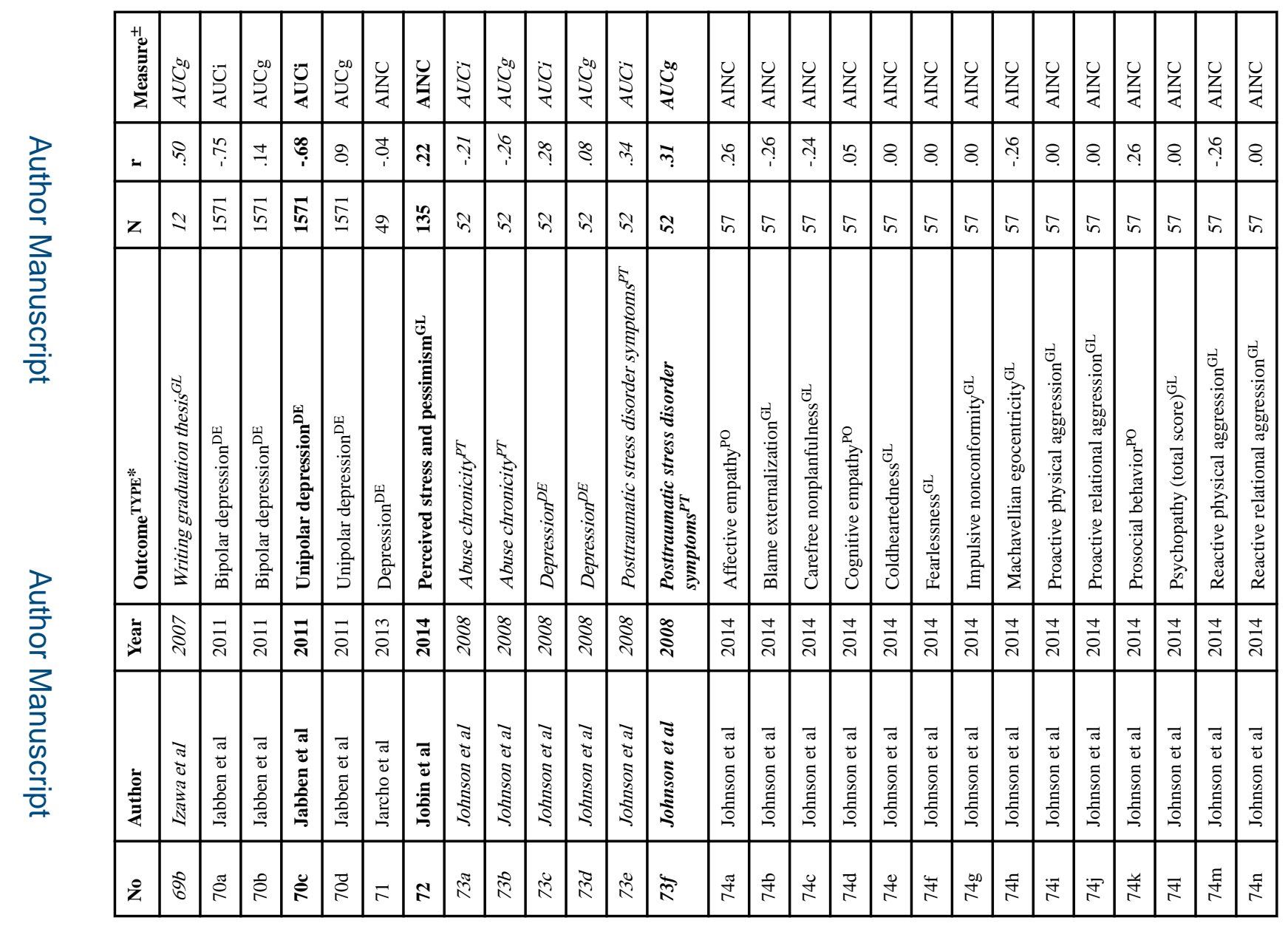

로을

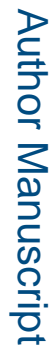

Biol Psychol. Author manuscript; available in PMC 2018 October 01. 


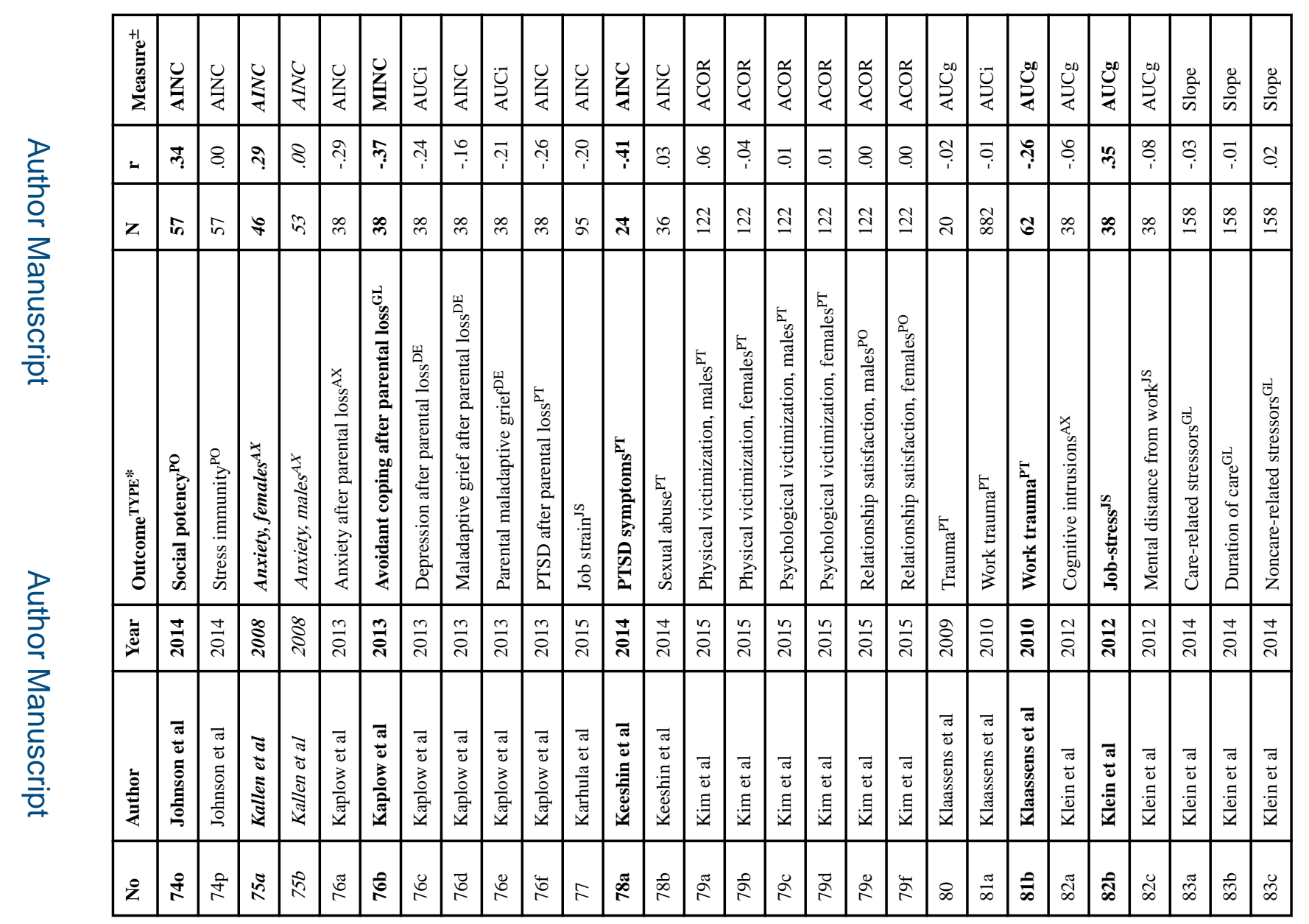

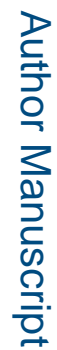

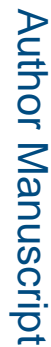

Biol Psychol. Author manuscript; available in PMC 2018 October 01. 


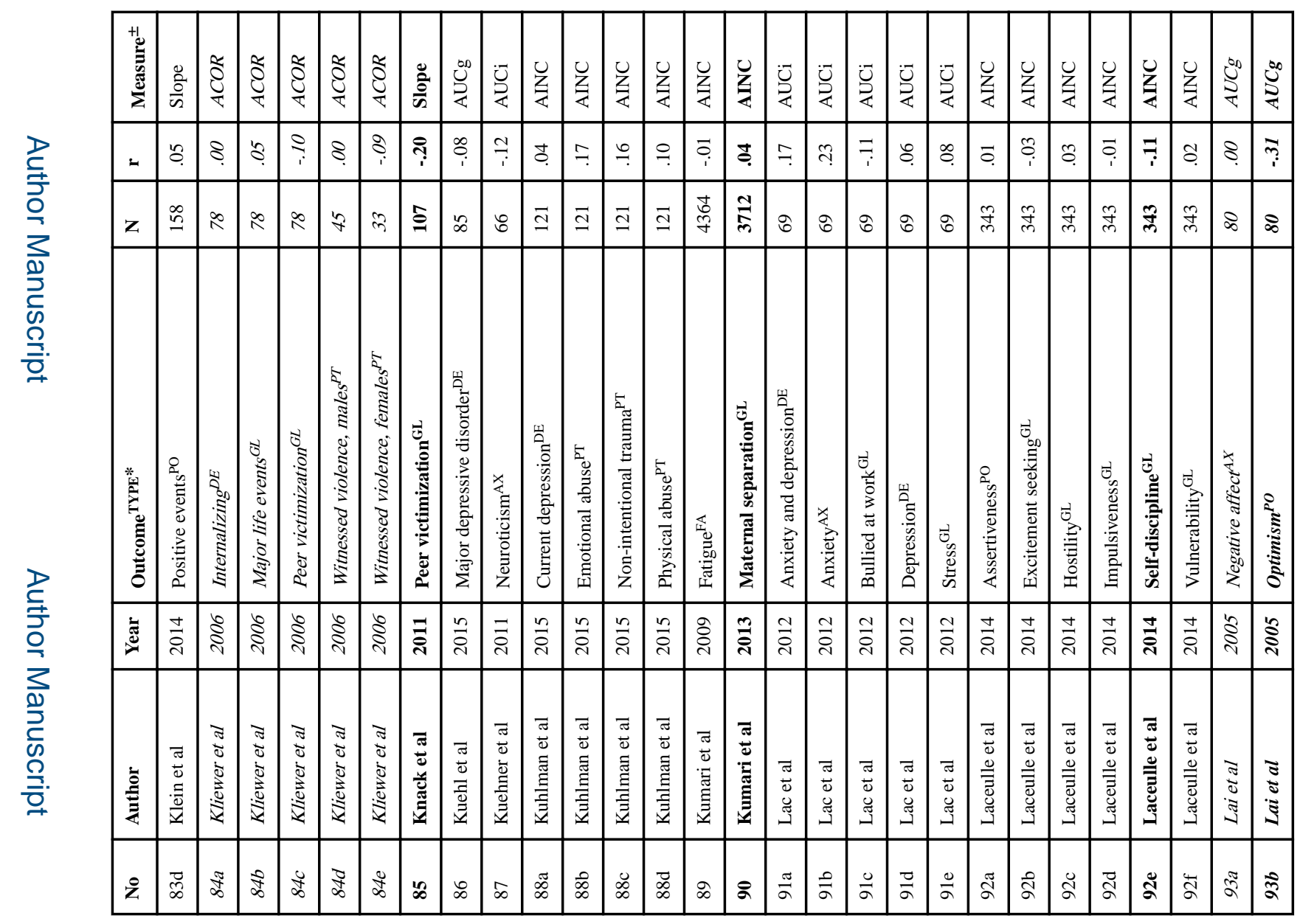

로을

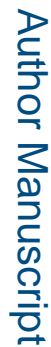

Biol Psychol. Author manuscript; available in PMC 2018 October 01. 


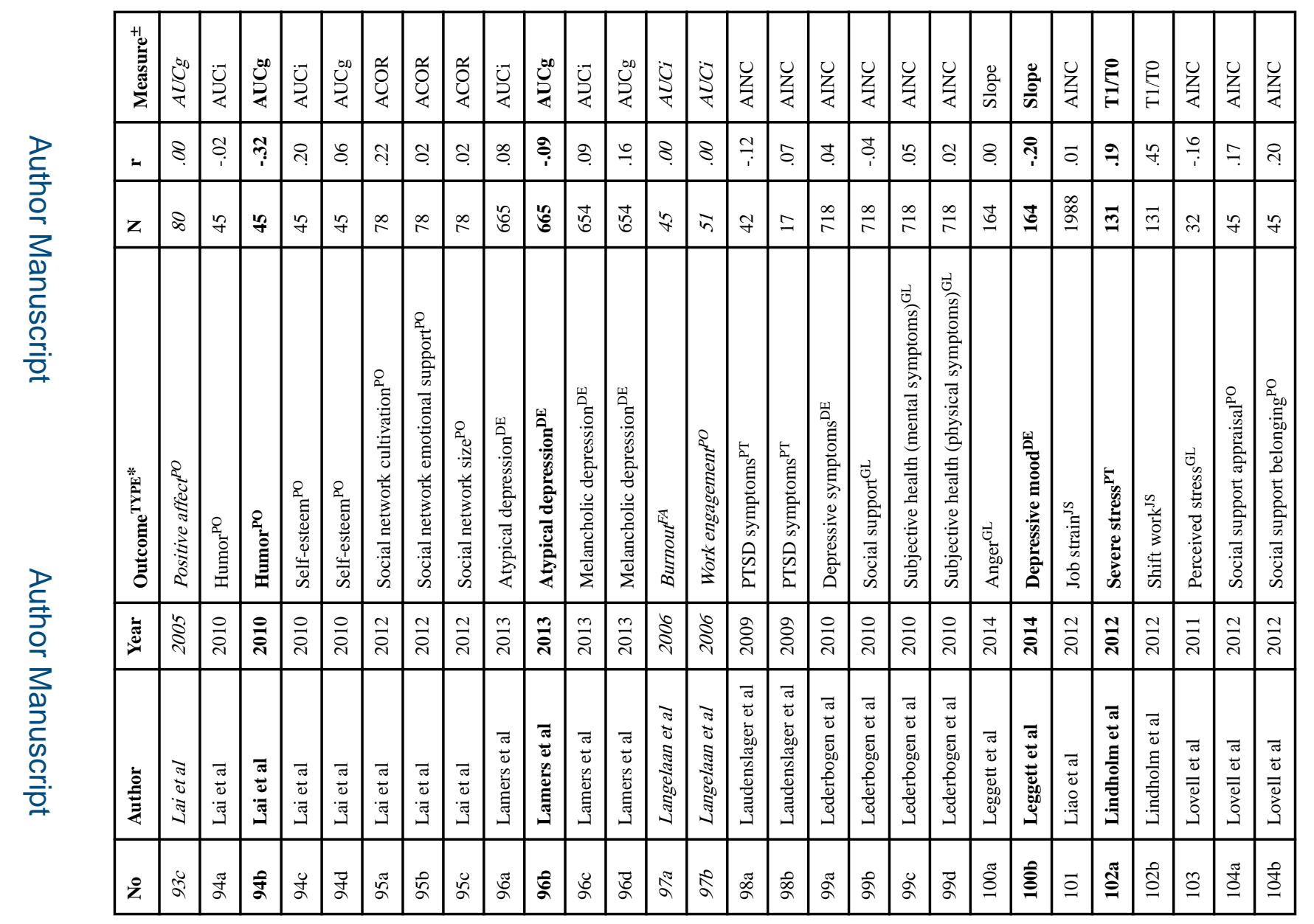

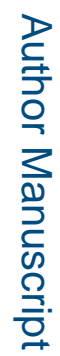

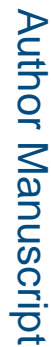

Biol Psychol. Author manuscript; available in PMC 2018 October 01. 


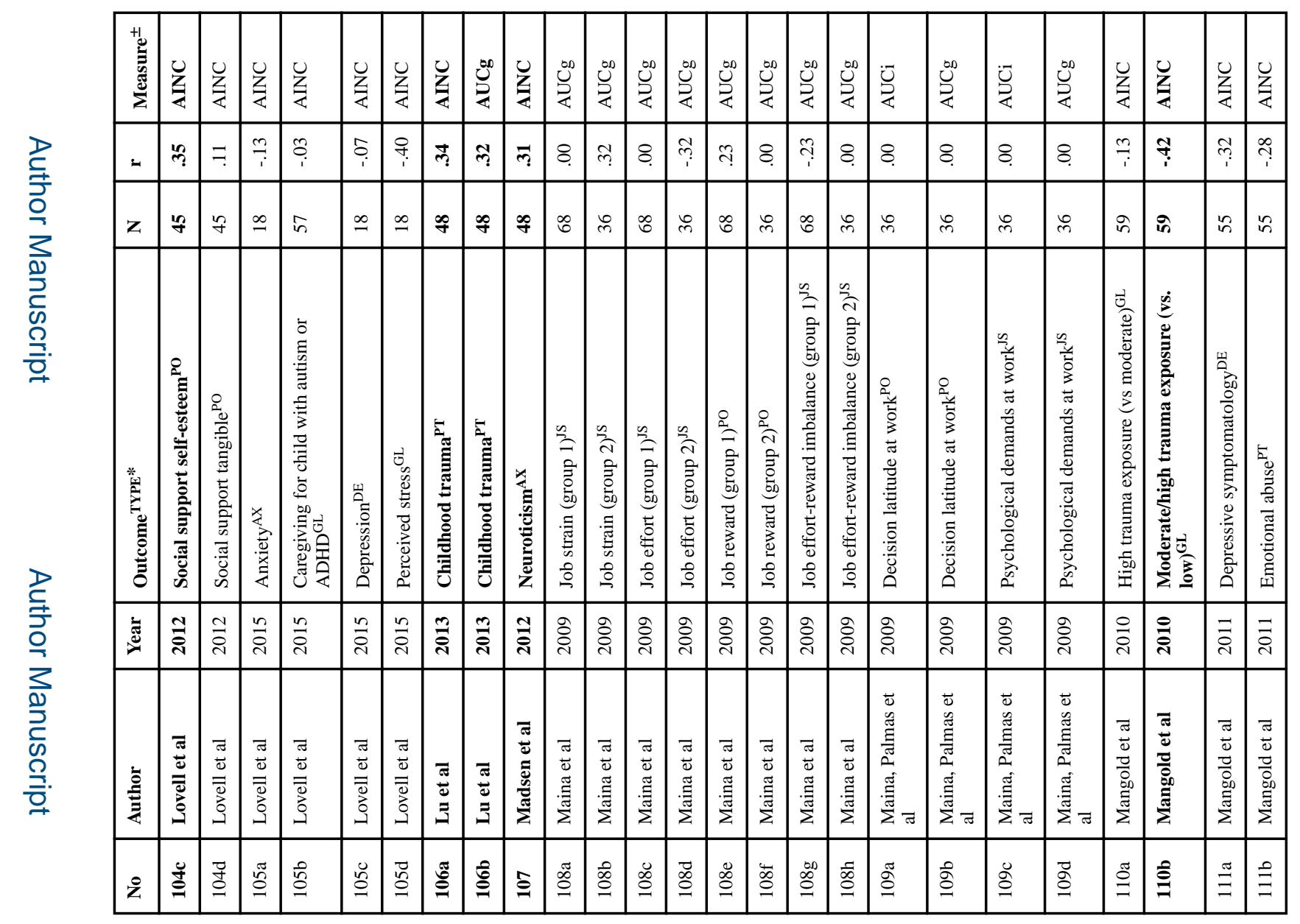

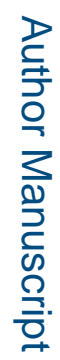

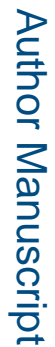

Biol Psychol. Author manuscript; available in PMC 2018 October 01. 


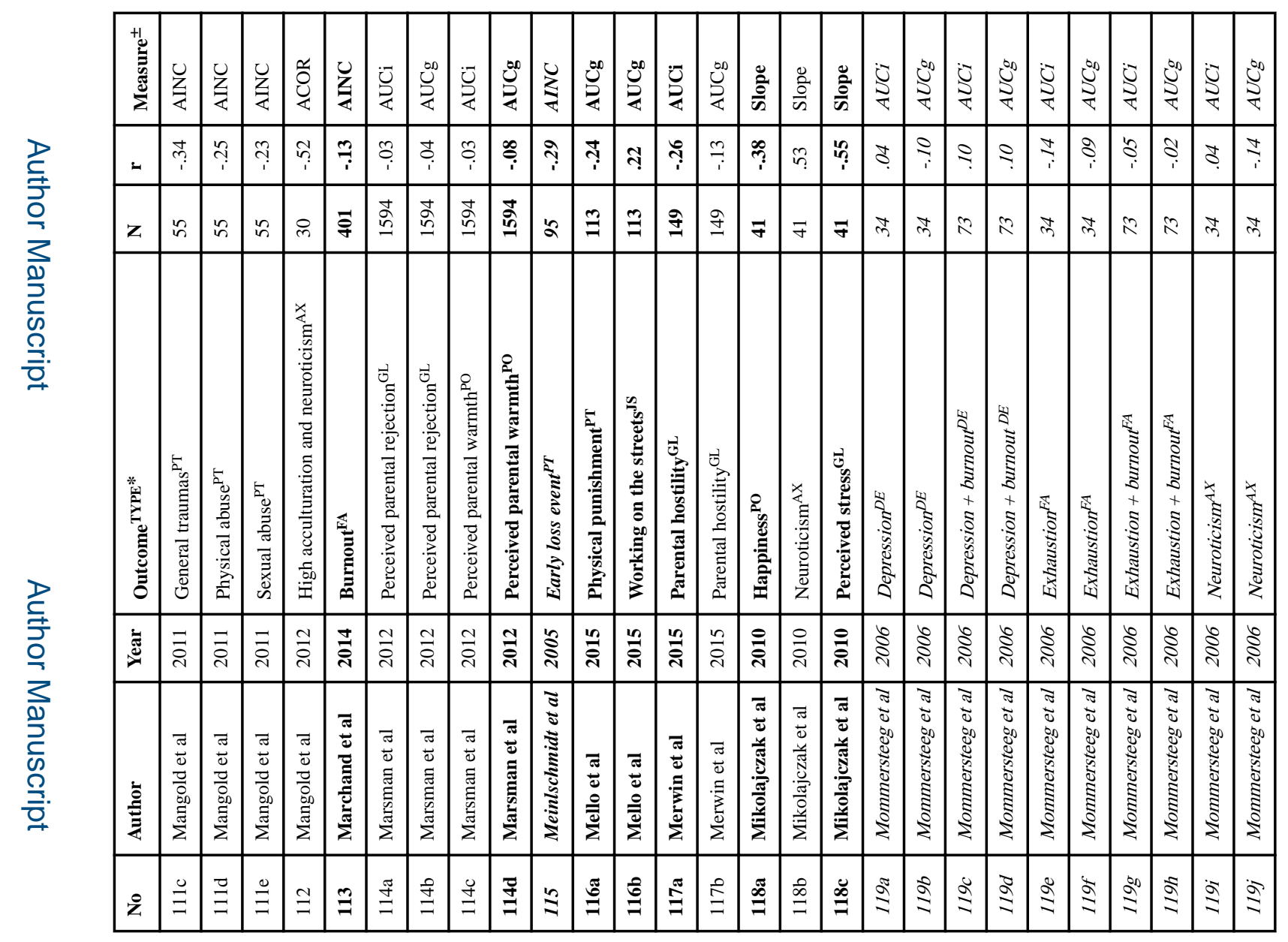

롤

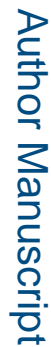

Biol Psychol. Author manuscript; available in PMC 2018 October 01. 


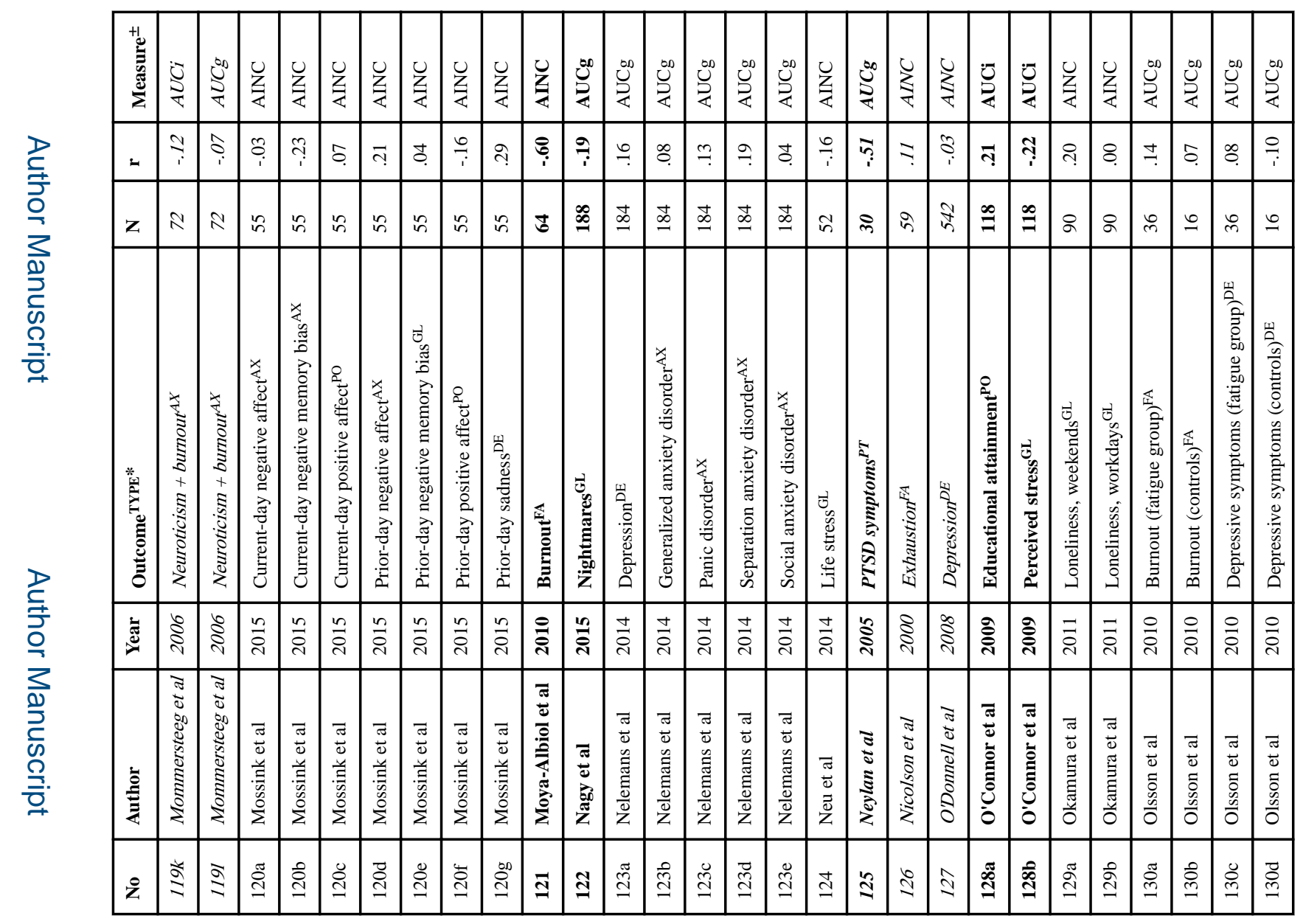

롤

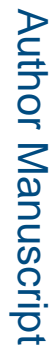

Biol Psychol. Author manuscript; available in PMC 2018 October 01. 


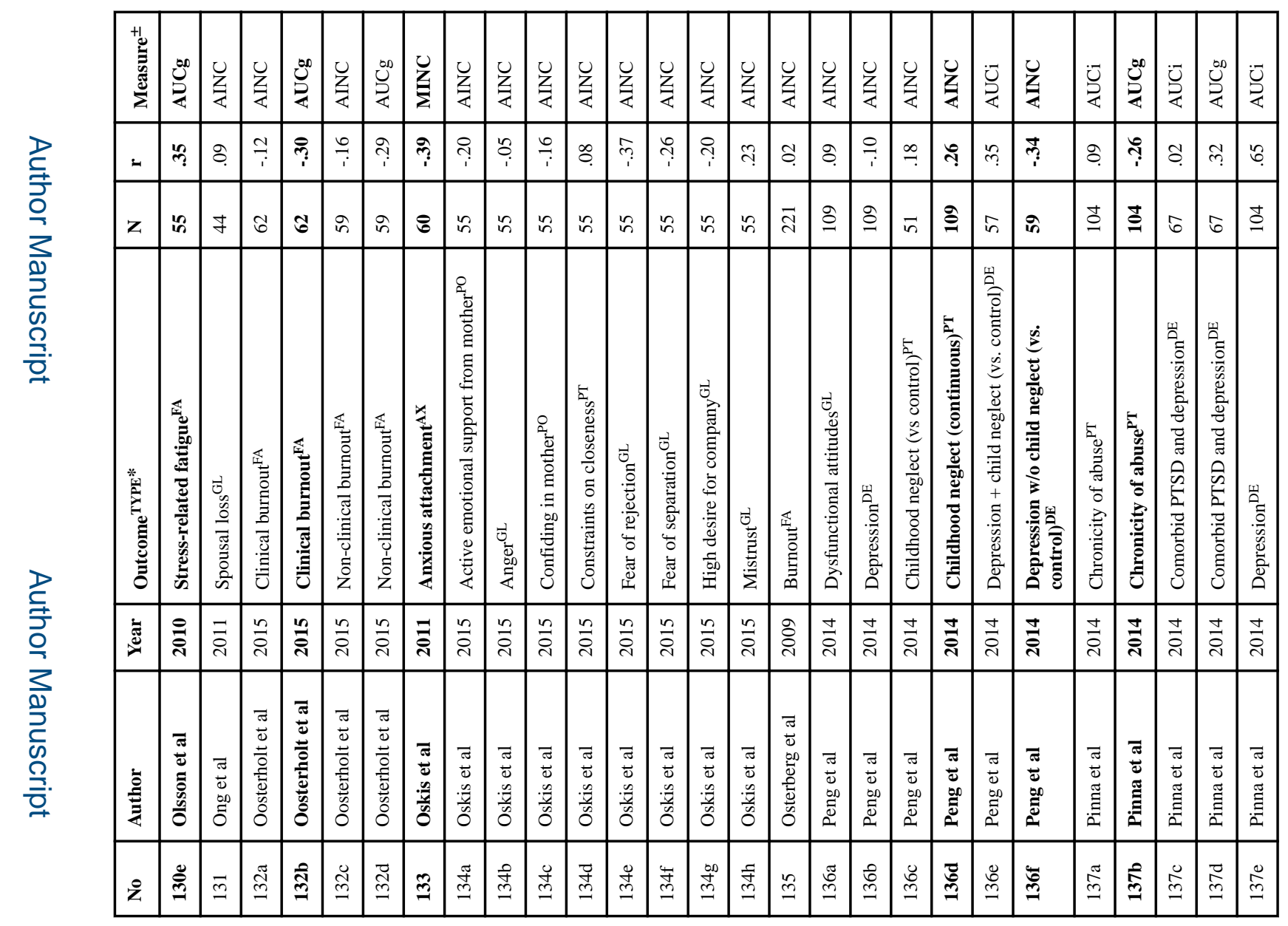

로을

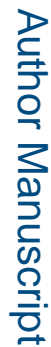

Biol Psychol. Author manuscript; available in PMC 2018 October 01. 


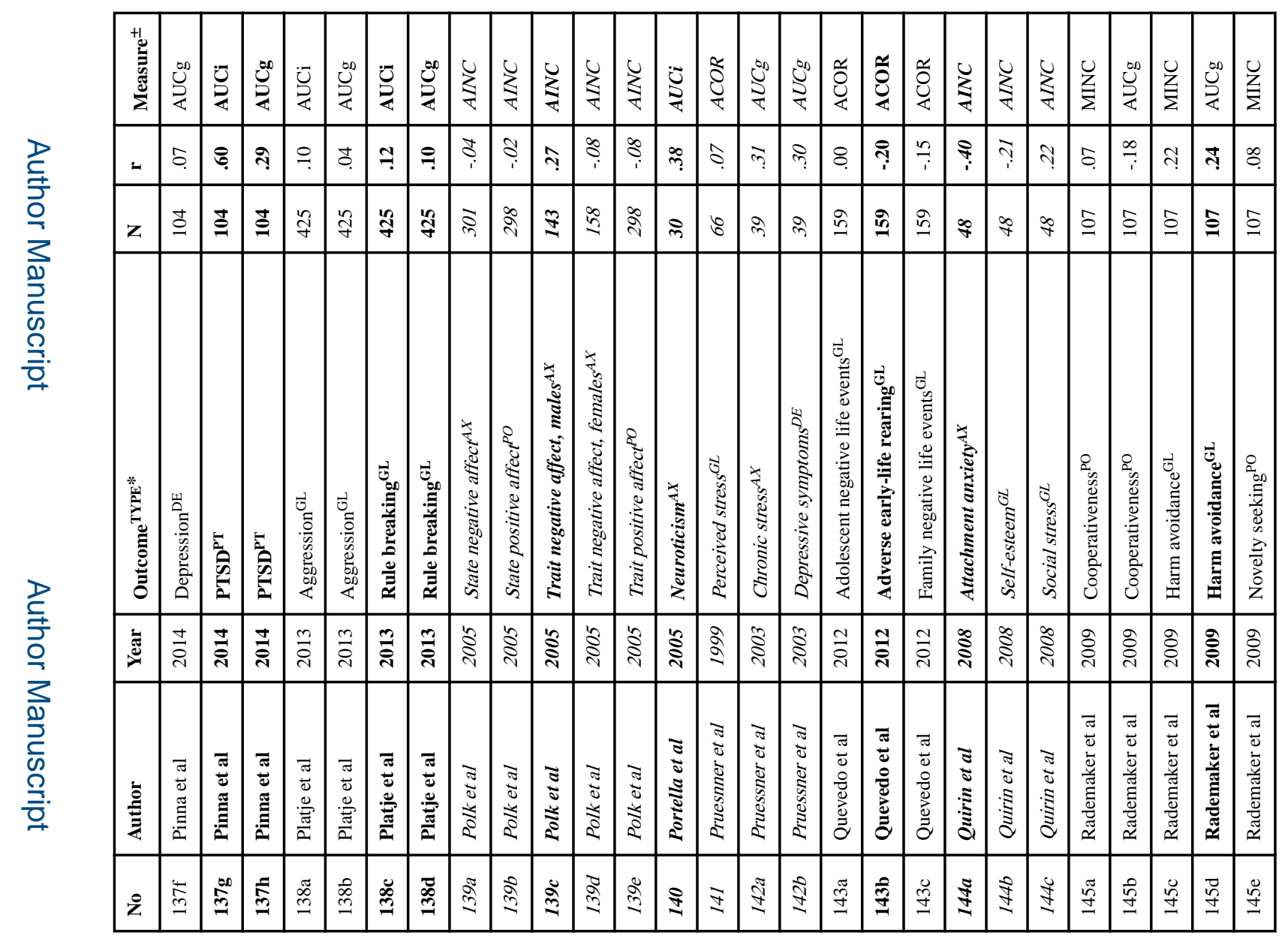

로을

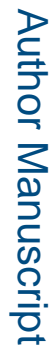

Biol Psychol. Author manuscript; available in PMC 2018 October 01. 


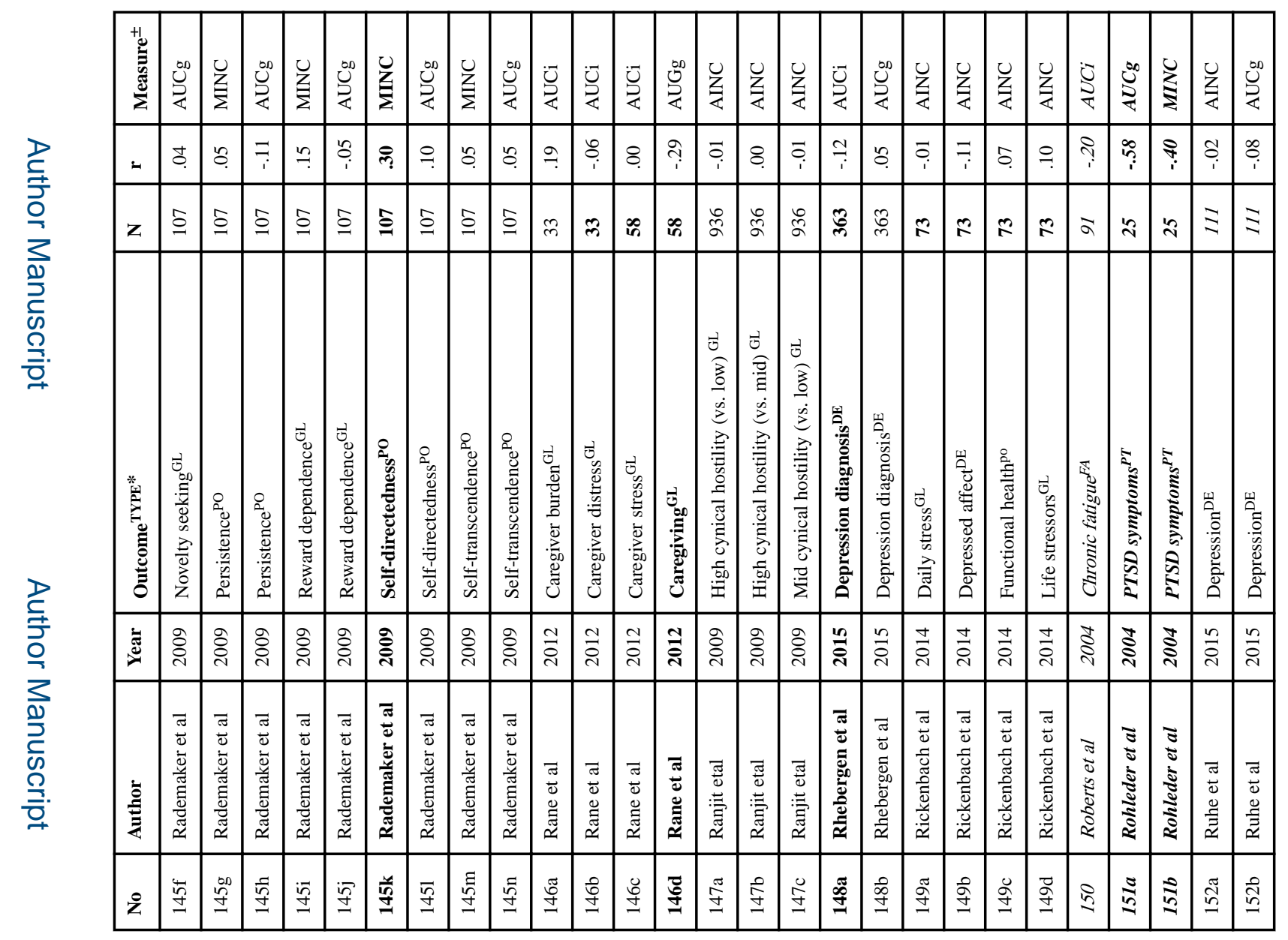

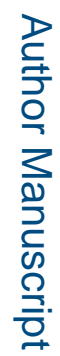

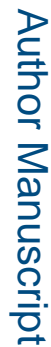

Biol Psychol. Author manuscript; available in PMC 2018 October 01. 


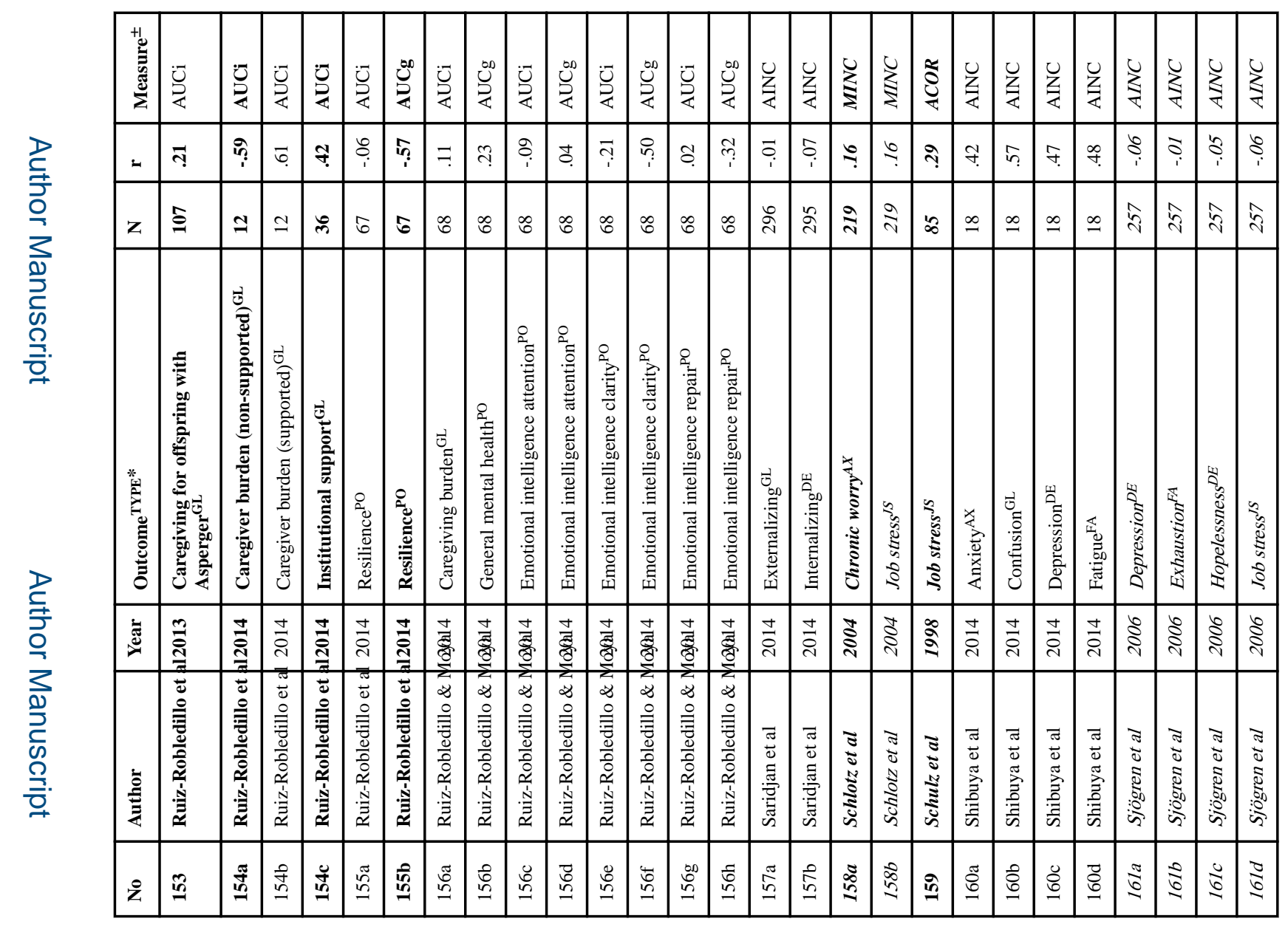

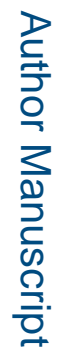

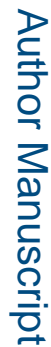

Biol Psychol. Author manuscript; available in PMC 2018 October 01. 


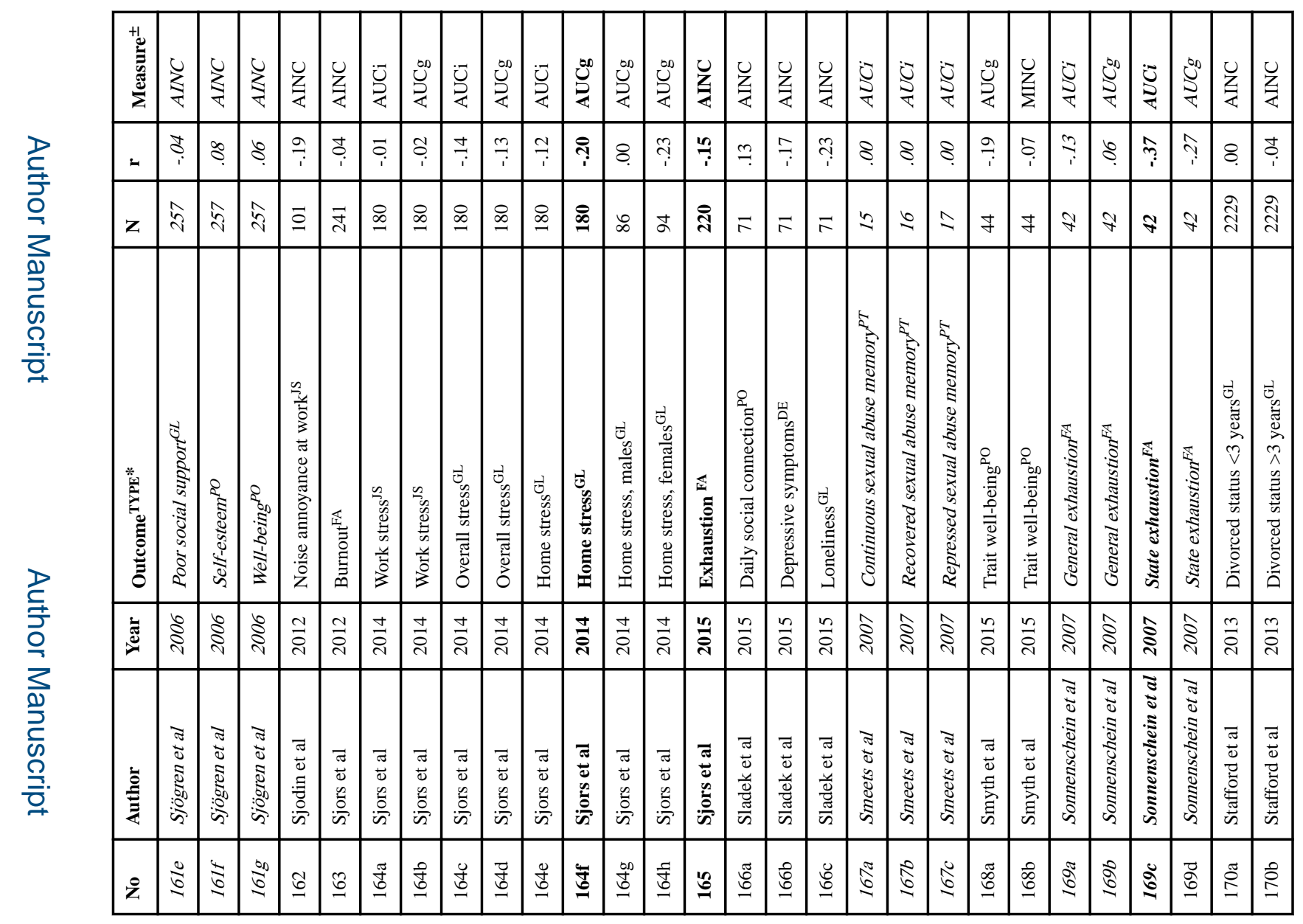

로을

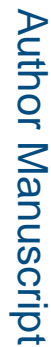

Biol Psychol. Author manuscript; available in PMC 2018 October 01. 


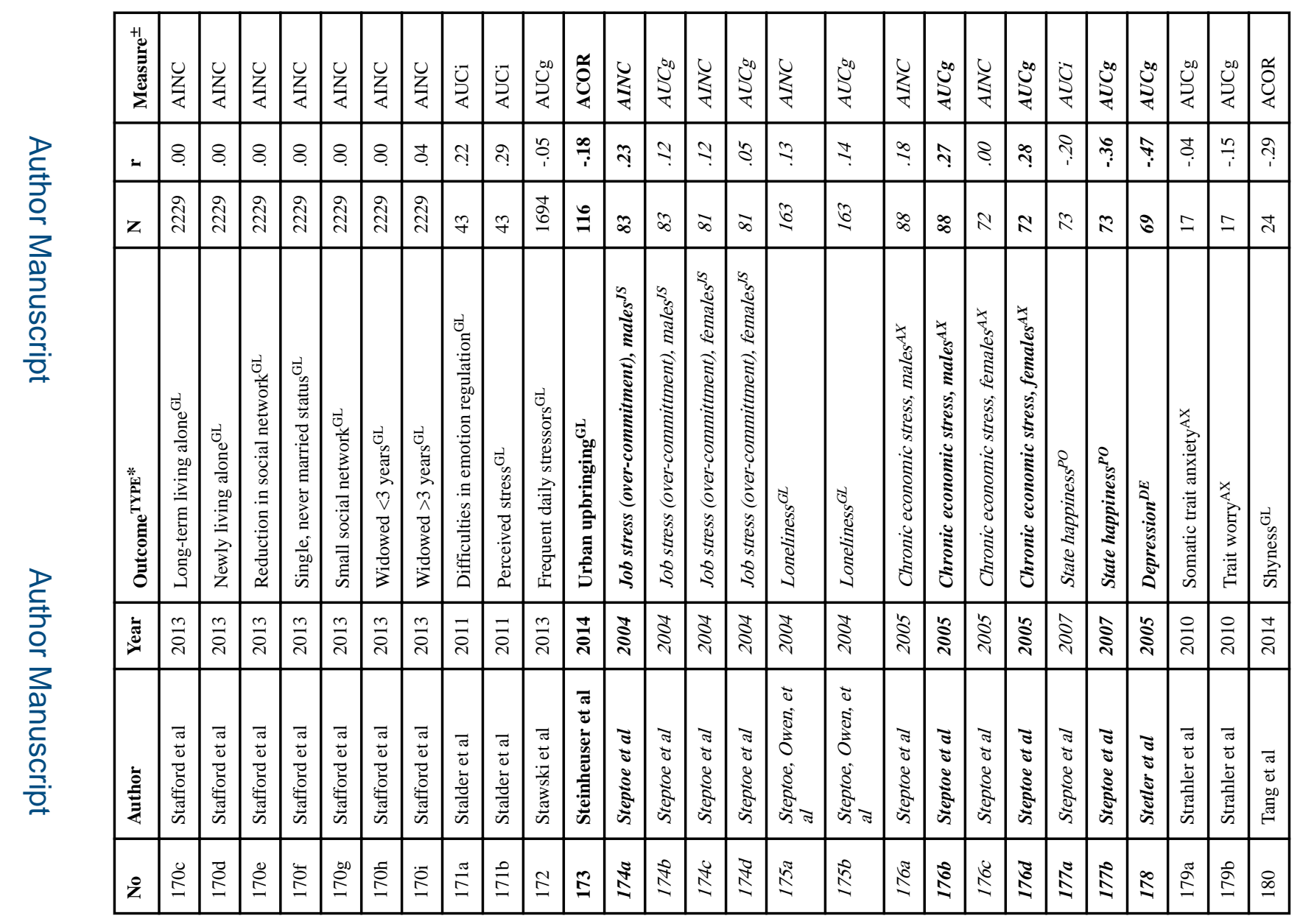

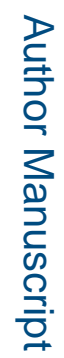

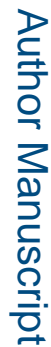

Biol Psychol. Author manuscript; available in PMC 2018 October 01. 


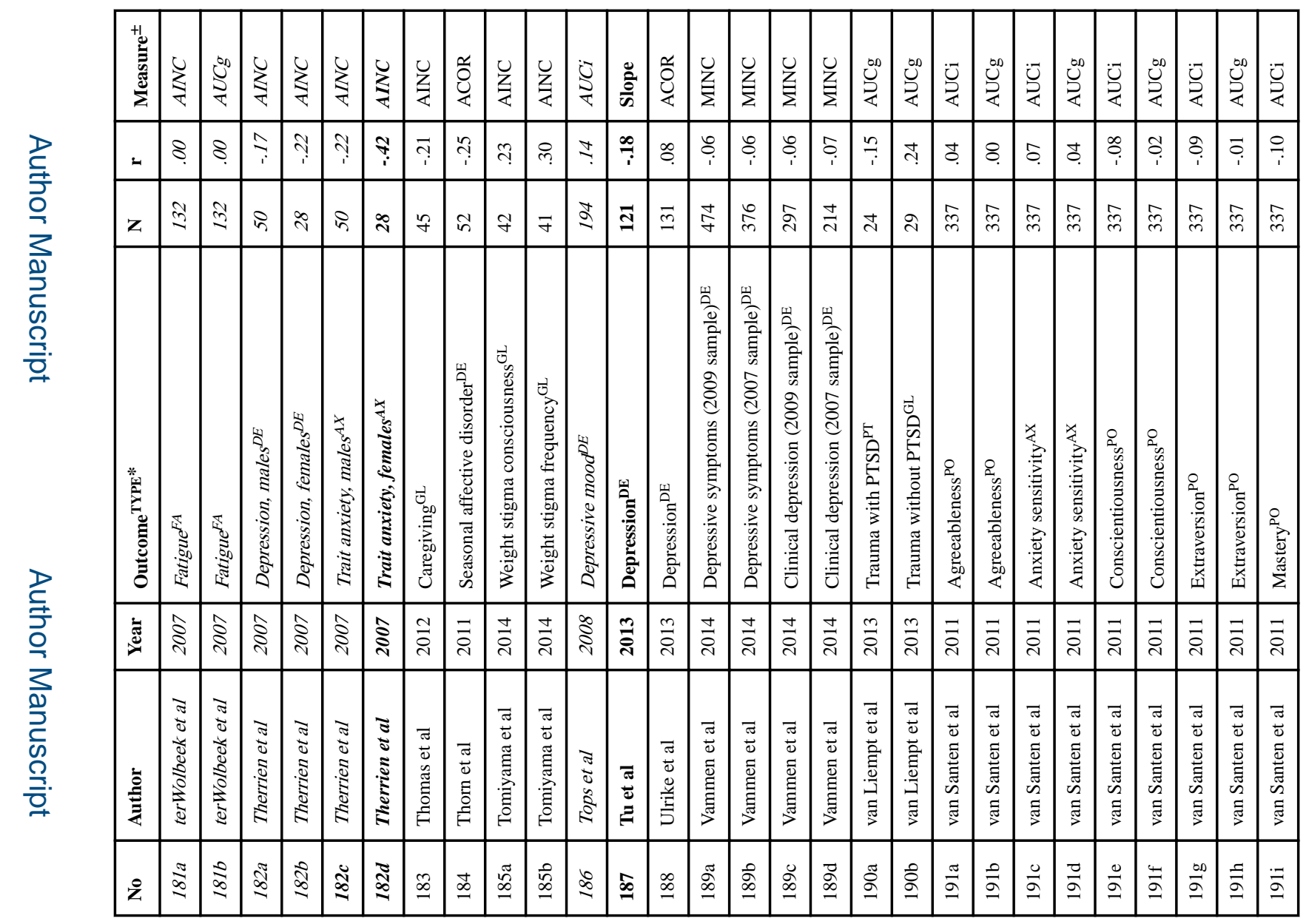

로을

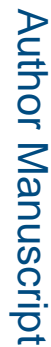

Biol Psychol. Author manuscript; available in PMC 2018 October 01. 


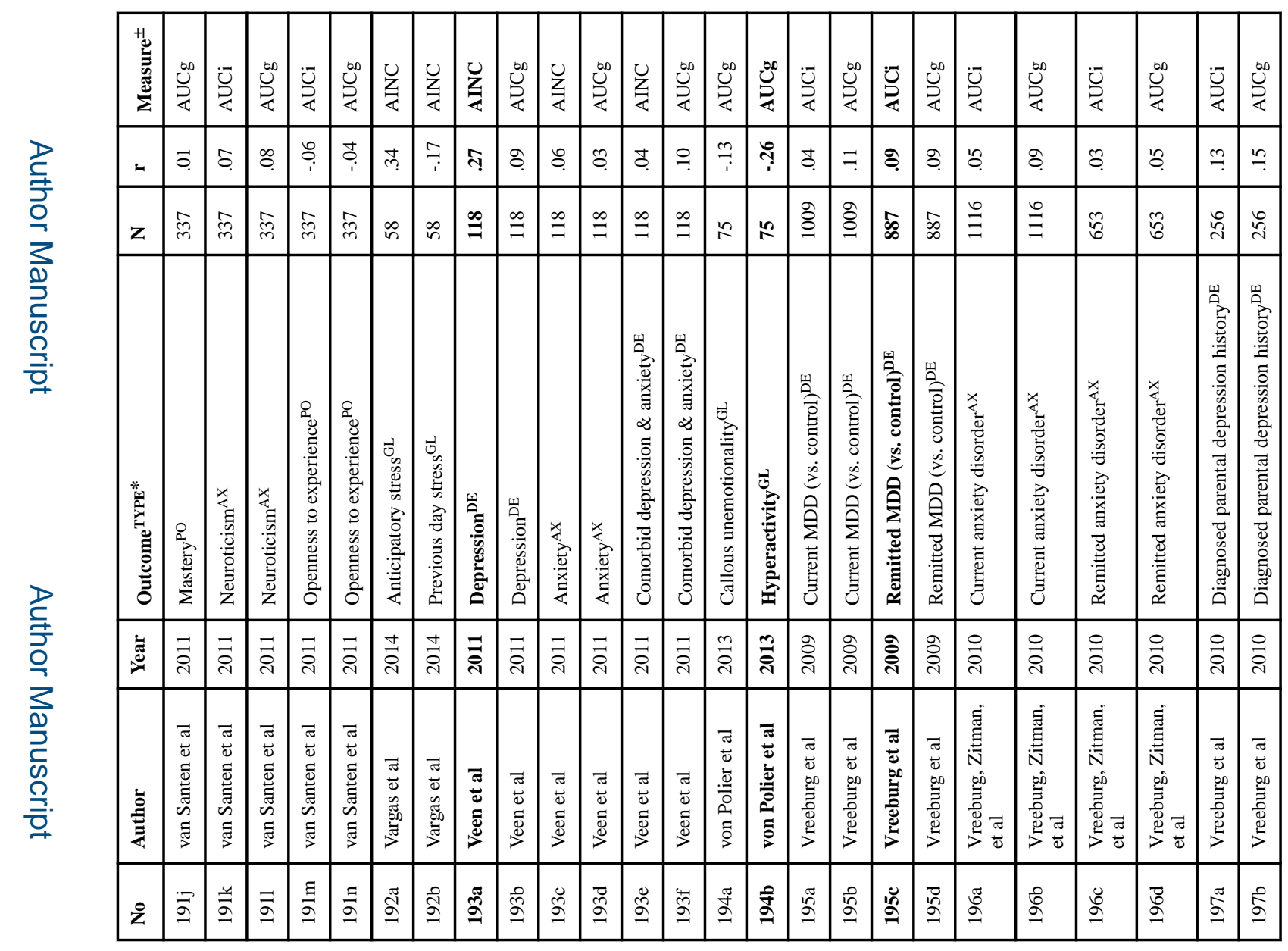

로을

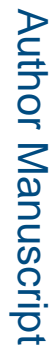

Biol Psychol. Author manuscript; available in PMC 2018 October 01. 


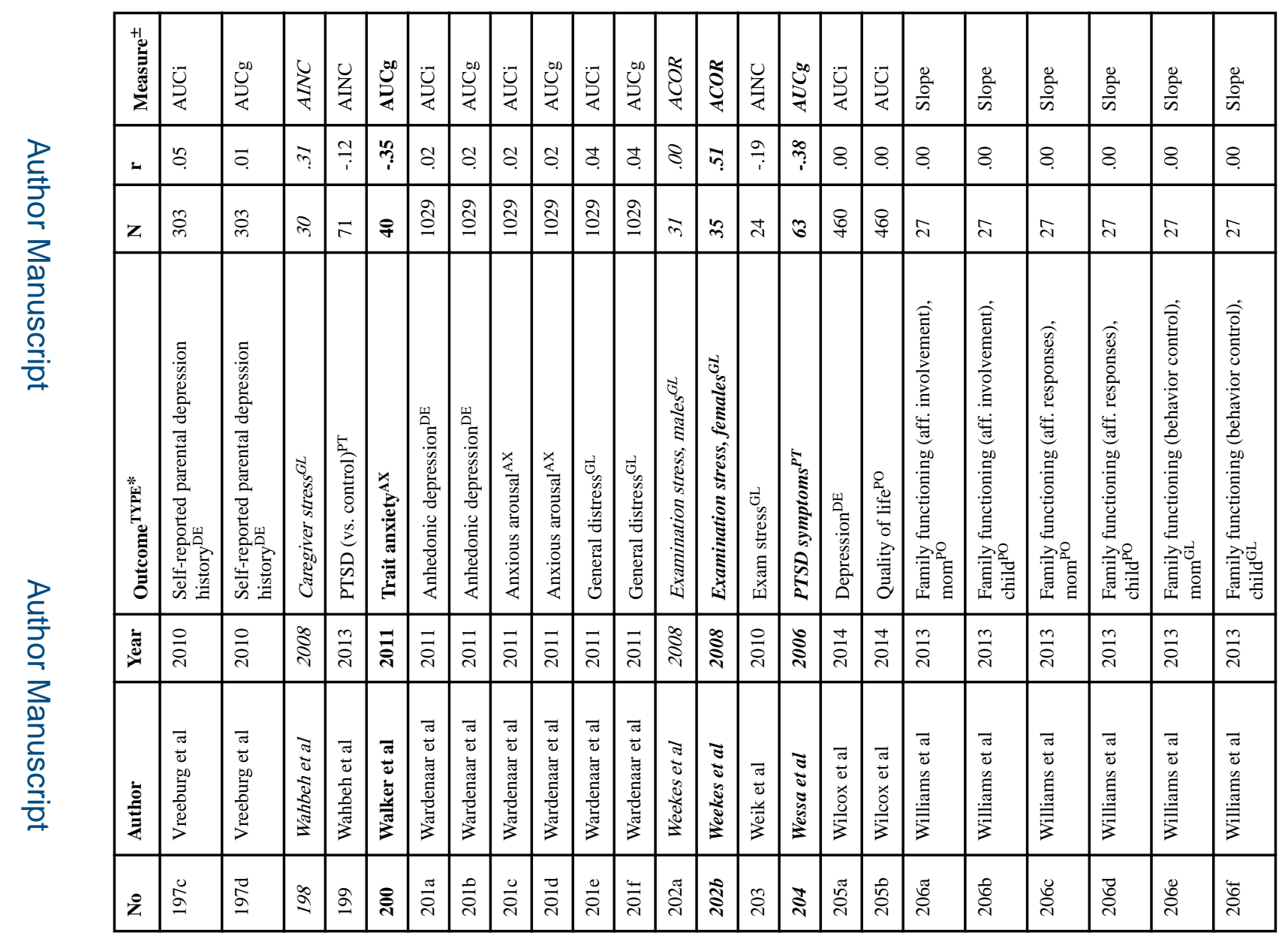

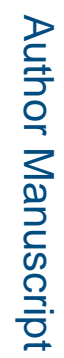

를

Biol Psychol. Author manuscript; available in PMC 2018 October 01. 


\begin{tabular}{|c|c|c|c|c|c|c|c|c|c|c|c|c|c|c|c|c|c|c|c|c|c|c|c|c|c|c|}
\hline 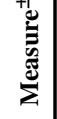 & $\frac{\stackrel{0}{0}}{\omega}$ & $\frac{\frac{0}{0}}{\omega}$ & $\frac{\frac{\partial}{0}}{\omega}$ & $\frac{0}{\stackrel{0}{a}}$ & $\frac{\stackrel{0}{0}}{\omega}$ & $\begin{array}{l}\frac{\partial}{0} \\
\frac{0}{\omega}\end{array}$ & $\begin{array}{l}\tilde{U} \\
\vec{Z}\end{array}$ & $\begin{array}{l}0 \\
0 \\
\end{array}$ & \begin{tabular}{|l}
$\dot{U}$ \\
$\dot{Z}$
\end{tabular} & $\mid \begin{array}{l}0 \\
? \\
Z\end{array}$ & $\mid \begin{array}{l}0^{\circ} \\
\vec{Z}\end{array}$ & $\begin{array}{l}\underbrace{\infty} \\
\vec{\varangle}\end{array}$ & $\begin{array}{l}0^{\infty} \\
\stackrel{Z}{Z}\end{array}$ & $\begin{array}{l}e^{\infty} \\
\stackrel{Z}{4}\end{array}$ & $\begin{array}{l}\underbrace{\infty} \\
己\end{array}$ & \begin{tabular}{l}
$0^{\infty}$ \\
\multirow{2}{*}{}
\end{tabular} & $\begin{array}{l}0 \\
\vdots \\
7\end{array}$ & 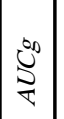 & 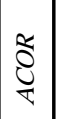 & 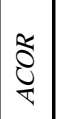 & $\underset{\tau}{\tilde{T}}$ & $\underset{\tau}{\tilde{T}}$ & 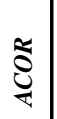 & 结 & 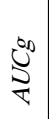 & క \\
\hline$=$ & 8 & fे & 8 & 8 & 8 & チ. & oे & $\bar{\sigma}$ & 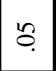 & $\hat{s}_{i}$ & $\bar{m}$ & q. & $\vec{m}$ & 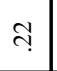 & $\because$ & $\delta$ & $€$ & $?$ & 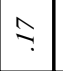 & 8 & 8 & 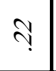 & ণ্ & $\stackrel{?}{i}$ & 8 & $\stackrel{?}{i}$ \\
\hline z & $\bar{\lambda}$ & $\hat{\imath}$ & $\hat{\lambda}$ & $\hat{\lambda}$ & $\bar{\lambda}$ & $\bar{\lambda}$ & $\tilde{\Xi}$ & $\Xi$ & $\Xi$ & 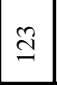 & $\bar{\lambda}$ & $\vec{\sim}$ & $\vec{\lambda}$ & $\vec{\sim}$ & $\vec{\lambda}$ & $\vec{\sim}$ & 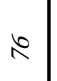 & $\gtrless$ & 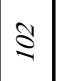 & $\cong$ & 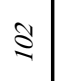 & 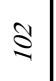 & $\S$ & $\stackrel{2}{2}$ & $\stackrel{+}{2}$ & $\stackrel{ \pm}{2}$ \\
\hline 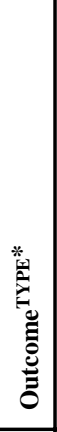 & 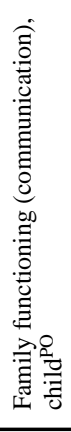 & 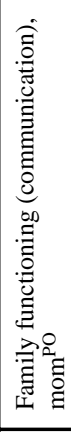 & 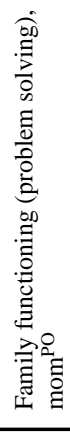 & 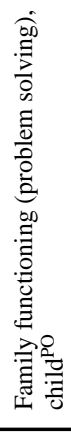 & 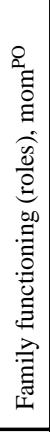 & 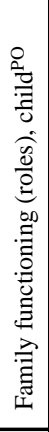 & 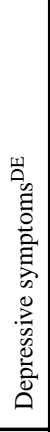 & 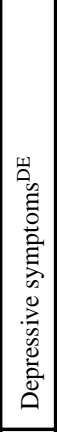 & 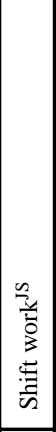 & 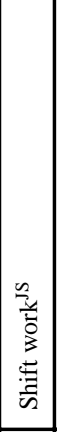 & 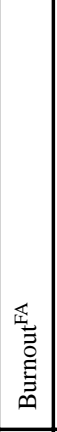 & 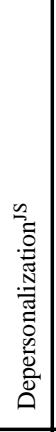 & 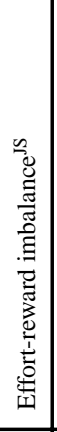 & 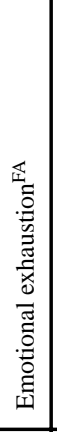 & 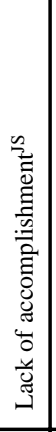 & 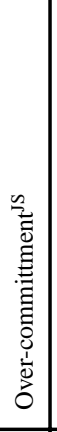 & 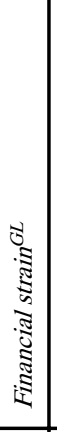 & 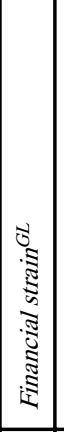 & 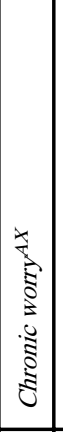 & 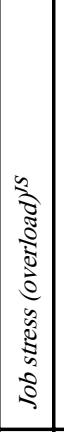 & 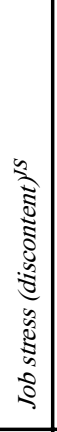 & 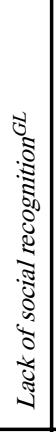 & 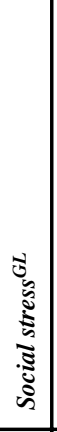 & 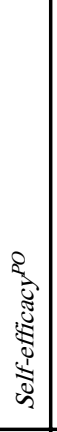 & 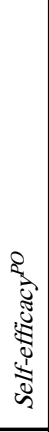 & 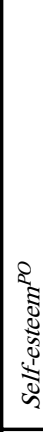 \\
\hline 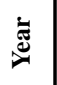 & $\stackrel{m}{\vec{i}}$ & $\stackrel{m}{\stackrel{i}{~}}$ & $\stackrel{m}{\vec{i}}$ & $\stackrel{m}{\stackrel{\sim}{\Lambda}}$ & $\stackrel{m}{\stackrel{i}{*}}$ & $\stackrel{m}{\stackrel{\sim}{*}}$ & $\overline{\vec{\sim}}$ & $\overline{\vec{i}}$ & $\overline{\vec{\nabla}}$ & $\overrightarrow{\bar{\nabla}}$ & $\stackrel{m}{\vec{\sim}}$ & $\stackrel{m}{\vec{\sim}}$ & $\stackrel{m}{\vec{d}}$ & $\stackrel{m}{\vec{N}}$ & $\stackrel{m}{\vec{N}}$ & $\stackrel{m}{\vec{\sim}}$ & 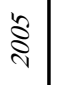 & ¿े & 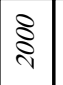 & 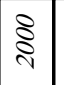 & $\underset{\sim}{ః}$ & 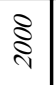 & ฐิ & $\stackrel{్}{\$}$ & $\underset{\sim}{\S}$ & \& \\
\hline 兽 & 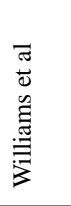 & 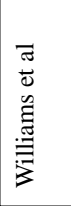 & 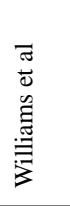 & 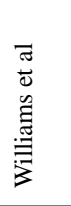 & 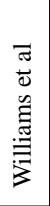 & 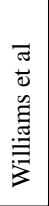 & 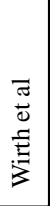 & 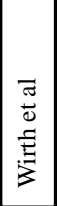 & 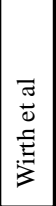 & 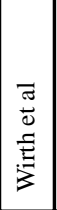 & 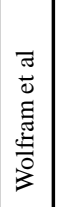 & 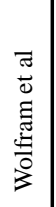 & 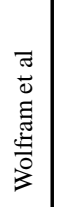 & 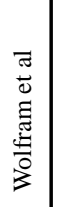 & 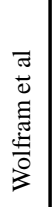 & 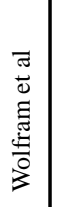 & 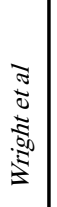 & 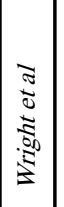 & 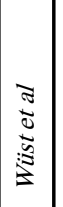 & $\begin{array}{l}\vdots \\
\vdots \\
\vdots \\
\vdots \\
\vdots \\
\vdots\end{array} \mid$ & 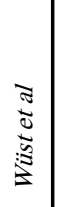 & 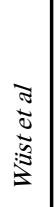 & 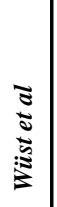 & $\frac{\pi}{\frac{\pi}{3}}$ & 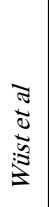 & 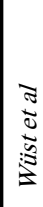 \\
\hline 2 & "ై & & ఫ্ণ & ర্ণ & & $\bar{\circ}$ & $\stackrel{\pi}{\stackrel{\pi}{\sim}}$ & 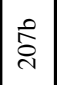 & $\stackrel{0}{\stackrel{\sim}{\sim}}$ & $\overrightarrow{\grave{C}}$ & $\stackrel{\pi}{\mathscr{0}}$ & $\overrightarrow{\stackrel{\otimes}{े}}$ & 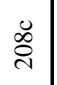 & $\begin{array}{l}\overrightarrow{0} \\
\stackrel{\sim}{\sim}\end{array}$ & 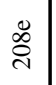 & $\begin{array}{l}4 \\
\stackrel{\sim}{*}\end{array}$ & จั & จे & $\stackrel{\Xi}{\sim}$ & $\stackrel{8}{2}$ & 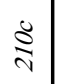 & $\underset{\sim}{\stackrel{2}{2}}$ & 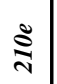 & $\stackrel{\varpi}{\downarrow}$ & $\stackrel{80}{2}$ & $\stackrel{\Xi}{\sim}$ \\
\hline
\end{tabular}

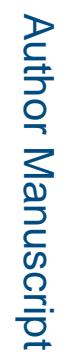

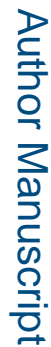

Biol Psychol. Author manuscript; available in PMC 2018 October 01. 


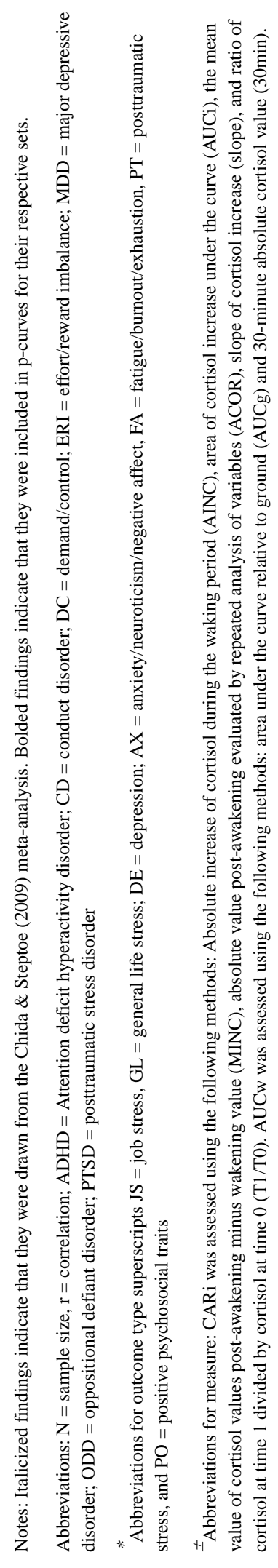

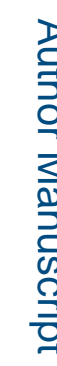

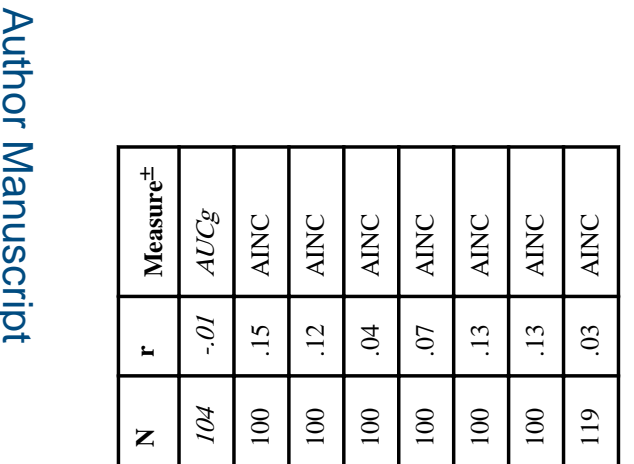

를

\begin{tabular}{|l|l|l|l|l|l|l|}
\hline & & & & & & \\
\hline
\end{tabular}

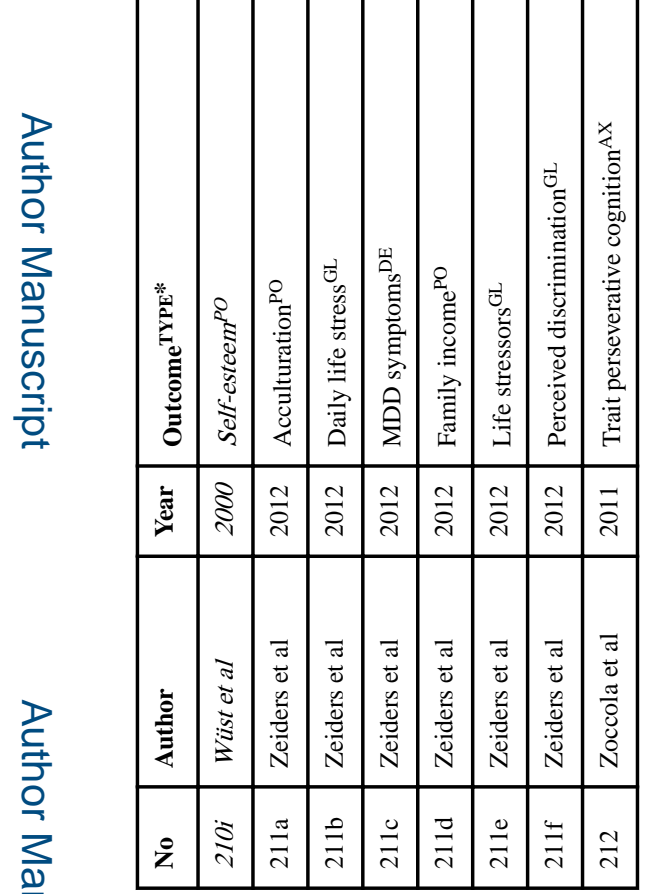

, 


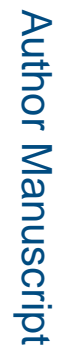

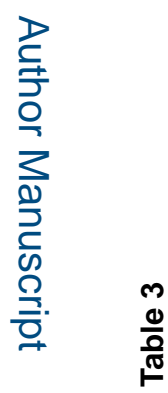

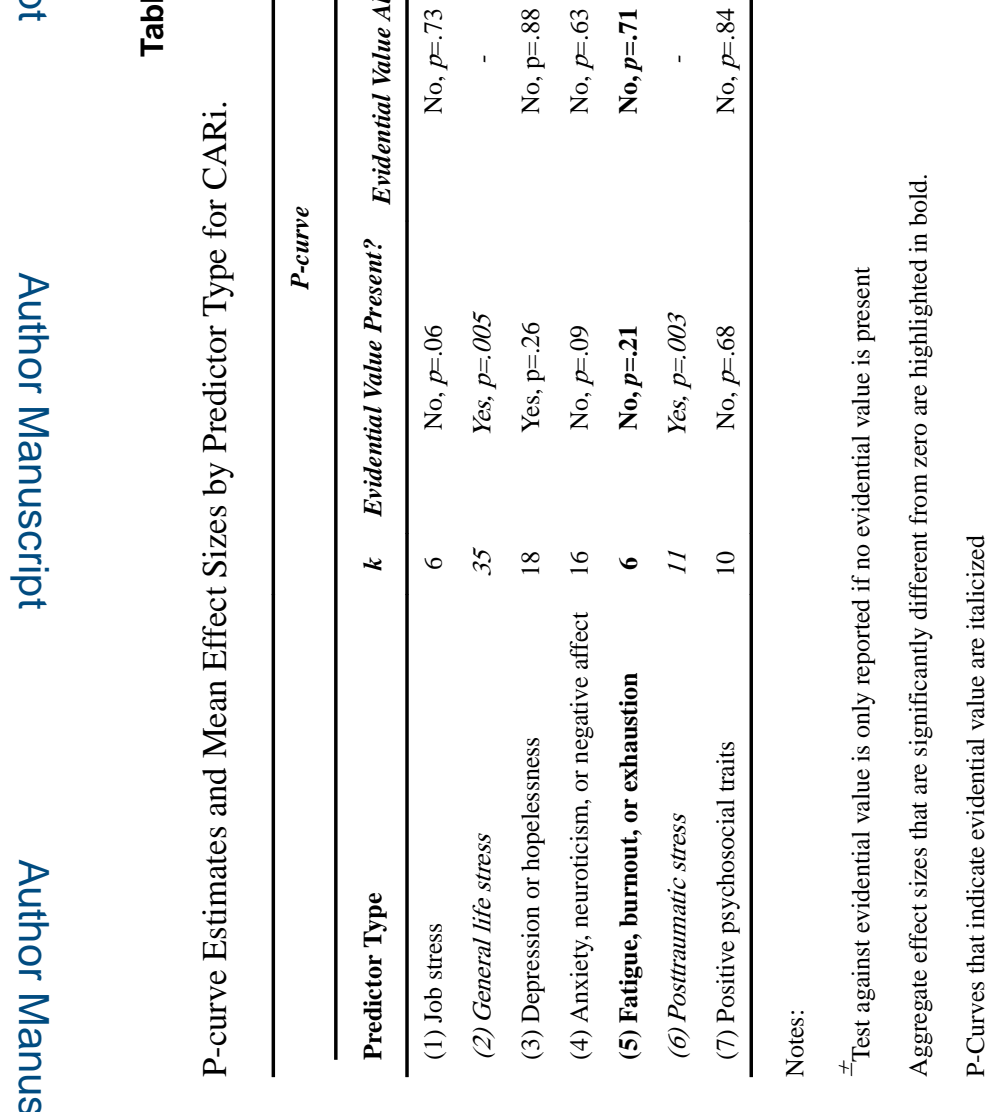

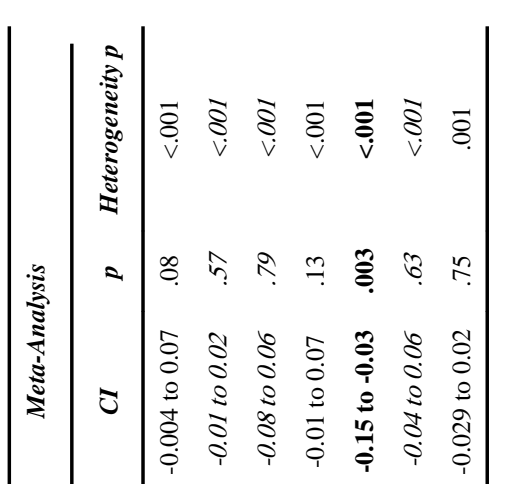

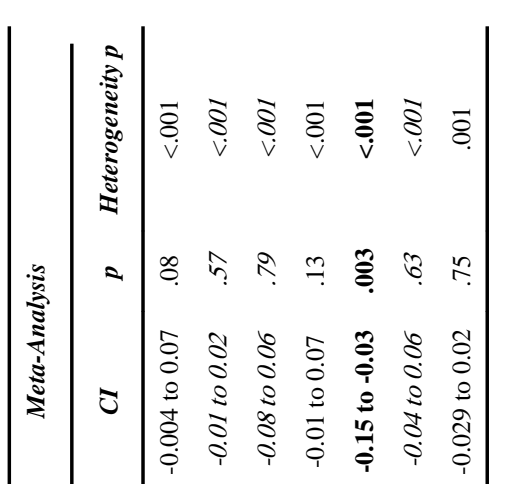

ช.

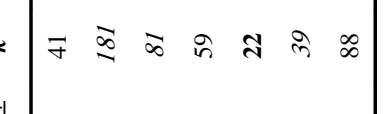

Biol Psychol. Author manuscript; available in PMC 2018 October 01. 


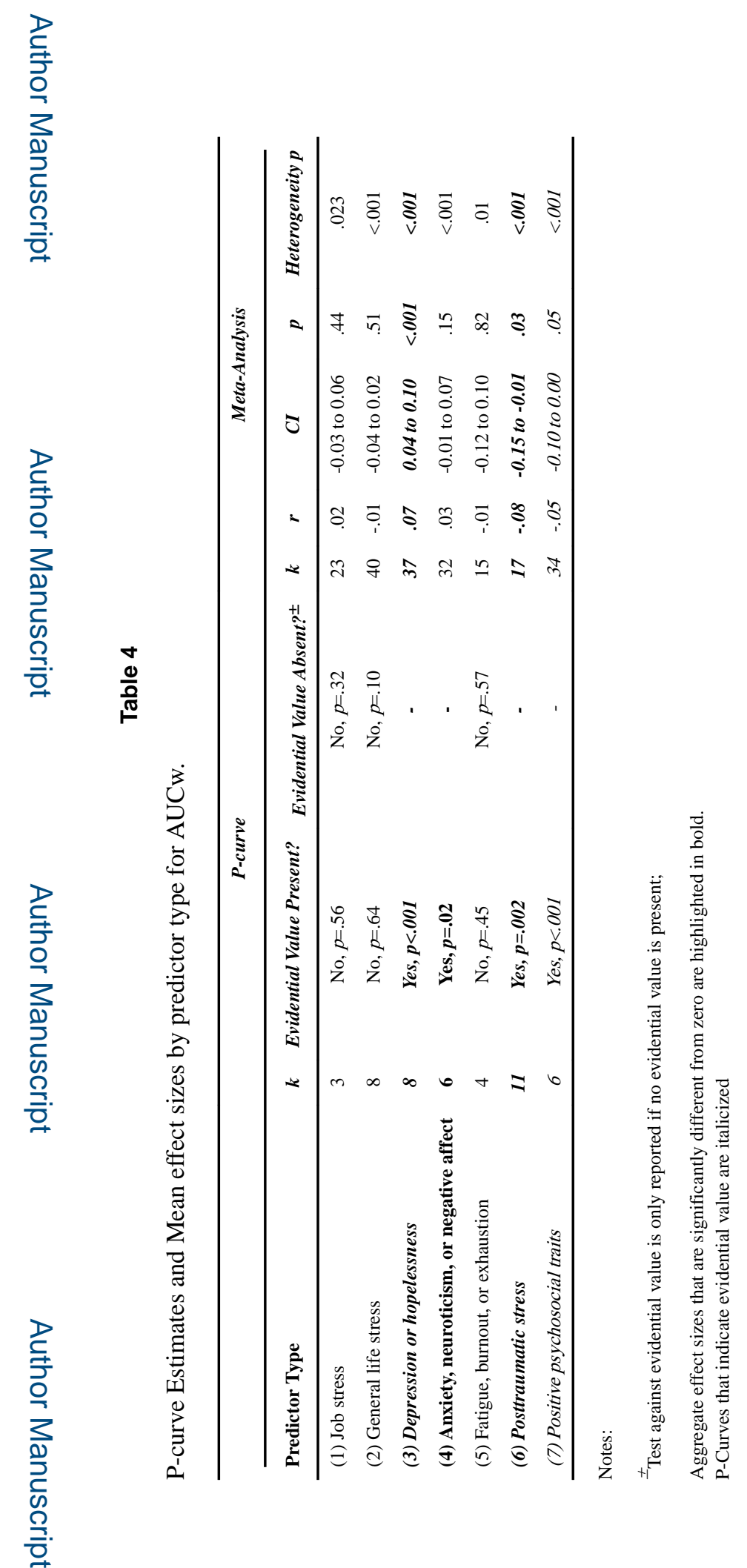

Biol Psychol. Author manuscript; available in PMC 2018 October 01. 